San Jose State University

SJSU ScholarWorks

Master's Theses

Master's Theses and Graduate Research

Spring 2019

\title{
Creating a Cultural Context for Dong and Miao Folk Music Using an Orff-Inspired Methodology
}

Ke Guo

San Jose State University

Follow this and additional works at: https://scholarworks.sjsu.edu/etd_theses

\section{Recommended Citation}

Guo, Ke, "Creating a Cultural Context for Dong and Miao Folk Music Using an Orff-Inspired Methodology" (2019). Master's Theses. 5000.

DOI: https://doi.org/10.31979/etd.qdzu-4xbz

https://scholarworks.sjsu.edu/etd_theses/5000

This Thesis is brought to you for free and open access by the Master's Theses and Graduate Research at SJSU ScholarWorks. It has been accepted for inclusion in Master's Theses by an authorized administrator of SJSU ScholarWorks. For more information, please contact scholarworks@sjsu.edu. 


\title{
CREATING A CULTURAL CONTEXT FOR DONG AND MIAO FOLK MUSIC USING AN ORFF-INSPIRED METHODOLOGY
}

\author{
A Thesis \\ Presented to \\ The Faculty of the School of Music and Dance \\ San José State University
}

In Partial Fulfillment

of the Requirements for the Degree

Master of Music

by

Ke Guo 
(C) 2019

Ke Guo

ALL RIGHTS RESERVED 
The Designated Thesis Committee Approves the Thesis Titled

CREATING A CULTURAL CONTEXT FOR DONG AND MIAO FOLK MUSIC USING AN ORFF-INSPIRED METHODOLOGY

by

Ke Guo

APPROVED FOR THE SCHOOL OF MUSIC AND DANCE

SAN JOSÉ STATE UNIVERSITY

May 2019

Diana Hollinger, Ph.D. School of Music and Dance

Gordon Haramaki, Ph.D. School of Music and Dance

Fred Cohen, Ph.D. $\quad$ School of Music and Dance 


\title{
ABSTRACT \\ CREATING A CULTURAL CONTEXT FOR DONG AND MIAO'S FOLK MUSIC USING AN ORFF-INSPIRED METHODOLOGY
}

\author{
by Ke Guo
}

As children grow up surrounded by various ethnicities, races, and religious

beliefs, we teach them music and dance to cultivate respect and empathy for the diverse people in our multicultural society. On the other side of the globe, China is also a multiethnic country and is home to 56 ethnic minority groups that speak multiple different languages. "Chinese music" is thus a collective term for the many disparate styles and genres of music in the country, which is especially rich in the varieties of folk music heard and played. Although Chinese folk music frequently appears in music textbooks in elementary schools, the selection of songs is often monolithic. Little effort has been made to include music from non-urban regions and non-Han traditions. The purpose of this study is to enrich the Chinese folk music resources found in elementary music education by introducing music from the Dong and Miao ethnic groups using an Orff-inspired methodology. The scope of this study is limited to child-appropriate folk music from the Dong and Miao ethnic communities of Guizhou province in China with suggestions about how to introduce these songs and dances into elementary classroom settings. Through building up cultural contexts for educators and students, this study manifests an accessible way for Dong and Miao folk music to be adapted into elementary music classrooms. 


\section{ACKNOWLEDGEMENTS}

I would first like to thank my thesis advisor Dr. Diana Hollinger of the School of Music and Dance at San José State University (SJSU). She always encouraged me to continue my research when I encountered any setbacks and steered me in the right direction whenever she thought I needed it. I would also like to thank Dr. Gordon Haramaki and Dr. Fred Cohen for sitting on my thesis committee. The door to Dr. Haramaki's office was always open whenever I ran into difficulty or had a question about my research or writing. Dr. Cohen, Director of the School of Music and Dance at SJSU, also offered tremendous support and help with my thesis writing.

I would also like to thank the musicians I interviewed in Miao and Dong villages in Guizhou. Tang Wengweng, an award-winning Miao singer, Wan Zhengwen, the National Intangible Cultural Heritage Bearer of Miao Music and Dance, and Wu Rongde, a renowned Dong singer in Xiaohuang village, all kindly gave me permission to collect information from them for my research.

Finally, I must express my very profound gratitude to my parents, my husband Carl, and my daughter Nora for providing me with unfailing support and continuous encouragement throughout my years of study and throughout the process of researching and writing this thesis. This accomplishment would not have been possible without them. Thank you. 


\section{TABLE OF CONTENTS}

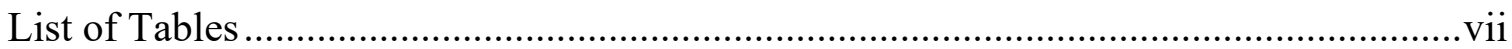

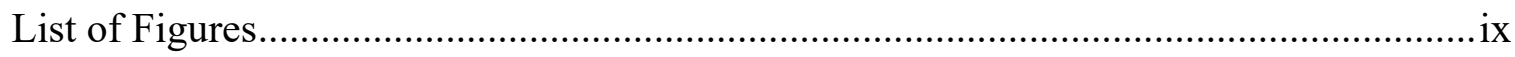

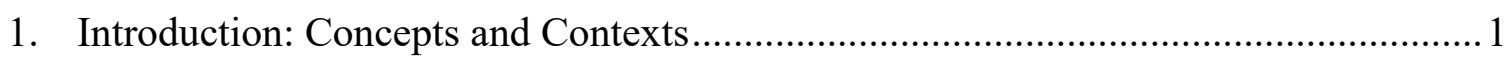

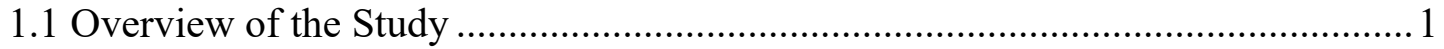

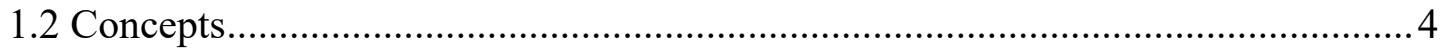

1.2.1 Multicultural Music Education ................................................................

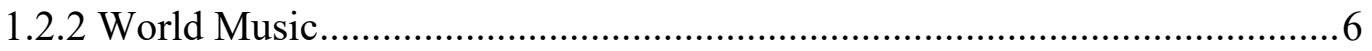

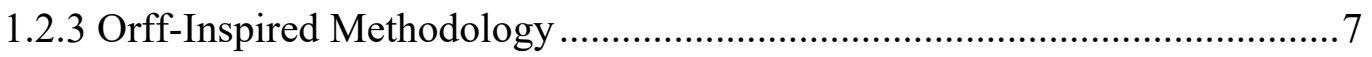

1.2.4 Chinese Folk Music and Related Terms ................................................... 8

1.2.5 Miao and Dong ........................................................................................ 11

1.3 Contexts

1.3.1 Multiculturalism in American Music Education .........................................12

1.3.2 Issues of Authenticity in Folk Music ........................................................... 15

1.3.3 Chinese Folk Music in the West ............................................................19

1.3.4 From the "New Folk Song" to the "Original Ecology Folk Song".............22

1.3.5 Ethnic Minorities in China ....................................................................24

1.3.6 Miao and Dong Ethnic Groups in Guizhou Province ................................2

1.3.7 Why Orff-Inspired Methodology? ...........................................................31

2. Quantitative Observations of Chinese Music in American Elementary Music

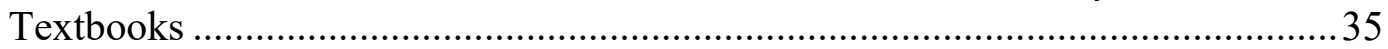

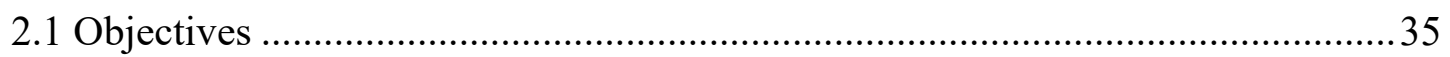

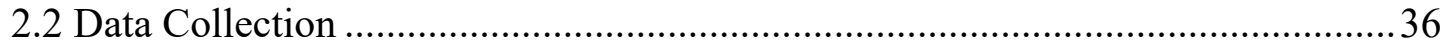

2.3 Tracing the Origins of Chinese Folk Music in Music Textbooks..........................4 40

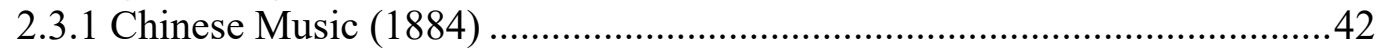

2.3.2 The Flower Drum and other Chinese Songs (1943)...................................43

2.3.3 Folk Songs From China (1943)................................................................

2.3.4 The Pagoda: Thirteen Chinese Songs (1946) ………..................................45

2.3.5 Folk Songs of China-Japan-Korea (1964).................................................46

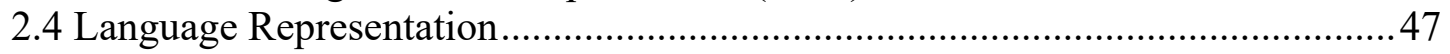

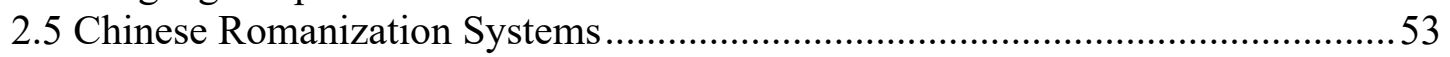

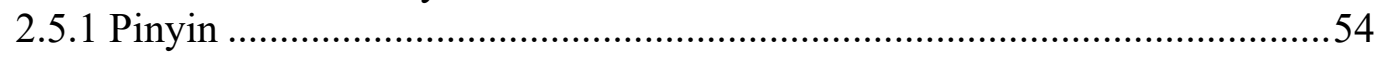

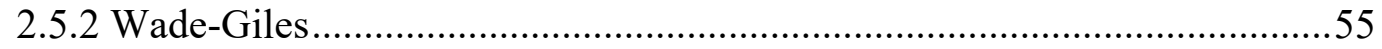

2.5.3 English Phonetic Spelling ……………...................................................5

2.5.4 The Complex Situation of Chinese Romanization.......................................57

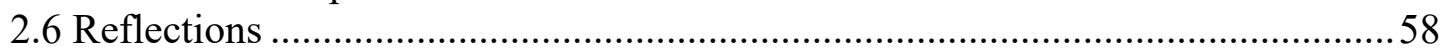

3. The Cultural Context of the Dong and Miao Ethnic Groups .......................................61

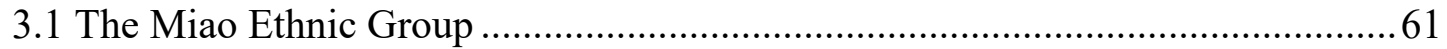

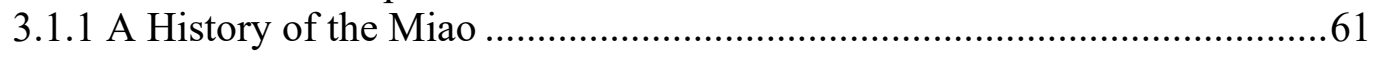




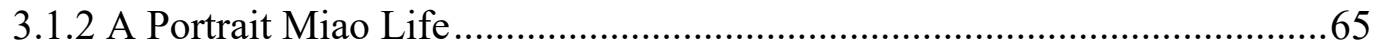

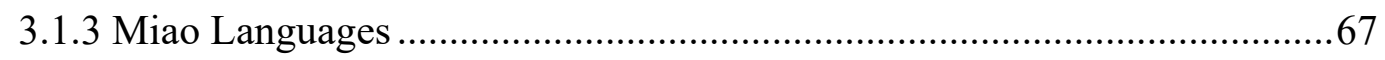

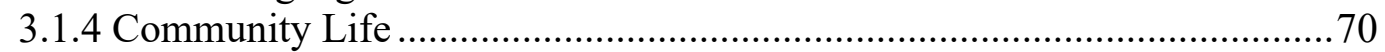

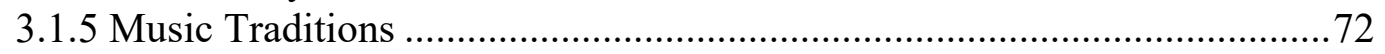

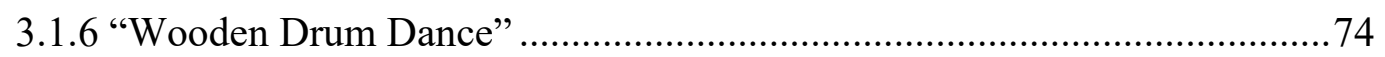

3.2 The Dong Ethnic Group .......................................................................................

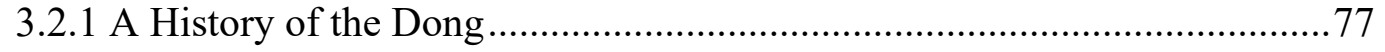

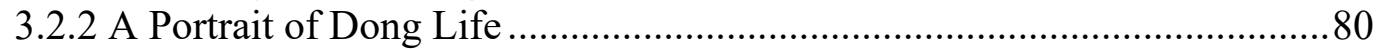

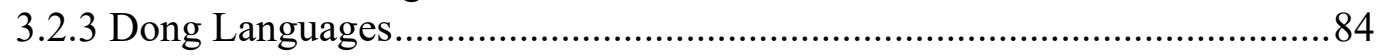

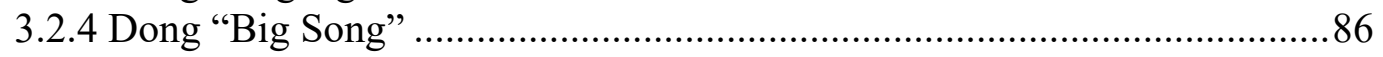

3.2.5 Music Education for Children ................................................................... 89

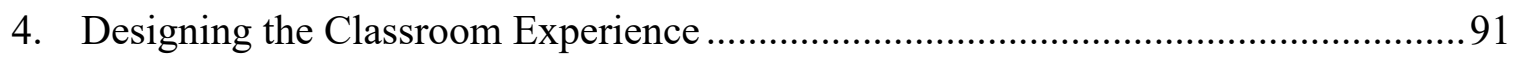

4.1 The Orff Schulwerk Approach ........................................................................

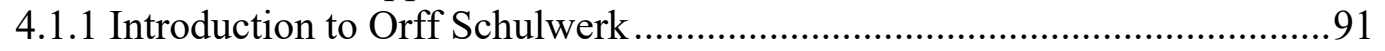

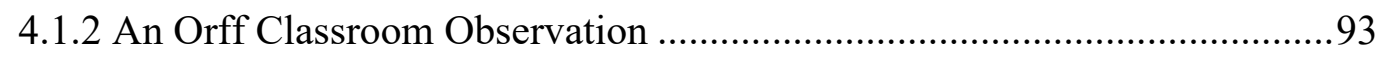

4.2 Synergy between Orff Schulwerk and Cultural Music .........................................95

4.2.1 Adaptation in Teaching Dong and Miao Ethnic Music ..............................99

4.2.2 Crafting the Cultural Experience .............................................................. 100

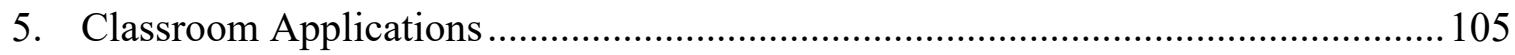

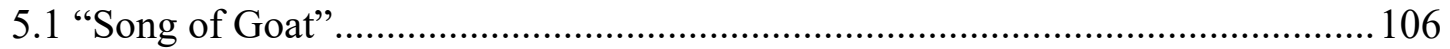

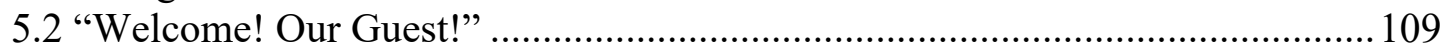

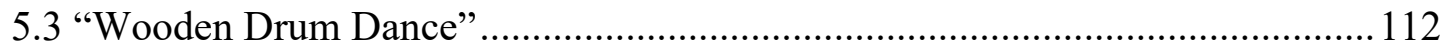

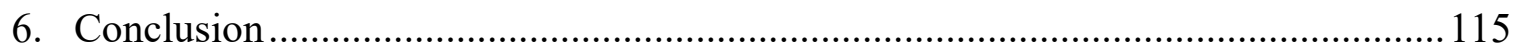

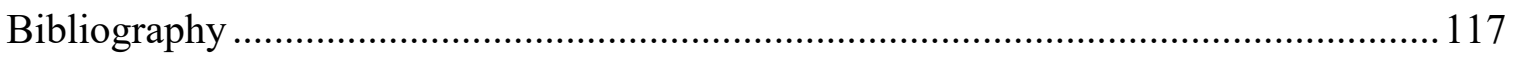

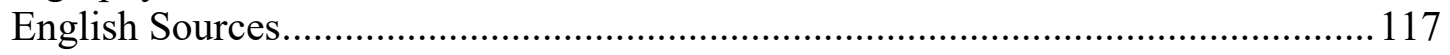

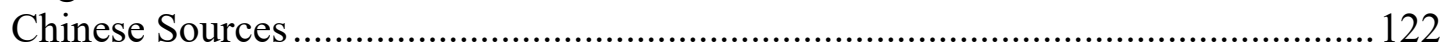

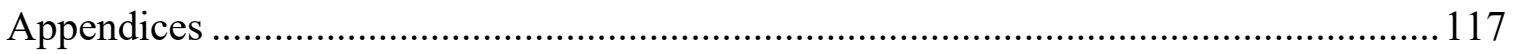

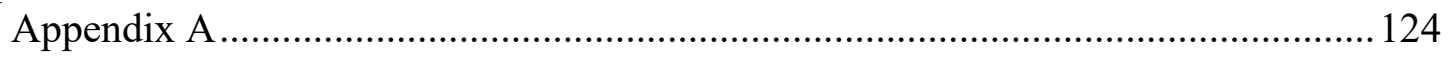

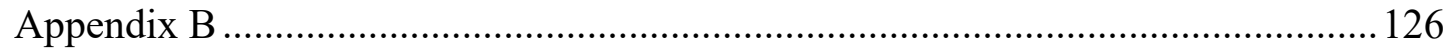

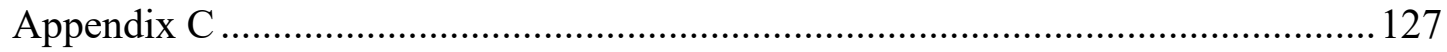

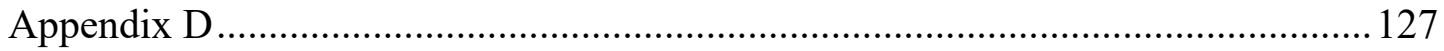




\section{LIST OF TABLES}

Table 1: Chinese Folk Songs in U.S. Elementary Music Textbooks.........................39

Table 2: Top 10 Chinese Songs in U.S. Elementary Music Textbooks and Their Source Texts ............................................................................. 41

Table 3: Comparison of Chinese Romanization Systems and IPA .........................56

Table 4: Examples of the Miao Written Language Ntawv Hmoob ............................69

Table 5: Comparison of Dong Written Language and English ...............................85

Table 6: Pronunciation Guide for Transcribed Lyrics ......................................... 100 


\section{LIST OF FIGURES}

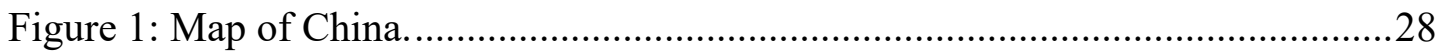

Figure 2: Ethnic minorities areas in Guizhou. ....................................................29

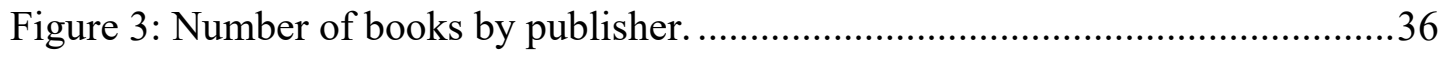

Figure 4: Number of books by publishing date. ................................................ 37

Figure 5: Presence of Chinese characters in lyrics in textbooks.............................49

Figure 6: Romanized Chinese in lyrics of Chinese songs in textbooks....................49

Figure 7: Romanized Chinese in lyrics in textbooks from 1990 to 2014 ...................51

Figure 8: Chinese characters in lyrics of Chinese songs in textbooks......................51

Figure 9: Romanized Chinese in lyrics in textbooks from 2000 to 2014 ...................52

Figure 10: Chinese characters in lyrics of Chinese songs in textbooks......................52

Figure 11: Traditional Miao costume display in Guizhou Provincial Museum. ........62

Figure 12: Miao Village in Guizhou. Photo by Ke Guo (2018). ..............................66

Figure 13: Tang Wenwen and Author. Photo by Ke Guo (2018)............................73

Figure 14: A photo of Wan Zhengwen on the wall. ............................................... 74

Figure 15: Wan Zhengwen playing the wooden drum. Photo by Ke Guo (2018)......75

Figure 16: Distribution of Dong (Kam) population in 2010 ................................. 79

Figure 17: Dong residential buildings and the Grand Bridge of Wind and Rain (Feng Yu Qiao 风雨桥). Photo by Ke Guo (2018).....................................8 82

Figure 18: The Xiaohuang Village Choir performing at the Drum Tower.................83

Figure 19: Wu Rongde, a chef and a singing master in Xiaohuang Village...............84 


\section{Introduction: Concepts and Contexts}

\subsection{Overview of the Study}

When we walk into an elementary school music classroom, we will often observe young students from different ethnic and cultural backgrounds singing, dancing, and playing together. As noted by Campbell, "the field [music education] has the potential to hold court in a child's holistic development as a core avenue for the discovery of human cultural heritage and the celebration of multiple identities based upon race, ethnicity,

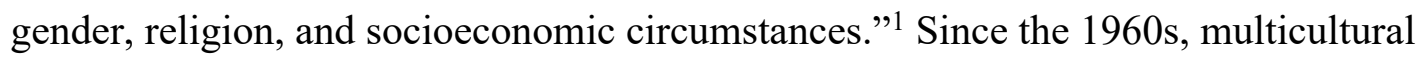
music content has gradually permeated United States' elementary music education. We can easily find multicultural music content in any music textbook currently in use; however, many types and genres of music from other cultures are still under-represented or misrepresented in music textbooks. Thus, music educators should continue to work toward improving the quality and representativeness of multicultural music literature.

There are a few Chinese folk songs that have been used repeatedly in music textbooks since the 1960s, with the music genres represented limited to folk music from the urban Han ethnic community. ${ }^{2}$ This restricted representation of Chinese music introduces the danger that students will perceive Chinese music as a monolithic tradition with a uniform cultural context. China is a multi-ethnic country made up of heterogeneous people who speak entirely different languages and live in vastly different environments. Although it

\footnotetext{
${ }^{1}$ Patricia Shehan Campbell, "Series Foreword.” In World Music Pedagogy Vol. 2. Elementary Music Education, Christopher Roberts and Amy Beegle (New York: Routledge, 2018), viii.

2 This point is further illustrated in the data analysis conducted in chapter two.
} 
is nearly impossible to fully represent every aspect of Chinese music in elementary music classrooms, it is important to accurately represent China as a multi-ethnic state with diverse languages and cultures.

A similar situation occurs when music from other countries and regions is taught. For example, "music of Africa" is another broad term that includes diverse genres of music practiced across the different countries on the continent of Africa. As with Chinese music literature selections, music literature selections of African music in music textbooks also display limitations in representing Africa as a multi-ethnic and multicultural region. Imagine, for example, a music teacher who finds a percussion arrangement from the Democratic Republic of the Congo and presents it as the "music of Africa." The teacher's students may be misled to believe that this specific percussion arrangement is representative of the music of Africa, ignoring the vast regional differences in African music. Similarly, the American folk music represented in textbooks is also limited in multicultural representation, as most "American folk music" is from Western European traditions brought to the United States by early immigrants, while native American folk music is typically neglected. It is anticipated that this study will foster a better approach to multiculturalism in music education, an ambition that has motivated my efforts to introduce multicutural folk music from China to music classrooms.

My mother was born in Guizhou and my grandfather often recounted stories of his visits to Miao villages on the top of mountains and Dong villages in the valleys. The purpose of this study is to contribute Chinese folk music resources to elementary music education by introducing music from the Dong and Miao ethnic groups using an Orff- 
inspired methodology. The scope of this study is limited to child-appropriate folk music from Dong and Miao ethnic minorities in the Guizhou province of China and how to introduce these songs and dances into elementary classroom settings. The global distribution of Dong and Miao populations has given rise to the development of differentiated musical cultures in different regions. For instance, the Miao people in Southeast Asia and United States are usually referred to as "Hmong" and celebrate different rituals and traditions from the Chinese Miao; thus their music is reserved for future study. Since the folk music cultures of Dong and Miao differ between villages and across different celebrations, it is nearly impossible to select music that is representative of entire ethnic groups or regions; nevertheless, the curated songs and dances in this study provide insight into certain aspects of these ethnic groups' lifestyle and culture.

As part of my research, I carried out an explorative field study in Miao and Dong villages in Guizhou's Qiandongnan region in summer 2018. Here, I observed and interviewed several local singers, dancers, and teachers, and collected songs and dances from these primary sources. Following the field trip, I attended the Orff introduction course with senior instructor Janet Green at The San Francisco School to connect my research in Dong and Miao ethnic music with practical classroom teaching processes. The incorporation of Orff Schulwerk methodology into World Music pedagogy provides a viable and natural way of teaching for elementary school music teachers. Specifically, the integrated musical play, dances, and story-telling facilitate the learning experience for children, creating an encouraging and respectful environment for multicultural music study. 
The first chapter of this paper provides an overview of the study as well as the rationale and motivation for conducting this research. In chapter two, data analysis of the current presentation of Chinese music in United States' elementary music textbooks demonstrates the lack of diversity in Chinese music literature selections. In chapters three and four, the history, cultural traditions, and languages of the Dong and Miao ethnic groups are presented to provide contextual information. Chapters five and six explore the synergy between the Orff Schulwerk approach and Chinese folk music and provide a suggested curriculum for teaching the Dong and Miao folk songs collected in this study. The concluding chapter contains reflections on this study and explores future possibilities for this topic.

\subsection{Concepts}

\subsection{1 "Multicultural Music Education"}

As defined by Banks in Handbook of Research in Multicultural Education, the term "multicultural music education" "technically includes the study not only of the music of groups distinguished by race or ethnic origin, but also of the music of people of different ages, social classes, genders, religions, lifestyles, and exceptionalities."3 Johnson defines "culture" as the learned ways of thinking and behaving that enable an individual to survive in a society, ${ }^{4}$ while Volk adds that "music education" is the transmission of that part of culture expressed through music and thus that "multicultural music education"

\footnotetext{
${ }^{3}$ James A. Banks and Cherry M. Banks, Handbook of Research in Multicultural Education (New York: Macmillan, 2004).

${ }^{4}$ Norris B. Johnson, "On the Relationship of Anthropology to Multicultural Teaching and Learning," Journal of Teacher Education 28, no. 3 (May/June 1977): 10.
} 
enables one to function effectively in multiple music cultures. ${ }^{5}$ Campbell explains that the reason for multicultural music education is to study and teach music from the perspective of more than a single "dominant culture."

The perspectives on and practice of multicultural music education have varied according to the political and social norms of different times. From the turn of the twentieth century to the modern day, scholars have shifted the focus of multicultural music education from the ethnocentric standpoint to place greater value on the differences in music across cultures. Building on Pratte's definition of "multicultural" as the coexistence of unlike groups in a common social system, ${ }^{6}$ Elliot further asserts that "multicultural" connotes a social ideal, a policy of support for exchange among different groups of people to enrich all while respecting and preserving the integrity of each. ${ }^{7}$ In fact, Elliot questions the notion of "music" itself by claiming that "MUSIC is inherently multicultural." ${ }^{\prime 8}$ However, for the sake of music educators faced with the practical task of working within this conceptual framework, the catch-all phrase "multicultural music education" is used in the literature. In this study, the term "multicultural music education" refers to the transmission of music from people of diverse races, ethnicities, religions, lifestyles, and geographic locations in elementary music classroom settings.

${ }^{5}$ Terese M. Volk, "The History and Development of Multicultural Music Education as Evidenced in the "Music Educators Journal,"' Journal of Research in Music Education 41, no. 2 (summer, 1993): 137-155

${ }^{6}$ Richard Pratte, Pluralism in Education: Conflict, Clarity and Commitment (Springfield, Il: Charles C. Thomas, 1979).

${ }^{7}$ David Elliot, "Key Concepts in Multicultural Music Education,” International Journal of Music Education 13, no. 1, (1989): 11-18

${ }^{8}$ David Elliot, Music Matters: A New Philosophy of Music Education (New York: Oxford, 1995). 


\subsection{2 "World Music"}

"World Music," as defined in Britannica Academic, was introduced in the 1980s and was used to broadly characterize the music of non-English-speaking cultures worldwide. Although purists argued that no musical style should be identified as World Music, the term was coined to bring "foreign" music closer to mainstream Western popular music. By the early 1990s the term had precipitated a change in the consciousness of musicians and producers, and World Music had become a bona fide musical genre. The term is now frequently used in commercial markets to refer to non-English, non-Western recordings. Paradoxically, World Music is often synonymous with local or regional music with varied implications in different contexts and geographical regions.

Patricia Shehan Campbell distinguishes World Music education from multicultural music education as prioritizing the study of musical components over the study of cultures. World Music education is concerned with cross-cultural comparisons that span a great many musical styles across the globe instead of concentrating more narrowly and more deeply on a smaller selection of ethnic groups. It may also allow less contextualization of musical experiences as the emphasis is placed on more extensive (instead of intensive) sonic musical (instead of cultural) experiences. ${ }^{9}$

In this study, the term "World Music" is a complementary concept to "multicultural music education" and aims to describe music from cultures unfamiliar to English-

\footnotetext{
${ }^{9}$ Patricia Shehan Campbell and Carol Scott-Kassner, Music in Childhood: From Preschool through the Elementary Grades, 4th ed. (Boston: Schirmer, 2014), 384.
} 
speaking elementary students and that is not from the Western European classical genre or of American folk origin.

\subsection{3 "Orff-Inspired" Methodology}

Several main teaching methodologies are actively used by elementary music teachers in classrooms, such as the Kodaly concept, the Dalcroze method, Music Learning Theory (MLT) and the Orff Schulwerk. All of these methodologies can effectively serve the purpose of promoting active music making and interactive music learning for children, who are expected to listen, sing, play instruments, create, and move along with music.

The Orff music teaching methodology originates from the German composer and music educator Carl Orff (1895-1982), who integrated music and movement in his Schulwerk (school work) pedagogy and publications. The principal components of the Orff Schulwerk as conceived and practiced in Europe are the imitation and exploration of music with some improvisation opportunities, whereas in the adaptation in United States, the process is expanded into four stages: imitation, exploration, literacy, and improvisation. ${ }^{10}$ The official website of the American Orff-Schulwerk Association states that the purpose of Orff Schulwerk is to awaken the artistic potential in every individual and offer a context in which this can be exercised. The approach is a model for learning that involves a much broader spectrum of artistic activity than is traditionally included in music. The emphasis is on process, participation, and the cultivation of skills for creating and developing ideas within music and dance rather than on professional performance.

${ }^{10}$ Ibid. 
In this study, the Orff approach serves as the core educational philosophy guiding the curriculum design; however, it is modified in terms of the practical details to better suit the teaching of Chinese ethnic minority music. Consequently, the term "Orff-inspired methodology" is appropriate here. For example, the use of Orff instruments may be replaced by the use of instruments of Chinese origin, such as drums, and the improvisation session using Orff instruments or voice in the Orff approach may be replaced by experimenting with rhythm and note durations as it is especially difficult for children to learn to improvise in the musical style of a Chinese ethnic minority in a short time period.

\subsection{4 "Chinese Folk Music" and Related Terms}

The concept of "folk music" has been developed and discussed in many ways by scholars, musicians, and the media. The term has created issues when it has been used sometimes to construct and at other times to negate certain identities in relation to social class, ethnicities, and nations worldwide. The International Folk Music Council (IFMC), founded in 1947, attempted a definition of "folk music" at its conference in São Paolo (1955) that incorporated Sharp's three criteria and the notions of "tradition" and "oral transmission." Folk music was "the product of a musical tradition that has been evolved through the process of oral transmission." This concept embraces only music that has evolved within a community uninfluenced by "popular" and "art" music. ${ }^{11}$ Adopting this definition, I will discuss several terms related to "Chinese folk music."

\footnotetext{
${ }^{11}$ Carole Pegg, "Folk music," Grove Music Online, last modified 2001, accessed
} November 27, 2018, http://www.oxfordmusiconline.com. 
Chinese music is as diverse as the Chinese population and refers to the musical practices of people who live in China, including the Han people as well as 55 other ethnic minority groups. ${ }^{12}$ Based on the purposes of music making, Du Yaxiong categorizes Chinese music into royal court music, religious music, literati music, and folk music. ${ }^{13}$ As mentioned by Frederick Lau, folk music, or “min jian yin yue” 民间音乐 in Mandarin, simply means music "among the folk." ${ }^{14}$ Chinese folk music includes vocal music (folk songs), instrumental music, and ensemble music. However, the disparate styles and genres of folk music found in different geographic locations are closely tied to regional ethnic composition, language, and culture. The sub-categorization of Chinese folk music further indicates regional musical styles and genres. For example, the "Fengyang Flower Drum" is a piece of Han folk music from Anhui province; "Cicada Song" is a Dong folk song from Guizhou province; the "Pastoral Song" is a Mongolian folk song from Inner Mongolia, and so.

Chinese folk music and Chinese traditional music are not interchangeable terms. Chinese folk music indicates the type of musical activities carried out by the common people locally and informally for the purposes of entertainment or celebration and that has not been influenced by foreign or Western music. In contrast, Chinese traditional music refers to the music that was composed and practiced during the Qing Dynasty

\footnotetext{
12 China National Academy of Arts School of Music, An Overview of Chinese National Music 民族音乐概论 (Beijing: People's Music Publishing House, 1964).

${ }^{13} \mathrm{Du}$ Yaxiong (杜亚雄), Chinese Ethnic Minority Music (Zhong guo shao shu min zu yin yue 中国少数民族音乐) (Beijing: China Federation of Literary and Art Circles Publishing, 1986).

${ }^{14}$ Frederick Lau, Music in China (New York: Oxford, 2008), xiii.
} 
(1616-1912). To separate it from later developments in Chinese folk music in the twentyfirst century, the term "Chinese traditional folk music" is used to describe Chinese folk music that existed before the end of the Qing Dynasty.

After the twentieth century, Chinese folk music was profoundly influenced by sociopolitical factors. Scholars identify two types of folk music that are currently widespread in China. First, Zhou identifies “new folk songs” (xin min ge 新民歌), which are songs composed after the 1950s under the supervision of the communist government using some elements of existing Chinese folk music arranged with Western orchestras and electronic instruments and performed in a singing style that is profoundly influenced by the Western classical bel canto style (a style of operatic singing that originated in Italy). ${ }^{15}$ Second, “original ecology folk songs" (yuan sheng tai min ge 原生态民歌), as defined by Rees, are folk songs sung in a simple local village style and dialect by local traditionbearers. This term was invented by the Chinese media in the twenty-first century and provide a contrast to the professionally re-composed "new folk songs." ${ }^{16}$ The visibility of original ecology folk songs in China marks a revival of Chinese traditional folk music, which is untouched by the socio-political factors of modern China, and this term is favored by the modern Chinese commercial music industry. Nonetheless, the focus of original ecology folk songs is on vocal music. In this study, all the music and songs

${ }^{15}$ Zhou Qing Qing (周青青), Chinese Folk Songs (zhong guo min ge 中国民歌) (Beijing: People's Music Publishing, 1993).

${ }^{16}$ Helen Rees, "Environmental Crisis, Cultural Loss, and a New Musical Aesthetic: China's "Original Ecology Folksongs" in Theory and Practice," Ethnomusicology 60, no. 1 (2016): 54-55. 
collected from culture-bearers in Dong and Miao villages in Guizhou are considered to be original ecology folk songs in Chinese folk music.

\subsection{5 "Miao" and "Dong"}

The nomenclature of "Miao" (苗) as representing a single ethnic group has been standard in Mandarin Chinese since 1949, although historically there were variations. ${ }^{17}$ Today, the Miao people are widely distributed not only in southwest China, but also globally in Southeast Asia, Europe, America, and Australia. The Miao use various selfdesignations due to language differences within the ethnic group, such as "Hmub," "Hmong," "Mong," or even, at a stretch, "Ghaob Xiongb" in west Hunan regions, ${ }^{18}$ among other variations. In this paper, I will use the term "Miao" as the collective designation of all these people.

Similar to the nomenclature of Miao, the name "Dong" (侗) is also a standardized Mandarin term that was authorized by the Chinese government after 1949. The Dong people's self-designated name in their native language is "Kam," or "Gaeml," with less variations compared to those of Miao people. In this paper, I will use the standard name "Dong" to represent all people of this ethnicity.

\subsection{Contexts}

${ }^{17}$ Louisa Schein, "The Miao in contemporary China," in The Hmong in Transition, ed. G.L. Hendricks, B.T. Downing, and A.S. Deinard (Staten Island: Center for Migration Studies, 1986), 73-85.

${ }^{18} \mathrm{Wu}$ Xiaodong (吴晓东), “The Origin of Names and Surnames in the Eastern Miao Dialect” (dong bu fang yan miao zu zi cheng yu xing shi lai yuan kao 东部方言苗族自称 与姓氏来源考), Journal of Huaihua Teachers College (huai hua shi zhuan xue bao 怀化 师专学报) 16, no. 2 (June 1997). 


\subsubsection{Multiculturalism in Music Education}

Music education was brought to the United States by European immigrants from the seventeenth century. It was used as a key tool to establish cultural identities as well as to enhance community bonding among European settlements but was restricted to mostly religious content. ${ }^{19}$ After the constitution was ratified in 1788 , a new republic replaced the previously loose confederation and brought together people of different origins and religions. A new form of music education was needed to reflect the diverse cultures in the "melting pot" of the United States.

By the early twentieth century, immigration had led to increasingly complex domestic ethnic composition. Belief in music universalism and "Americanization" grew as the United States' population became a more incongruous mix. Assimilation and amalgamation were thought to be important purposes of music education. ${ }^{20}$ At the time, scholars promoted the idea of music as a "universal language" in music curricula, assuming that understanding the music of one culture (in this case Western European music culture) would provide an understanding of music in all cultures. ${ }^{21}$ In music education literature, music diversity was mainly reflected in the inclusion of folk songs from all regions of Europe, which were stylistically similar to the music of Western Europe and Great Britain.

\footnotetext{
${ }^{19}$ Michael L. Mark and Charles L. Gray, A History of American Music Education, 3rd ed. (Lanham, MD: Rowman \& Littlefield Education, 2007), 49-58.

${ }^{20}$ Terese M. Volk, "Folk Music and Increasing Diversity in American Music Education," Journal of Research in Music Education 42 (1994): 285-305.

${ }^{21}$ Sangmi Kang, "The History of Multicultural Music Education and Its Prospects: The Controversy of Music Universalism and Its Application," Update: Applications of Research in Music Education 34, no. 2 (2016): 21-28.
} 
According to Volk's study into folk music in U.S. music education in 1900-1916, music of non-European origin, such as Native American and African American music, was also introduced. This music, however, was thought to be "primitive" or "in the stage of the development toward the style of Western classical music," based on music evolution theory proposed by scholars such as Stumpf, Hornbostel, and Sachs. ${ }^{22}$ The unfamiliar characteristics of the music of these cultures, such as unique vocal ornamentations and quarter tones, was not addressed in music education. Only the pieces that had appealing melodies or were similar in style to the dominant Western music style were selected, and these pieces were arranged with Western harmonies and piano accompaniments. $^{23}$

From the second half of the twentieth century, an alternative view of music emerged as non-universalism took root in academia in various fields such as anthropology, ethnomusicology, and psychology. In 1956, scholars including David McAllester, Alan Merriam, Willard Rhodes, and Charles Seeger established the Ethno-Musicology Society, which explores musical and social phenomena relating to cultural pluralism. ${ }^{24}$ The concept of "music non-universalism" was finally elucidated by Bruno Nettl's proposition that, "We are moving towards greater specialization. Were we to continue this line of thought, our next step would be to find non-universals which nevertheless are very

\footnotetext{
${ }^{22}$ Ibid, 22.

${ }^{23}$ Volk, "Folk Music and Increasing Diversity in American Music Education," 295.

${ }^{24}$ Peter G. Toner, "The Gestation of Cross-Cultural Music Research and the Birth of Ethnomusicology," in Humanities Research: Historizing Cross Cultural Research ed. B. Penny (Canberra, Australia: The Australian National University Press, 2007), 86.
} 
widespread." ${ }^{25}$ John Blacking argued, "It is the activities of Man the Music Maker that are of more interest and consequence to humanity than the particular musical achievements of Western man," and believed that since music is culture-specific, every music type should be analyzed in its social and cultural context. ${ }^{26}$

The awareness of cultural diversity in music education raised in United States after several significant milestones in the 1960s. In 1967, the Tanglewood Symposium, a project undertaken by the Music Educators National Conference, was held to discuss and define the role of music education in contemporary U.S. society and to improve the effectiveness of music education. Participants were not limited to music educators, and in fact were mainly musicologists, sociologists, scientists, and people involved with other aspects of music. It was declared that, "Music of all periods, styles, forms, and cultures ... including avant-garde music, American folk music, and the other cultures" should form part of music education curricula. ${ }^{27}$

The term "multicultural education" was adopted in the 1970s, replacing formerly problematic terms such as "intercultural education" and "multi-ethnic education." Scholars such as Gibson, Gay, Banks, and Pratte outlined "approaches" or "concepts" of multiculturalism and the purposes and educational implications of each. The concept of

${ }^{25}$ Bruno Nettl, “On The Question of Universal," The World of Music 19 (1977): 2-13.

${ }^{26}$ John Blacking, How Musical Is Man? (Seattle: University of Washington Press, 1973), 3-4.

${ }^{27}$ A.C. Robert, B.F. Charles, E.B. Charles, and L.G. Wersen, "The Tanglewood Symposium: Music in American Society," Music Educators Journal 54, no. 3 (1967): 4980 . 
multiculturalism expanded throughout the 1980s to include differences of religion, age, gender, socio-economic status, and mental and physical ability. ${ }^{28}$

In the United States, the diversity of the population continues to grow at an astonishing rate. Between 2000 and 2010, 92\% of population growth was that of ethnic minorities, a trend that shows no sign of stopping. ${ }^{29}$ Multicultural music education will become the norm in elementary school music education in the near future, and we as music educators must continue to improve the representation of all cultures worldwide.

\subsubsection{Issues of Authenticity in Folk Music}

In the early twenty-first century, the concept of music as the universal language in U.S. music education led to inauthenticity when introducing music from other cultures. As social unification was the primary goal of education in this period, people made efforts to find similarities rather than differences, which reflected the strong belief in music universalism. ${ }^{30}$ As multicultural music content in music textbooks continues to grow rapidly, the controversial topic of authenticity constantly emerges in multicultural music education. The popular practice of "Westernizing" World Music has become problematic as Western-style harmonies, mistranslations of texts, and modifications of rhythms and pitches found their way into music literature and teaching. ${ }^{31}$

In 1992, Palmer defined "absolute authenticity" in multicultural music as follows:

\footnotetext{
${ }^{28}$ Volk, "The History and Development of Multicultural Music Education," 138.

${ }^{29}$ J. Christopher Roberts and Patricia Shehan Campbell, "Multiculturalism and Social Justice," in The Oxford Handbook of Social Justice in Music Education, ed. C. Benedict et al. (Oxford University Press, 2015), 283.

${ }^{30}$ Kang, "The History of Multicultural Music Education and Its Prospects," 22.

${ }^{31}$ Anthony J. Palmer, "World Musics in Music Education: The Matter of Authenticity," International Journal of Music Education 19, no. 1 (1992): 32-40.
} 
1. Performance by the culture's practitioners, recognized generally by the culture as artistic and representative.

2. Use of instruments as specified by the composer or group creating the music.

3. Use of the correct language as specified by the composer or group creating the music.

4. For an audience made up of the culture's members.

5. In a setting normally used in the culture. ${ }^{32}$

Palmer also notes that although these standards are nearly impossible to achieve in practical settings due to music's natural fluidity, music educators should be aware of what they are taking away from the "authentic" experience when making compromises.

In discussions of acceptable degrees of compromise, Campbell proposes the pedagogical concept of "teaching and learning in its original context." ${ }^{33}$ In addition to its meaning in relation to performance, space, occasion, and/or function, Waterman suggests that "context" is commonly used as a catchall referring to "any and all factors that may be shown to impinge directly upon the production of musical sound" or its meanings. ${ }^{34}$ Changes from the original language and mediums are significant alterations; artistic expression is weakened when it becomes generalized and losses specificity. There is no

\footnotetext{
${ }^{32}$ Ibid, 35.

${ }^{33}$ J. Christopher Roberts and Amy C. Beegle, World Music Pedagogy Vol. 2: Elementary Music Education (New York: Routledge, 2018), 17.

${ }^{34}$ Christopher A. Waterman, Jùjú: A Social History and Ethnography of an African Popular Music (Chicago: University of Chicago Press, 1990), 214.
} 
empirical evidence to show that generalization and simplifications of cultural music increases students' musical abilities or their understanding and appreciation of music. ${ }^{35}$

David Elliot also elaborated on the notion of authenticity, as summarized by C. K.

Szego:

First, authenticity is a call to performance: making music is the most genuine musical endeavor as well as the source of all musical experience. Second, musicianship and listenership are authentic to the extent that they are grounded in authentic performance of styles and genres. Achieving authenticity can therefore necessitate a set of mutually dependent conditions. Third, one can assess the authenticity of a performance on the basis of how true to style the performers sing or play, as well as the context in which the music is sung or played. And finally, there are some styles and genres of music that are inherently authentic, while others, such as school music, which have been contrived for pedagogical or other purposes, are not. ${ }^{36}$

Elliot expresses concern over the degree of authenticity in school music, particularly regarding the loss of context and purpose of music from other cultures. Elliot recognizes, however, that any type or form of musical practice is genuine musical endeavor, and thus "authentic" exists, in some sense, between the performer and audience. In pedagogical settings at elementary school, necessary compromises in authenticity contribute to the success of the classroom music teaching process, but music teachers should always utilize local resources from communities, such as professional musicians or culturebearers, to honor the authenticity of music from other cultures.

Another question in multicultural music education concerns the selection of music literature that is representative of its culture of origin. China contains dramatically

${ }^{35}$ Palmer, "World Musics in Music Education." 35.

${ }^{36}$ Kati Szego, "Praxial Foundations of Multicultural Music Education," in Praxial Music Education: Reflections and Dialogues, ed. David J. Elliot (New York: Oxford University Press, 2003), 196-198. 
disparate languages and musical cultures and is one of the most difficult countries to represent in music classes. Bell Yung, an ethnomusicologist specializing in Chinese music, raised the question of the authentic representation of Chinese music saying, "There are so many kinds of Chinese music, catering to so many kinds of Chinese people. What is considered to be authentic by some Chinese may not be so to others." ${ }^{37}$

In my interview with Tang Desong ${ }^{38}$ (唐德松), Dean of Guizhou Minzu University’s

School of Music and Dance, he expressed his view on the "authentic" folk music of Miao traditions:

The music of our ethnic group [Miao] is fluid like a river, it evolves with history. Each singer had their own interpretation and taste, and they made changes to the song when passing it down to the children. The song sung by my grandmother may sound different than the same song sung by my great-grandmothers, and for sure will be different from how my daughter sings it, but the song is still a traditional Miao folk song with our unique characteristics. Simply speaking, the music is authentic if our Miao people approve it as our folk music, even though it might have been changed or influenced by other cultures over time." 39

Bruno Nettl also points out that too often Native American music is still taught as a static and unchanging phenomenon in music classrooms, while in reality, dynamic processes are continually present and the music is constantly in flux due to "cultural interaction, acculturation, and transculturation." ${ }^{40}$

\footnotetext{
${ }^{37}$ Patricia Shehan Campbell and Bell Yung, "Bell Yung on Music of China: As Part of the "Music in Cultural Context" Series," Music Educators Journal 81, no. 5 (1995): 3946.

${ }^{38}$ In Chinese, people's last names always precede their first name in formal and casual settings.

${ }^{39}$ The original interview was in Mandarin Chinese and took place on July 12, 2018.

${ }^{40}$ Bruno Nettl, The Western Impact on World Music, Change, Adaptation, and Survival (New York: Schirmer Books, 1985), 33-36.
} 
When talking about "authenticity", it is also important to recognize that within any given culture there is probably no single authoritative musical representation of a group. ${ }^{41}$ Even in the most homogeneous musical cultures, there may be many different stylistic approaches to the same song. Some differences are simply due to the nature of oral transmission. There are various versions of the five music pieces collected and presented in this study even in Guizhou province alone. This should not, however, undermine the authenticity of any one of these different versions. Almost all types of folk music in China have been passed down through oral traditions. Even if there are written notations, these transmit only minimal instructions for performance and allow a large degree of freedom for individual interpretation. Unlike the Western tradition of honoring composers for their individual contributions, most Chinese traditional music and almost all folk music was composed anonymously. Music educators must recognize these heterogeneities and communicate them effectively to students or students will be at risk of misunderstanding or over-generalizing the complexity and multidimensionality of music making as a human and social endeavor.

\subsubsection{Chinese Folk Music in the West}

According to the 2017 population estimates published by the United States Census Bureau, Asian Americans make up $6.3 \%$ of the total population, with $1.3 \%$ of the total population being of Chinese ethnicity. ${ }^{42}$ The various languages spoken in China, collectively referred to as "Chinese," is the third most-spoken language in the United

\footnotetext{
${ }^{41}$ Szego, "Praxial Foundations of Multicultural Music Education," 200-201.

${ }^{42}$ United States Census Bureau. Accessed March 20, 2017.
} 
States. People come from different parts of China, speak different dialects or languages and live vastly different lives in their regional cultures, and yet "Chinese" is used to describe all Chinese languages and cultures. Within music education, the Chinese music literature selected for inclusion in U.S. music textbooks fail to reflect the diversity of Chinese cultures. Eight million Uyghurs live in the northwest province of Xinjiang, an ethnic minority who speak Turkic languages, practice Islam, and have developed extraordinary music and dance through their long history. In the southwest Yunnan and Guizhou provinces reside more than 40 distinct ethnic groups, each of which have a unique music culture and language. In the northern province of Inner Mongolia, four million people of Mongolian descent live on the rolling grasslands and practice their unique vocal art inherited from the time of Genghis Khan. Unfortunately, the music of these ethnic groups is rarely, if ever mentioned in music textbooks in the U.S.

For many years, music scholars both inside and outside China have turned their attention to the written literature and the important role of the Han people's music traditions while overlooking the music of other ethnic groups in formal historical terms. ${ }^{43}$ Due to the social turbulence experienced in China in the twentieth century, China's musical culture went through a tremendous transformation, shaped by the political influences of central government as well as the perceived supremacy of Western civilizations. From metropolitan areas, such as Beijing, Shanghai, and Hong Kong, then gradually to more rural regions, major changes occured in folk music in terms of structure, form, genre, and lyrical content.

${ }^{43}$ Frederick Lau, Music in China (New York, Oxford University Press, 2008), 13. 
The earliest Chinese folk song to become well-known in the West was "Mo Li Hua" (茉莉花) or “Jasmine Flower.” Puccini included it in his opera Turandot, after he heard of the tune from the booklet Chinese Music by J. A. Van Aalst. ${ }^{44}$ This famous tune still appears frequently in current elementary music textbooks, although the song name and lyrics often change.

At the end of the nineteenth century, the first batch of Chinese music scholars were sent to Europe and Japan to study Western classical music. Among this group were the founding fathers of Chinese modern music education and compositional styles. Musicians such as Wang Guangqi (王光祈), Xiao Youmei (萧友梅), Li Shutong (李叔同), and others invented a new genre called “Classroom Songs” (xue tang ge 学堂歌), ${ }^{45}$ which are rooted in Chinese traditional urban folk music and innovated using Western music theories. These musicians and scholars collected volumes of folk music and re-edited many of them to ease the transmission of Chinese folk music worldwide for political propaganda, Westernized urban music education, and missionaries to adopt as hymns.

When the United States joined World War II, a series of books on Chinese music and culture was published as the U.S. government acknowledged the need to change stereotypes and images of China among the public as China was now an ally. ${ }^{46}$ The

\footnotetext{
${ }^{44}$ William Ashbrook and Harold Powers, Puccini's Turandot: The End of the Great Tradition (Princeton, New Jersey: Princeton University Press, 1991).

${ }^{45} \mathrm{Yu}$ Jiafang (余甲方), Chinese Modern Music History (zhong guo jin dai yin yue shi 中 国近代音乐史) (Shanghai: Shanghai Renmin Press, 2006), 224-230.

${ }^{46}$ Jennifer Lynn Talley, "An American Song Book: An Analysis of the Flower Drum and Other Chinese Songs by Chin-Hsin Chen and Shih-Hsiang Chen" (master's thesis, Florida State University, 2010), x-xi.
} 
Christian church in China also helped promote Chinese folk music in Europe and the U.S. during this period. Bliss Wiant, the founder (in 1919) and chair of the Music Department at Yenching University, and Tz-Zeung Koo, who was a YMCA leader during the 1920s, both published collections of Chinese folk songs in the 1940s for publication in the United States and United Kingdom respectively. ${ }^{47}$ Prominent Chinese scholars and musicians in the U.S. also contributed to Chinese folk music collections, such as ChinHsin Yao Chen and Shih-Hsiang Chen's The Flower Drum and Other Chinese Songs published in 1943. In addition, service members of the American Education Mission gathered materials from their experiences in Asia. For instance, Betty Warner Dietz published her Folk Songs of China-Japan-Korea after her service in Korea during 19521953. ${ }^{48}$ These Chinese song collections were the first of these types of resources available to American music textbook editors, and many of the songs that appeared in these collections were included in textbooks and are still taught to children today. ${ }^{49}$

\subsubsection{From the "New Folk Song" to the "Original Ecology Folk Song"}

Upon the establishment of the People's Republic of China (P.R.C.) in 1949, almost all foreigners left China faced with an unclear political outlook and strict diplomatic policies. This made it difficult for the rest of the world to learn about the changes that took place in China's domestic urban culture and socio-political environment in the 1950s-1980s. Traditional folk songs that used to be popular in urban cities were now

\footnotetext{
${ }^{47}$ Tz-Zeung Koo, Folk Songs From China (London: The Hon. Lady Cripps, 1943). ${ }^{48}$ Betty Warner Dietz and T.C. Park, Folk Songs of China, Japan, Korea (New York: The John Day Company, 1964).

${ }^{49}$ As will be illustrated in the data discussed in chapter two.
} 
considered to be the remnants of feudalism and were replaced by "new folk songs" (xin min ge 新民歌). One of the purposes of new folk songs was to reflect China as a "unified multi-national socialist country, ${ }^{, 50}$ and thus these songs included many elements from Chinese ethnic minority folk songs. Many traditional folk songs were given new lyrics that primarily praised the new and better life people could now enjoy under the governance of the Communist Party and the joy of freedom granted by the Red Army (hong jun 红军). These revised folk songs were mostly converted into Mandarin Chinese and their original lyrics were often lost. The government also encouraged professional musicians to write original compositions using elements from traditional folk music from Chinese ethnic minorities for professional song and dance troupes to perform on stage. These new compositions were called "new folk songs" as well. The result was that all new folk songs were performed in Mandarin and featured a standard staged performance style that reflected little of their origins. Nevertheless, the popularity of new folk songs greatly promoted the nationwide study of ethnic minority music, bringing these overlooked musical heritages into view and marking the beginning of systematic ethnomusicology studies in non-urban areas.

From the turn of the millennium, the term "original ecology folk songs" began to emerge in the Chinese media and quickly gained popularity among the public. As Helen Rees points out in her research, "these songs and the related discourse stress ties to place, cultural authenticity, and the interrelationship of physical environment with human

${ }^{50}$ Helen Rees, Echo of History (Oxford University Press, 2000), 23. 
culture." ${ }^{51}$ Through oral transmission, many original ecology folk songs remained relatively unaltered in terms of their lyrics, melody, and styles for generations, preserving pre-industrialized and pre-Westernized regional music cultures. In the last few decades, ethnomusicologists from China and worldwide have conducted extensive research and fieldwork in the residential regions of Chinese ethnic minorities and the media has highlighted the stage performances of original ecology folk songs. This interest emphasizes the importance of ethnic minorities' cultural heritages in the study of Chinese music.

Due to the lack of communication between the West and the P.R.C. from the 1950s to the 1970s and the tremendous change in Chinese society and cultural environment after 1949, a fissure in cultural conversation between the two sides still exists today. Consequently, Chinese music literature in elementary music textbooks is dated and unrepresentative of the whole of Chinese culture. Beginning in the 1970s, Western ethnomusicology scholars have become increasingly interested in the study of the music of Chinese ethnic minority groups. Nonetheless, even today, specialized books published in English and aiming to introduce the music of China still devote little attention to ethnic minority music, and elementary music textbooks in U.S. rarely contain any music literature from diverse cultures in China.

\subsubsection{Ethnic Minorities in China}

Dating back to the Tang Dynasty (618-907), the central government of China deployed the Tusi (土司) system to incorporate ethnic minority states along the borders

\footnotetext{
${ }^{51}$ Helen Rees, "Environmental Crisis, Cultural Loss, and a New Musical Aesthetic," 53.
} 
into Chinese territory. This system recognized tribal leaders as imperial officials, allowing them autonomy in their own reigns. During the Ming (1368-1644) and Qing Dynasties (1644-1912), ethnic minority states in the southwest experienced multiple insurgencies, which signaled to the royal court that new policy was necessary to enhance centralized control over those states. Based on the philosopher-official Wang Yangming’s (王阳明) advocation of joint administration by local chiefs and central government officials to promote gradual sinification, named “gai tu gui liu (改土归 流)," 52 the Ming government replaced many of the tribal leaders with Han officials from the royal court. ${ }^{53}$ With military forces and family members entering the southwest region along with the Han government officials, communication and assimilation between the Han and other ethnic groups started to appear. ${ }^{54}$ As a result, people from different ethnic backgrounds in the southwest went through a gradual process of integration, which was reflected in their cultures and music. Looking both ways, the impact of this policy not only manifested in the Han people's awareness of ethnic minorities in China and their distinct musical cultures, but also enriched regional folk music with imported music elements and instruments from the central plains and foreign lands.

52 “改土归流” (gai tu gui liu). The literal translation of this phrase is "to change soil back to fluid (officer)." This refers to the political reformation movement that centralized control over ethnic minority regions. “流官制” (liu guan zhi) is the name of the system whereby Han officials were appointed to office in remote ethnic regions for a specific term.

${ }^{53}$ Patricia Buckley Ebrey, The Cambridge Illustrated History of China, 2nd ed., (Cambridge: Cambridge University Press, 2010), 197.

${ }^{54} \mathrm{Yu}$, Chinese Modern Music History, 68. 
As of 2010, the P.R.C. officially recognizes 56 nationalities (minzu 民族) and 55 ethnic minorities who collectively make up $8.5 \%$ of the total population in China. ${ }^{55}$ Adopting the principles outlined by Stalin, specifically that, "A nation is a historically constituted, stable community of people, formed on the basis of a common language, territory, economic life, and psychological make-up manifested in a common culture," the process of classifying ethnicities in China started in 1950 and ended in 1987. Although the dominance of the Han ethnicity prevailed in Chinese society into the late twentieth century, the government of the P.R.C. aimed to promote a sense of unity and equality among all ethnicities. As opposed to the cultural assimilation policies pursued by Imperial China, the P.R.C. government encouraged ethnic minorities "to develop their dialects and languages, to preserve or reform their traditions, customs and religious beliefs," as noted in the 1949 The Common Program of the Chinese People's Political Consultative Conference.

Among the 55 ethnic minority groups in China, many have developed their written languages only in recent centuries, while a significant portion of these ethnic groups do not have or have lost their written languages. Therefore, music was a fundamental tool used to pass down memories, social customs, cultures, traditions, and religions to the next generation and a cornerstone of educational content. In contemporary society, the majority of the young generations of these ethnic groups are well-educated in both speaking and writing Mandarin Chinese. Traditional ethnic folk music, however, is

\footnotetext{
${ }^{55}$ National Bureau of Statistics of China, accessed March 27, 2019.

${ }^{56}$ Joseph Stalin, Marxism and the National Question (Moscow: Co-operative Publishing Society of Foreign Works in the U.S.S.R, 1935).
} 
indispensable in children's education to enable them to establish their cultural identity, to understand social mores, and to comprehend their history.

\subsubsection{Miao and Dong Ethnic Groups in Guizhou Province}

As Mark Bender explains, "The broken uplands of southwest China range from the dry, pine-and-rhododendron-covered hills of northern Yunnan Province to the fantastic limestone karst peaks nestled along the green river valleys of Guangxi and Guizhou. In these uplands live millions of members of some of China's 55 ethnic minority nationalities. ${ }^{\prime 57}$ Due to the difficulty of physically accessing these areas, the ethnic groups in the southwest mountain areas have passed down their diverse traditions for thousands of years and display extremely different styles and genres of music to Han people with little interference from the central plain regions (Fig. 1).

${ }^{57}$ Mark Bender, "Hunting Nets and Butterflies: Ethnic Minority Songs from Southwest China," Manoa 12, no. 1 (2000): 80-86. 


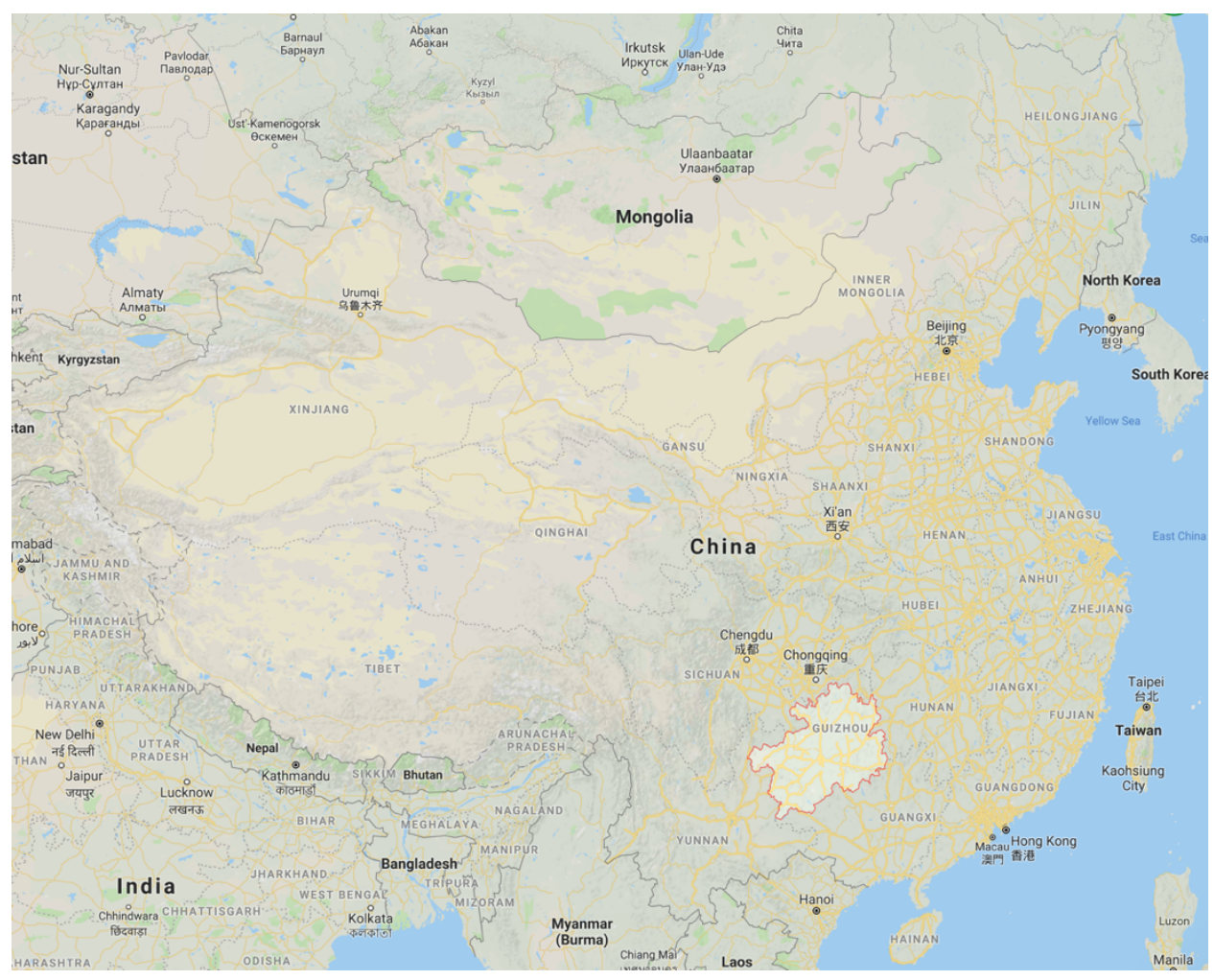

Figure 1: Map of China. ${ }^{58}$

In Guizhou province, there are seven ethnic minority groups with larger populations than others, among which are the Miao and the Dong, which account for $12.2 \%$ and $4.6 \%$ of Guizhou's provincial population respectively. ${ }^{59}$ The geographic distribution of the seven ethnic minority groups is illustrated in Figure 2, with Miao (苗) areas highlighted in blue, Buyei (布依), Shui (水) areas in yellow, Dong (侗) in pink, Tujia (土家) in brown, Gelao (仡佬) in light blue, and Yi (彝) in light green. The numbers in the map represent the nine prefectures of Guizhou province. Region number 9 is the Qiandongnan

\footnotetext{
${ }^{58}$ Google Map. Accessed March 27, 2019.

${ }^{59}$ National Bureau of Statistics of China (中华人民共和国国家统计局), accessed March 27, 2019.
} 
Miao and Dong Ethnic Autonomous Prefecture, ${ }^{60}$ where I conducted my exploratory field research (Fig. 2).

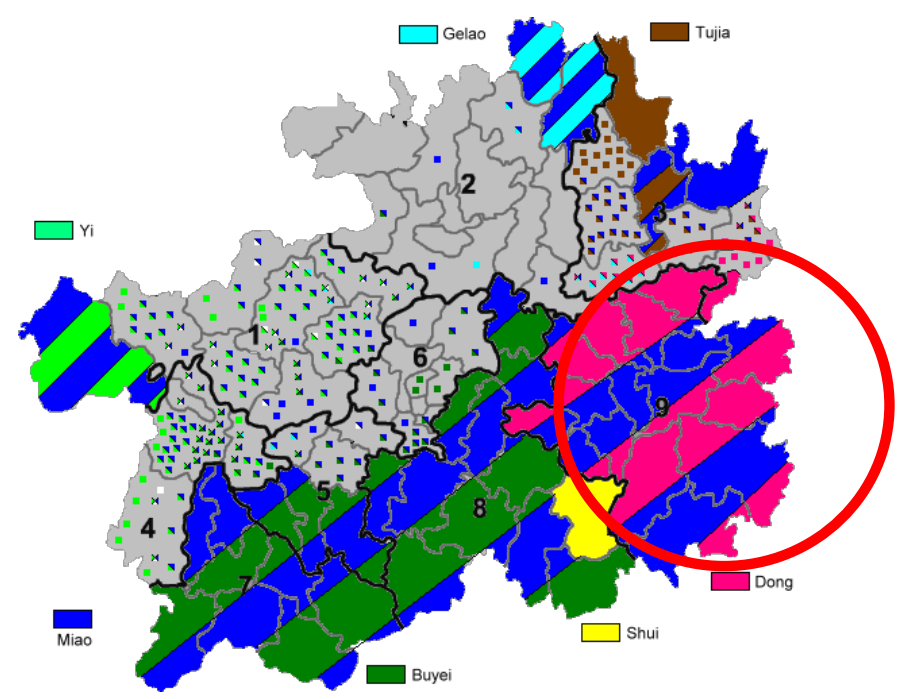

Figure 2: Ethnic minorities areas in Guizhou. ${ }^{61}$

Although Miao and Dong villages are relatively close in terms of absolute distance, the natural terrain, disparate languages and cultures, and separate religions have hindered communication and marriage between the two groups. Although almost all languages in China belong to the Sino-Tibetan language family, the Miao and Dong languages are remarkably different from the Han languages and dialects of the central plain. According to linguistic studies, Miao languages are branches of Miao-Yao languages, also known as Hmong-Mien languages, which are geographically distributed across Southern China and Southeast Asia (mainly in Vietnam and Laos) ${ }^{62}$ Dong languages belong to Tai-Kadai languages, also known as Kra-Dai languages, which are geographically distributed in

${ }^{60}$ Qian dong nan miao zu dong zu zi zhi zhou 黔东南苗族侗族自治州

${ }^{61}$ Kaiyr, Autonomies in Guizhou in Wikipedia.

${ }^{62}$ Christina Eira, "Hmong and Hmong-Mien (Miao-Yao) Languages," in Routledge Encyclopedia of Linguistics, ed. Philipp Strasny (London: Routledge, 2005). 
Southern China, Northeast India and Southeast Asia (mainly in Myanmar and Thailand). ${ }^{63}$ These linguistic studies provide evidence that suggests a possible connection between the residents of continental Southeast Asia and ethnic minority groups in southwest China. Dong and Miao music also shares similar characteristics to some regional music in Southeast Asia, thus the music literature presented in this study may relate to a broader audience in Asia and worldwide; however, this hypothesis is not examined in this study.

Miao and the Dong folk music has had a profound influence on modern Chinese musical culture and is highly visible in the domestic media, while their polyphonic vocal and instrumental music has even attracted international attention among ethnomusicologists. Scholars and musicians worldwide have come to conduct fieldwork in Miao and Dong villages and in so doing have recorded their traditional folk music, published studies with song collections, and helped the indigenous musicians reach a global audience. Despite the academic interest from the field of ethnomusicology, Miao and Dong folk music has yet to be included in multicultural music education in music classrooms.

In the summer of 2018, I boarded a plane to China and carried out an exploratory field trip in southeast Guizhou around the city of Kaili 凯里 (region number 9 in Figure 2 named Qiandongnan). This is an area where the musical cultures of the Miao and Dong peoples have previously been well-documented and studied extensively by scholars and

\footnotetext{
${ }^{63}$ Britannica Academic, s.v. "Tai languages,” accessed November 28, 2018,
} https://academic.eb.com/levels/collegiate/article/Tai-languages/109796. 
musicians. I drove to a variety of villages in Congjiang 从江 county, Rongjiang 榕江

county, Liping 黎平 county, and Taijiang 台江 county and recorded the music and dance performances I observed in both formal, staged settings and informal settings and I visited a few senior musicians who are certified as "Inheritors of Intangible Cultural Heritage." ${ }^{64}$ I also interviewed two university professors on how Dong and Miao folk music could be successfully introduced into an elementary classroom setting and who enlightened me on this topic by sharing their experiences and insights.

\subsubsection{Why Orff-Inspired Methodology?}

From the very beginnings of the Orff Schulwerk, ${ }^{65}$ Carl Orff was influenced by the music of other cultures and times. He wrote that it is "never music alone but a unity with movement, dance, and speech." ${ }^{\prime 66} \mathrm{He}$ employed drums and rattles of "exotic models, mostly African"67 to accompany dance at the Guntherschule he established in Munich. Orff recalled in his writing that "a small Chinese drum was the source of inspiration for a whole scene" as he was familiar with Chinese and other Asian music. The Orff Institute Guidelines note that Orff methodology is "sustained by a humanist world philosophy, and an educational concept marked by anthropological conditions which recognizes the

\footnotetext{
64 “Inheritors of Intangible Cultural Heritage" in Mandarin Chinese is 非物质文化遗产 传承人 (fei wu zhi wen hua yi chan chuan cheng ren).

${ }^{65}$ Schulwerk means "school work" in German. Thus Orff Schulwerk is often simplified as Orff or the Orff methodology/approach in English.

${ }^{66}$ Carl Orff, "Orff-Schulwerk: Past and Future," in Orff Re-Echoes, ed. Isabel McNeill Carley (Cleveland, OH: American Orff-Schulwerk Association, 1977), 6.

${ }^{67}$ Carl Orff, "The Schulwerk", Carl Orff/Documentation: His Life and Works Volume 3, trans. Margaret Murray (Tatzing: Schott, 1976), 18.
} 
capacity in all human beings to communicate and express themselves through speech, movement, and music." 68

In many elementary schools today, music teachers who adopt Orff methodology often find their classes connect with many other subjects, such as arts, sciences, language studies, and social studies. Orff music classrooms that are rich in World Music content provide a friendly and inclusive environment for children to learn how to transcend cultural, racial, and socioeconomic barriers. ${ }^{69}$ Notable case studies include that of the Indian-raised music teacher Manju Durairaj in the Chicago Orff Chapter who introduced Carnatic music and Sargam syllables with simple percussive accompaniment using Orff methodology, ${ }^{70}$ and Chet-Yeng Loong, who demonstrated Chinese children's singing games using the Orff approach at the 2006 AOSA National Conference. ${ }^{71}$ These and other such examples have inspired more teachers to consider Orff methodology when practicing multicultural music education in elementary schools.

The Orff Schulwerk guidelines do not impose a one-size-fits-all curriculum, but rather help illuminate basic concepts inherent in Orff practices that should be common to all contexts. Comparing the Orff approach guidelines and the traditional Dong and Miao music education methods, parallels are observed in the two education settings:

\footnotetext{
${ }^{68}$ Orff Institute Guidelines, Orff Schulwerk Informationen - "50 Jahre Orff-Institut”. (Jahre Orff-Institut, 2011), 85.

${ }^{69}$ Pam Hetrick, "International Voices: An Introduction," Orff Echo 39, Issue 2 (2007).

${ }^{70}$ Manju Durairaj, "Introducing Indian Music and Dance through Orff Schulwerk," Orff Echo 46, Issue 2 (2014).

${ }^{71}$ Beth Iafigliola, "From the AOSA Video Library: Chinese Children's Songs and Singing Games," Orff Echo 39, Issue 2 (2007).
} 
1. Using the vernacular and the rhythm of spoken language.

2. Teaching through an imitative call-and-response process.

3. Building layers of melody in multiple parts.

4. Incorporating dance and body movements.

5. Improvising within a cultural context.

When teaching American folk songs to children, teachers sometimes ask their students to speak the words to the right rhythm before singing. Similarly, Chinese folk songs are often first taught through being spoken with a melody added later. Dong and Miao languages, however, are tonal languages, in which the tonal inflections of the lyrics are connected with the melody of a song. ${ }^{72}$ Although the various Dong and Miao languages and dialects have different tonal structures, in their folk music it is typically the case that the melody of a song will conforms to the tones of the lyrics. When they study these folk songs, the connection between languages and music can open a door for children into language studies and social studies, and interdisciplinary study is often welcomed in Orff music classrooms.

The oral tradition of music education in Dong and Miao cultures is similar to the imitative call-and-response process used in Orff music classrooms. Senior Miao and Dong music teachers would employ something similar to what we observe in the Orff teaching process, dividing children into two or three parts and layering distinct melodies one on top of the other. Through this process children gradually develop a sense of inner-

\footnotetext{
${ }^{72}$ Murray Schellenberg, "Does Language Determine Music in Tone Languages?" Ethnomusicology: Journal of the Society for Ethnomusicology 56, no. 2 (2012): 269-270.
} 
hearing through singing their own part concurrently with a harmony of sound, and they begin to perceive music as an integrated entity rather than disjointed sounds.

Much Chinese folk music is related to certain dances, activities, and festivals in local life, which provide scenarios and stories that can be woven into Orff music classroom experiences. It is essential for children to understand that music is contextual and exists within certain cultures, histories, and traditions. The final goal of teaching students how to improvise in the style of a particular cultural tradition in both the Orff approach and traditional Dong and Miao music education, is for the student to obtain a high level of mastery over a particular style of music. Since there is no written sheet music in Dong and Miao culture, the ability to improvise using the correct style, one that arouses people's emotions, is a crucial education goal when Dong and Miao teachers pass down musical traditions over the generations.

Designing a curriculum centered on the teaching of Chinese ethnic minority folk music in the setting of elementary music classroom is a daunting task. There are many roadblocks for teachers as they endeavor to fully comprehend a specific cultural context in a short amount of time, and more barriers in the actual teaching process. With this in mind, I will present my suggestions on how Dong and Miao folk music can be taught using Orff-inspired methodologies and will encourage teachers to incorporate their own understanding and practices in actual classroom teaching. 


\section{Quantitative Observations of Chinese Music in United States' Elementary Music Textbooks}

\subsection{Objectives}

The purpose of this chapter is to examine the historical background of Chinese folk music as represented in United States' elementary music education, to present the issues that arise in the current situation, and to demonstrate the importance of introducing Chinese ethnic minority folk music into multicultural music education. In this study, data are collected from New Music Horizons, published by the California State Department of Education in 1950, World of Music, a 1990 work by Silver-Burdett and Ginn, and Making Music by Silver-Burdett. These books are commonly used in education in California today and include Chinese music literature seen in elementary music textbooks collected by the San José State University (SJSU) music education library. After collecting this Chinese music, I attempted to identify the original or the earliest traceable source of the music in non-Chinese publications in the West.

Chinese music is frequently seen in music textbooks published in the U.S., although it is limited in quantity and variety. The culture-bearers, however, often feel distant from the Chinese songs presented in textbooks. In interviews with three Chinese international students at SJSU, all three stated that they had never heard of the song "Trot Pony Trot," which appears in several music textbooks as a Chinese folk song, and they consider this song to be a typical example of stereotyped Chinese music in the U.S. These three Chinese students, who grew up in China, do not acknowledge the Chinese music presented in these music textbooks as part of any Chinese musical culture they are familiar with. Cultural context is significantly weakened, often lost, when songs are sung 
in English, arranged with Western harmonies, and recorded by Western classical-style choirs. To better understand the representation of Chinese music in U.S. elementary music textbooks, this quantitative study was conducted to provide insights into where the Chinese folk music taught comes from and whether they can serve the purpose of fostering a respectful understanding of Chinese music in young children.

\subsection{Data Collection}

In the data collected, there are a total of 88 occurrences of Chinese folk songs $(\mathrm{N}=88)$ in 58 elementary music textbooks $(\mathrm{N}=58)$ published between 1950 and 2014 in the U.S. The following two charts illustrate the distribution of music textbooks according to the publishing company and the time of publishing.

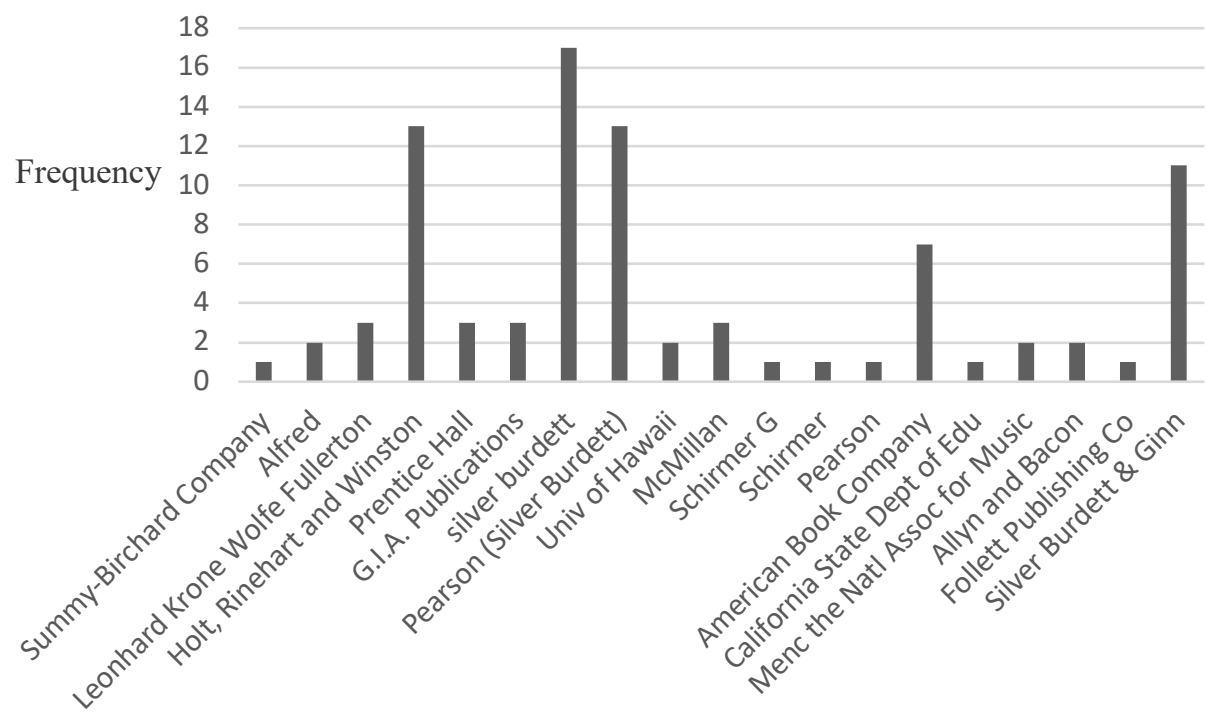

Figure 3: Number of books by publisher. 


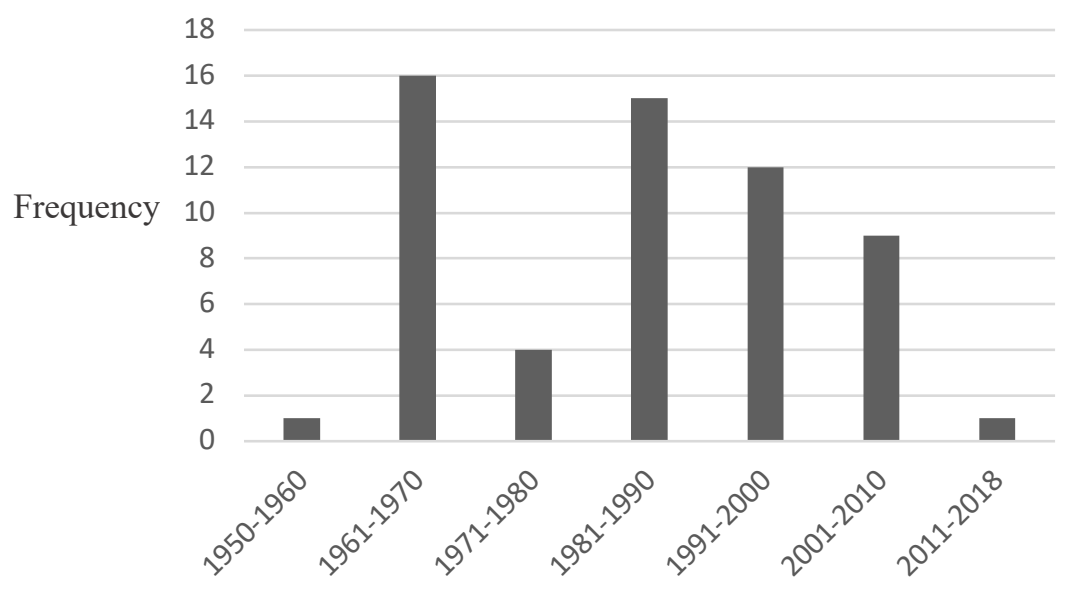

Figure 4: Number of books by publishing date.

The following table lists all the Chinese folk songs in the sample (Table 1). In many cases, a Chinese song may be presented in different languages and with different arrangements, titles, and even lyrics, but the melodic content should always be the same. For example, the Chinese folk song “Mo Li Hua” 茉莉花 (“Jasmin Flower”) appeared in multiple music textbooks with different lyrics and under different names such as "Jasmine Blossom," "Jasmine Flower," "Spring in China," "Spring Song," "Lotus Blossom," and "Flower Gift."

There is one special case in this data sample, the song “Fengyang Hua Gu” 凤阳花鼓 (“Fengyang Flower Drum”), which appears under different titles and with different lyrics, arrangements, AND melodic content. Alternative titles observed in music textbooks include "Fengyang Song," "Fengyang Flower Drum," "Fengyang Drum," and "Feng Yang Hua Ku.” In China, "Fengyang Hua Gu” represents a specific genre of folk music that is commonly practiced with dance and drum percussion in the Fengyang region of Anhui province. There are two songs of this genre that gained popularity across Chinese 
metropolitan areas in the twentieth century, both called "Fengyang Hua Gu" in Mandarin. Both songs are included in Chin-Hsin Yao Chen and Shih-Hsiang Chen's The Flower Drum and Other Chinese Songs under their Mandarin name. One of the two songs is much more commonly used in music textbooks than the other, which only appeared once in the data collection process. Thus, no distinction is made between the two songs that fall under the title "Fengyang Flower Drum" in this study. 
Table 1: Chinese Folk Songs in U.S. Elementary Music Textbooks

\begin{tabular}{|c|c|c|c|c|c|}
\hline No. & $\begin{array}{c}\text { Song Name } \\
\text { (standardized) }\end{array}$ & Count & No. & $\begin{array}{c}\text { Song Name } \\
\text { (standardized) }\end{array}$ & Count \\
\hline 1 & $\begin{array}{l}\text { Fengyang Flower } \\
\text { Drum }\end{array}$ & 11 & 21 & How Chun Koh & 1 \\
\hline 2 & $\begin{array}{l}\text { The Purple } \\
\text { Bamboo }\end{array}$ & 8 & 22 & The Young Monk & 1 \\
\hline 3 & Jasmine Blossoms & 6 & 23 & Song of three "Nots & 1 \\
\hline 4 & $\begin{array}{c}\text { Yangtze } \\
\text { Boatman's Chantey }\end{array}$ & 5 & 24 & Ancient Wisdom & 1 \\
\hline 5 & Crescent Moon & 5 & 25 & Tum Tum June & 1 \\
\hline 6 & Trot Pony Trot & 4 & 26 & Pai Pi Qiu & 1 \\
\hline 7 & Frogs & 4 & 27 & Diu Shou Juan & 1 \\
\hline 8 & Home from School & 4 & 28 & $\begin{array}{l}\text { Hua Yuan Li De } \\
\text { Yang Wa Wa }\end{array}$ & 1 \\
\hline 9 & $\begin{array}{l}\text { Rice Planting } \\
\text { Song }\end{array}$ & 3 & 29 & Colorful Boat & 1 \\
\hline 10 & Meng Jiang Nv & 2 & 30 & Spring in China & 1 \\
\hline 11 & Niu Lang Zhi Nv & 2 & 31 & Ai Hai Yo & 1 \\
\hline 12 & Yu Guang Guang & 2 & 32 & song of the crow & 1 \\
\hline 13 & Lak Gei Moli & 2 & 33 & $\begin{array}{l}\text { Entrance Hymn for } \\
\text { the Emperor }\end{array}$ & 1 \\
\hline 14 & $\begin{array}{l}\text { A Boat on the } \\
\text { Lake (Tai Hu) }\end{array}$ & 2 & 34 & Yi Mung Mountain & 1 \\
\hline 15 & Temple Bell & 2 & 35 & Spring Song & 1 \\
\hline 16 & Silver Moon Boat & 2 & 36 & Song of the Hoe & 1 \\
\hline 17 & Golden Bells & 2 & 37 & Little Friends ${ }^{`}$ & 1 \\
\hline 18 & $\begin{array}{l}\text { Dragon Boat } \\
\text { Festival }\end{array}$ & 1 & 38 & Nursery Song & 1 \\
\hline 19 & Chinese New Year & 1 & 39 & Thinking of You & 1 \\
\hline 20 & Chimes at Night & 1 & & & \\
\hline
\end{tabular}




\subsection{Tracing the Origins of Chinese Folk Music in Music Textbooks}

One of the challenges of tracing the origins of the Chinese folk songs collected for this study is the limited information on these songs provided by the textbooks, such as copyright information, name of the writer of the English lyrics, name of the arranger, name of the collector, and so on. Nevertheless, the spreadsheet has successfully led us to some of the most important source texts for Chinese folk music in U.S. music education. These early compilations of Chinese folk songs, published from the 1940s to the 1960s, have shaped people's view of Chinese music, and they can provide a critical sociopolitical context for scholars and music educators to better understand the Chinese folk music literature we see in today's textbooks.

Table 3 displays the ten songs found most frequently in data collection, along with the earliest recorded source texts of these songs published in Europe and the U.S. Three of the ten songs (colored in grey) appeared in music textbooks without an identifiable external source, while the other seven songs can be found in specialized Chinese folk music collections published in the West. Acknowledging the possibility that additional, unidentified sources exist, five of the source texts found collectively contribute 40 out of the 88 Chinese folk songs in this data sample. It is necessary to take a closer look at these five source texts to comprehend the historical context in which they were created and to examine the original form in which these songs were introduced to the U.S. 
Table 2: Top 10 Chinese Songs in U.S. Elementary Music Textbooks with Source Texts

\begin{tabular}{|c|c|c|c|c|}
\hline No. & $\begin{array}{l}\text { Song Names } \\
\text { (standardized) }\end{array}$ & Count & Source Text & Book Author \\
\hline \multirow[b]{2}{*}{1} & \multirow{2}{*}{$\begin{array}{r}\text { Fengyang } \\
\text { Flower Drum } \\
\text { 凤阳花鼓 }\end{array}$} & \multirow[b]{2}{*}{11} & $\begin{array}{l}\text { The Pagoda: Thirteen } \\
\text { Chinese Songs (1946) }\end{array}$ & Bliss Wiant \\
\hline & & & $\begin{array}{c}\text { The Flower Drum and } \\
\text { Other Chinese Songs } \\
(1943)\end{array}$ & $\begin{array}{l}\text { Chin-Hsin Yao Chen and } \\
\text { Shih-Hsiang Chen }\end{array}$ \\
\hline \multirow[b]{2}{*}{2} & \multirow{2}{*}{$\begin{array}{l}\text { The Purple } \\
\text { Bamboo } \\
\text { 紫竹调 }\end{array}$} & \multirow[b]{2}{*}{8} & $\begin{array}{l}\text { Folk Songs from China } \\
\text { (1943) }\end{array}$ & Tz-Zeung Koo \\
\hline & & & $\begin{array}{c}\text { The Flower Drum and } \\
\text { Other Chinese Songs } \\
(1943)\end{array}$ & $\begin{array}{l}\text { Chin-Hsin Yao Chen and } \\
\text { Shih-Hsiang Chen }\end{array}$ \\
\hline 3 & $\begin{array}{l}\text { Jasmine } \\
\text { Blossom } \\
\text { 茉莉花 }\end{array}$ & 6 & Chinese Music (1884) & J. A. Van Aalst \\
\hline 4 & $\begin{array}{c}\text { Yangtze } \\
\text { Boatman's Chantey } \\
\text { (Chinese name } \\
\text { unknown) } \\
\end{array}$ & 5 & $\begin{array}{l}\text { The Pagoda: Thirteen } \\
\text { Chinese Songs (1946) }\end{array}$ & Bliss Wiant \\
\hline 5 & $\begin{array}{c}\text { Crescent Moon } \\
\text { 康定情歌 }\end{array}$ & 5 & Music (1985) & Silver Burdett (Publisher) \\
\hline 6 & $\begin{array}{l}\text { Trot Pony Trot } \\
\text { (Chinese name } \\
\text { Unknown) }\end{array}$ & 4 & $\begin{array}{l}\text { Exploring Music } \\
\quad(1966)\end{array}$ & $\begin{array}{l}\text { Holt, Rinehart and Winston } \\
\text { (Publisher) }\end{array}$ \\
\hline 7 & $\begin{array}{c}\text { Frogs } \\
\text { 数蛤蟆 }\end{array}$ & 4 & $\begin{array}{l}\text { Folk Songs of China, } \\
\text { Japan, Korea (1964) }\end{array}$ & $\begin{array}{c}\text { Betty Warner Dietz and } \\
\text { T.C. Park }\end{array}$ \\
\hline 8 & $\begin{array}{l}\text { Home from } \\
\text { School } \\
\text { (Chinese name } \\
\text { unknown) }\end{array}$ & 4 & $\begin{array}{l}\text { The Pagoda: Thirteen } \\
\text { Chinese Songs (1946) }\end{array}$ & Bliss Wiant \\
\hline 9 & $\begin{array}{l}\text { Rice Planting } \\
\text { Song } \\
\text { 插秧舞 }\end{array}$ & 3 & $\begin{array}{l}\text { New Dimension In } \\
\text { Music (1970) }\end{array}$ & $\begin{array}{l}\text { American Book Company } \\
\text { (Publisher) }\end{array}$ \\
\hline 10 & $\begin{array}{l}\text { Meng Jiang Nu } \\
\text { 孟姜女 }\end{array}$ & 2 & $\begin{array}{c}\text { The Flower Drum and } \\
\text { Other Chinese Songs } \\
(1943)\end{array}$ & $\begin{array}{l}\text { Chin-Hsin Yao Chen and } \\
\text { Shih-Hsiang Chen }\end{array}$ \\
\hline
\end{tabular}




\subsubsection{Chinese Music (1884)}

The Belgian-born author J. A. Van Aalst was a foreign employee working for the Chinese Imperial Maritime Customs Service in the Qing Dynasty in the late nineteenth century. ${ }^{73}$ While providing his services as a government official, he chronicled the history of Chinese music and dance. Van Aalst's records served as the key source of information on Chinese music in the Western world until other sources emerged in the $1950 \mathrm{~s} .{ }^{74} \mathrm{His}$ book, Chinese Music, which was published in 1884 in Shanghai by the Statistical Department of the Inspectorate General, is not only an extensive documentation of the Chinese music present across Chinese society, such as the music of the royal court, literati music, religious music, and popular folk music in urban areas, but also provides a detailed explanation of traditional Chinese music theory and Chinese musical instruments. Although many of the music excerpts collected by Van Aalst are no longer played in modern China, this book remains an extremely valuable resource for Western scholars when studying Chinese traditional music.

This book may be the first publication written by a musician that introduced Chinese music to the West. Several songs from Van Aalst's Chinese Music have been selected for elementary music textbooks, such as “The Fresh Beautiful Flower” 鲜花 75 and “The Guiding March", which is named "Entrance Hymn of the Emperor" in New Dimension In Music.

${ }^{73}$ J. A. Van Aalst, Chinese Music (Shanghai: The Inspector General of Customs, 1887).

${ }^{74}$ Kuo-huang Han, "J. A. Van Aalst and His Chinese Music," Asian Music 19, no. 2 (1988): 127.

${ }^{75}$ This is an alternative name of the song “Mo Li Hua” 茉莉花 (“Jasmin Flower”). 


\subsubsection{The Flower Drum and Other Chinese Songs (1943)}

Collected and created by Chin-Hsin Yao Chen and Shih-Hsiang Chen, this songbook includes seventeen folk songs from both Northern and Southern China and was published in 1943 in the United States. Pianist Chin-Hsin Yao Chen contributed the piano arrangements for the folk songs based on simple counterpoint and open intervals that avoided "Pseudo-Oriental" harmonization stereotypes. ${ }^{76}$ Shih-Hsiang Chen wrote the English lyrics for all 17 songs. Chinese characters and Wade-Giles Romanization are provided in the book, as well as background information on the music written by ChinHsin Yao Chen .

The book was published immediately after the U.S. joined World War II, when the diplomatic policies and attitudes toward China had started to change due to their position as an ally of the U.S. in the war. Pianist Chin-Hsin Yao Chen was born and raised in China, spent four years studying music in California, when this songbook was published, and then returned to China to teach at the Chinese Central Conservatory of Music. The folk songs included in the collection are tunes that were popular in Chinese cities in the 1930s-1940s.

\subsubsection{Folk Songs From China (1943)}

This collection was published in the same year as The Flower Drum and Other Chinese Songs, first in London and then in New York. Ten Chinese folk songs were collected by Tz-Zeung Koo and then co-edited, arranged, and translated by Arthur

\footnotetext{
${ }^{76}$ Henry Cowell, "Preface," in The Flower Drum and Other Chinese Songs, Chin-Hsin Yao Chen and Shih-Hsiang Chen (New York: The John Day Company, 1943), 6.
} 
Waley, Irene Gass, and Reginald Redman. Each song is preceded by a brief introductory paragraph that tells us something about its history; the lyrics are presented in English using simplified solfege syllables for teaching purposes; and the songs are arranged with piano accompaniments.

The collector of these folk songs, Tz-Zeung Koo, was a Chinese Christian leader in the early twentieth century who was active overseas after being exiled from China and who later became a prisoner of war detained in Hong Kong. Until the late 1920s, traditional missionaries typically restrained from using Chinese instruments and tunes out of the fear that "uncivilized" ideas would infiltrate church services. In the late 1920s, TzZeung Koo, now the leader of the YMCA, started to collect Chinese folk songs in songbooks, some of which had only existed orally before Koo's transcription. He frequently traveled worldwide to deliver speeches advocating for the Chinese Christian church. He was well received in his visits and appreciated for his wisdom and charisma and made a significant contribution to transforming Christianity in China from a "daughter church" to a "sister church" of the West. ${ }^{77}$ Besides his religious influence, Koo also propagated Chinese music in the Western world by introducing Chinese folk music into church hymns and performing the flute for Western audiences. This songbook was edited and published in Britain after Koo was imprisoned. It reflects his impact as an ambassador of Chinese culture to the West in the early twentieth century.

${ }^{77}$ Ronald Hall, T. Z. Koo: Chinese Christianity Speaks to the West (London: SCM Press, 1950), 16. 


\subsubsection{The Pagoda: Thirteen Chinese Songs (1946)}

This book was named after the thirteen-story pagoda, "Water Tower Pagoda," at Yenching University, Peiping (now Beijing). It consists of thirteen songs all translated into English and arranged as Western harmonies. On the cover page, the editor writes:

This pagoda is the epitome of the spirit which dominates modern China, namely that the beauty of Chinese culture shall be combined with the utilitarian values of American life. In this small book of songs the same principle has been followed, namely, to accompany the beautiful melodies of China with Western harmonic and contrapuntal material so that community singing of the songs may be more easily achieved..$^{78}$

The editor, Bliss Wiant, was an missionary who went to China in 1923 and stayed for 28 years, assuming the Chinese name Fan Tian Xiang (范天祥). Wiant periodically returned to the U.S. for further study in music and obtained a Ph.D. in music from Peabody College in 1946 with his thesis entitled "The Character and the Function of Music in Chinese Culture." During his stay in China, he established the Music Department at Yenching University, a Christian University in Beijing established by John Leighton Stuart in 1919. He dedicated his life to writing and editing hymns for Chinese Christian churches that were more accessible to Chinese audiences. He collected folk songs in China, mainly from the urban area of Beijing, and wrote new Chinese lyrics that could serve a religious purpose. Building on the work of Tz-Zeung Koo and collaborating with Tzu-Chen Zhao (赵紫宸), Dean of Yenching University, in 1936, Bliss Wiant published the first Chinese psalm book, the Hymns of Universal Praise (Pu Tian Song

\footnotetext{
${ }^{78}$ Bliss Wiant, The Pagoda: Thirteen Chinese Songs (Delaware, Ohio: Cooperative Recreation Service, 1946).
} 
Zan 普天颂赞), which includes 72 songs. ${ }^{79}$ Later, when he returned to the United States because of the complicated political situation in China, he published The Pagoda:

Thirteen Chinese Songs (1946) to promote Chinese hymnody in the U.S. This book was one of the first Chinese folk song collections published in the United States, and it represented the Chinese urban folk music of the early twentieth century, although lyrics were translated into English and the songs were arranged according to Western harmonic rules.

\subsubsection{Folk Songs of China-Japan-Korea (1964)}

This folk song collection includes 25 songs from China, Japan, and Korea presented in both English and their native languages with mostly two-part harmonic arrangements. The lyrics are written in Chinese, Japanese, or Korean with both English phonetic spelling and hand-written original characters, which provides extremely valuable information and relevancy for teachers and students who know these languages or hope to learn these songs in their original languages.

The editor of this text, Betty Warner Dietz was a service member of the American Education Mission to Korea in 1952-53. A graduate of Northwestern University, she received her doctorate in education from New York University and became an assistant professor at Brooklyn College in 1950. The co-editor, T.C. Park, was a Korean educator who specialized in music, received his doctorate in education from the University of

\footnotetext{
${ }^{79}$ C. Michael Hawn, "History of Hymns Rise to Greet the Sun," The United Methodist Church, accessed October 10 2018, https://www.umcdiscipleship.org/resources/historyof-hymns-rise-to-greet-the-sun.
} 
Florida, and became an associate professor at Florida Memorial College in St.

\section{Augustine. ${ }^{80}$}

The importance of this songbook is manifested in many ways: the recognition of East Asian folk music in U.S. elementary school education, the respectful presentation of original languages, and the careful preparation of and research into the music selected. Through the inclusion of original language characters, Dietz gives us a way to expand music classes into language studies and social studies. Dietz also acknowledged the difficulty of tracing the origins of these folk songs. As she wrote, "such is the growth of a folk song! Origins are forgotten. Changes in melody, rhythm, and words develop as the song passes orally from one group to another...but we must remember that a folk song always has more than one version, and we must expect to find these variations." ${ }^{81}$ Dietz's work in this folk song collection is an excellent attempt to present World Music literature in elementary music education settings.

\subsection{Language Representation}

In U.S. elementary music textbooks, the lyrics of Chinese folk songs are presented in a few different ways, be it in English, Chinese, or a type of Chinese Romanization. Chinese Romanization is the use of the Latin alphabet to write Chinese as Chinese uses a logographic script and its characters do not represent phonemes directly. The English lyrics are usually written based on two methods: one is to translate directly from the Chinese, but the more common approach is to write new English lyrics. As the lyrics of

${ }^{80}$ Dietz and Park, Folk Songs of China, Japan, Korea.
${ }^{81}$ Ibid, 2. 
Chinese folk songs may change depending on who performs them and the time and place in which they are performed, it is difficult to determine whether the English lyrics are entirely new or inspired by a version of the Chinese lyrics. Chinese Romanization is sometimes included to provide guidance in pronunciation; however, Chinese characters are not always included with the Romanization. Without being visually presented alongside Chinese characters, it is challenging for culture-bearers to understand the lyrics through Romanization, not to mention the confusion caused by the different types of Chinese Romanization used. In general, presenting Chinese folk songs with English lyrics and using Chinese Romanization without including Chinese characters is problematic as the lyrical content is loosely connected with culture and Chinese Romanization itself speaks to neither American nor Chinese culture. These factors raise challenges for music teachers and students to understand the contextual meaning of the lyrics of Chinese folk songs found in textbooks.

Figures 5 and 6 display how the lyrics of Chinese songs are presented in the sample music textbooks from 1950 to 2014 . The first chart shows that $81 \%$ of all Chinese songs do not have Chinese characters included in the lyrics or in the references section, while $13 \%$ of the songs do include Chinese characters, and $6 \%$ are presented with vocables, which have no meaning. The second chart considers situations where Chinese lyrics are presented in Romanized format and finds that $34 \%$ of the Chinese songs in the sample textbooks contain pronunciation information on Mandarin or Cantonese Chinese lyrics, and $59 \%$ of the songs have only English lyrics. 


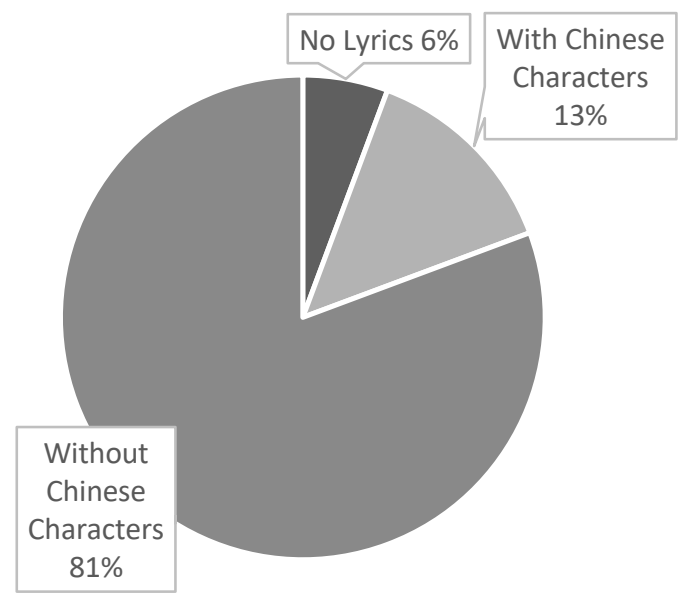

Figure 5: Presence of Chinese characters in lyrics in textbooks from 1950 to 2014.

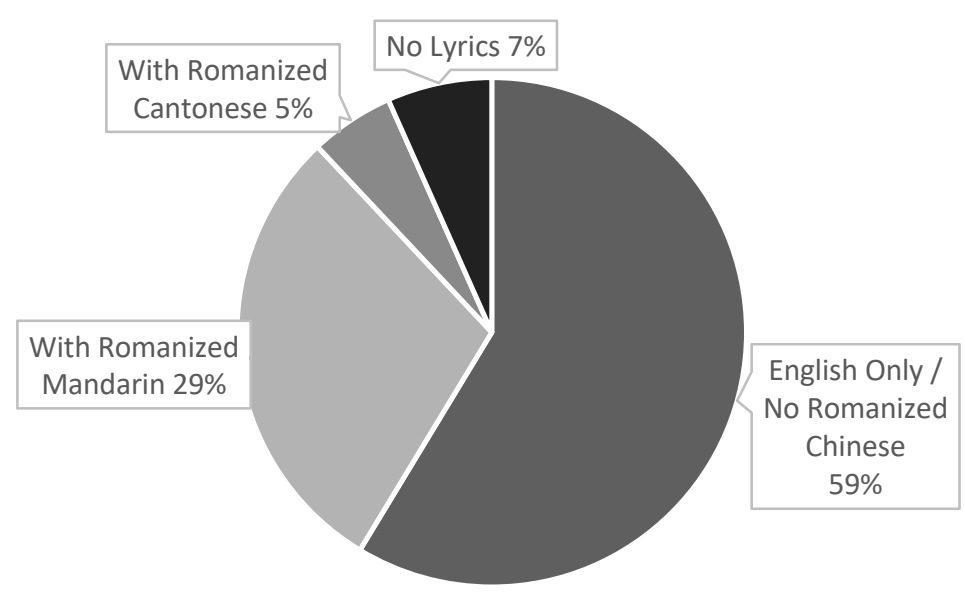

Figure 6: Romanized Chinese in lyrics of Chinese songs in textbooks from 1950 to 2014.

For the purpose of further exploring whether the lyrics of Chinese folk music are being better presented in elementary music textbooks today, the following charts compare language representation in different time periods: Figures 7 and 8 display the situation in 1990-2014, whereas Figures 9 and 10 shows language representation in more recent years 
in 2000-2014. We can conclude from the comparison of the three time periods 19502014, 1990-2014, and 2000-2014, that there were noticeable increases in the inclusion of Chinese characters and Romanized Chinese in the lyrics of Chinese folk songs that appear in elementary music textbooks. Among the sample textbooks published in 19502014, only 13\% of Chinese songs contained Chinese characters in their lyrics; however, in $1990-2014$, this percentage had increased to $23 \%$; and in the more recent period of 2000-2014, 44\% of Chinese songs included Chinese characters. Along with the improvement of language representation in Chinese folk songs in textbooks, nonMandarin folk songs have started to appear, such as Cantonese songs and Taiwanese songs, adding to the diversity of what are considered as "Chinese folk songs." 


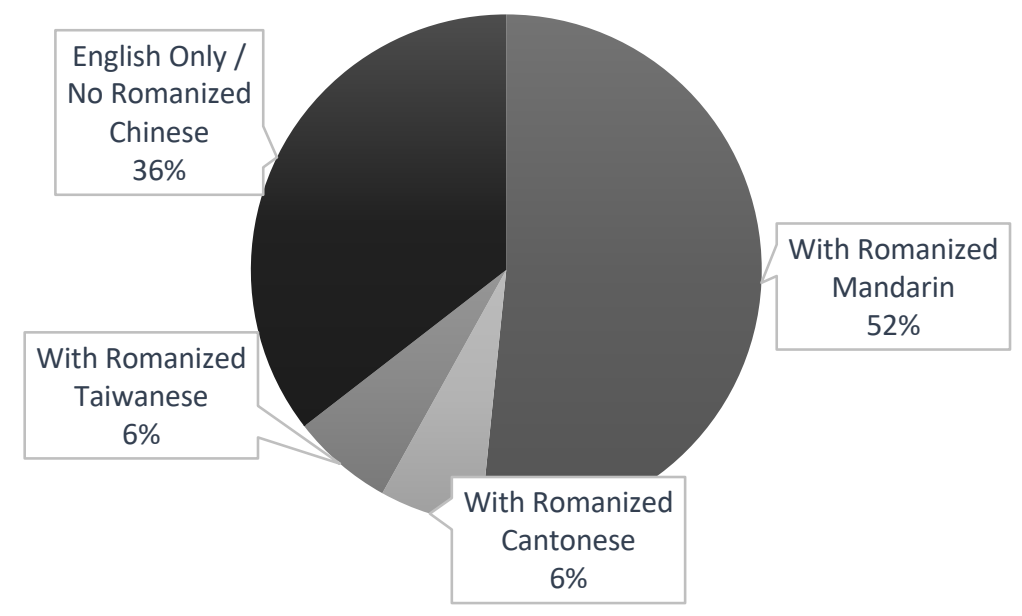

Figure 7: Romanized Chinese in lyrics in textbooks from 1990 to 2014.

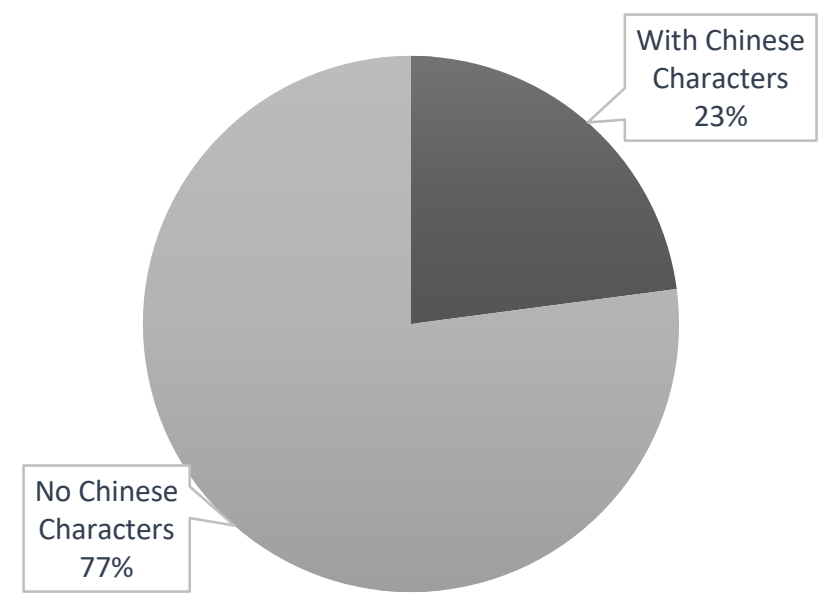

Figure 8: Chinese characters in lyrics of Chinese songs in textbooks from 1990 to 2014. 


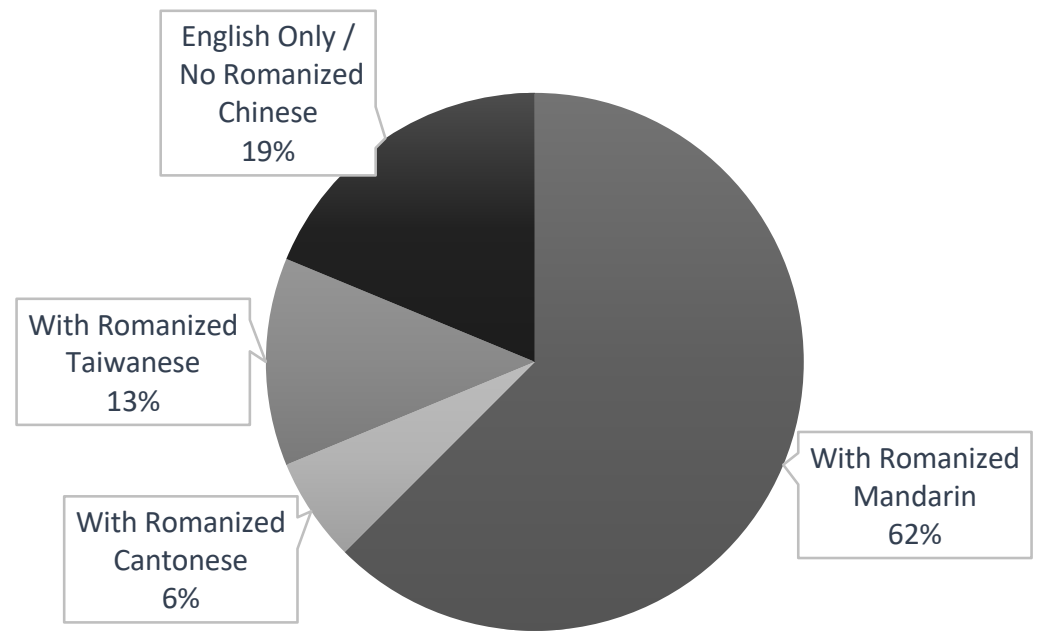

Figure 9: Romanized Chinese in lyrics in textbooks from 2000 to 2014.

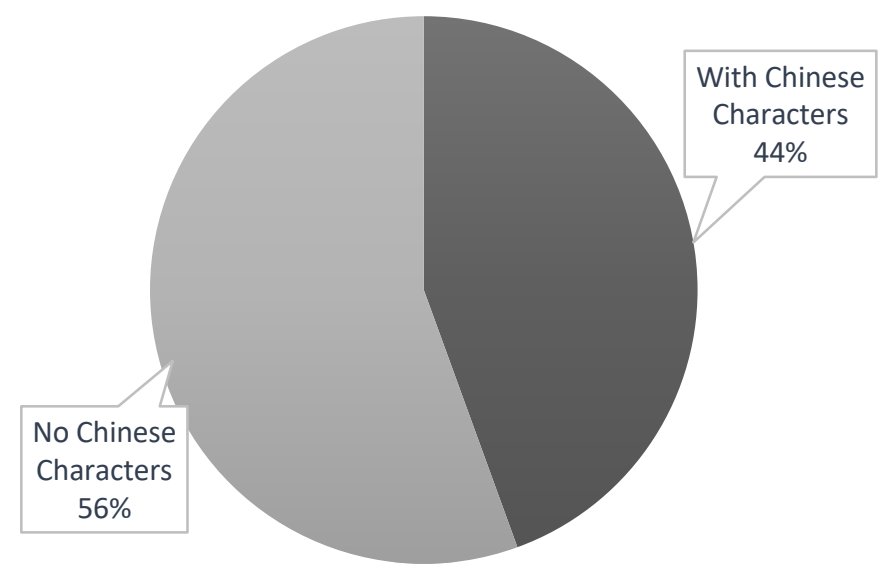

Figure 10: Chinese characters in lyrics of Chinese songs in textbooks from 2000 to 2014. 


\subsection{Chinese Romanization Systems}

Three main types of Chinese Romanization systems are used in the textbooks: Pinyin, Wade-Giles, and English phonetic spelling of Chinese characters. Other Chinese Romanization systems are less used, such as Tongyong Pinyin and Yale. It is important to recognize that different Chinese characters may have the same pronunciation and Romanization, thus Chinese Romanization are not truly a substitute for Chinese characters in written communication. The ultimate goal of employing any Chinese Romanization system should be to aid the learning of Chinese characters since Romanized Chinese does not contain semantic meanings only guidance on pronunciation. Although the Pinyin system is currently the standardized Romanization system for Chinese characters recognized worldwide, the Wade-Giles system continues to be used in some regions and has merged with Tongyong Pinyin in Taiwan, which is still in use today. The system of English phonetic spelling is a recent invention in the U.S. and is designed to help students connect English pronunciations with Chinese words; however, the system was never standardized and relies on individual discretion in choosing vowels and consonants to represent sounds.

Among the three Romanization systems, the internationally acknowledged Pinyin system requires the most training but provides the most accurate pronunciation of Mandarin Chinese; the Wade-Giles system, a historical legacy, requires less training but

provides less accurate pronunciation of Mandarin Chinese; and English phonetic spelling requires the least effort, correspondingly provides less accurate pronunciation of Mandarin Chinese, and exists as a non-standardized approach to Chinese languages. 


\subsubsection{Pinyin}

The Hanyu Pinyin (汉语拼音, “Chinese language spelled sound”) was developed in the 1950s by a group of linguists led by Zhou Youguang and was based on several existing systems namely, Gwoyeu Romatzyh of 1928, Latinxua Sin Wenz of 1931, and the diacritic markings from Zhuyin. ${ }^{48}$ The system employs some English letters in unfamiliar ways for English speakers, such as " $\mathrm{x}$ " for the fricative alveolo-palatal sound (6), and " $\mathrm{q}$ " for the aspirated affricate alveolo-palatal sound $\left(\mathrm{t}^{\mathrm{h}}\right)$. The diacritic markings of the four language tones are included in all pedagogical publications while being largely omitted in spellings of names and places for simplification in the printing process. However, diacritic markings are essential, along with semantic context, for native speakers to identify the Chinese characters that are represented by Pinyin.

Western media began using Hanyu Pinyin from the 1980s, influenced by the development of diplomatic relations between the United States and the P.R.C. in $1979 .{ }^{49}$ Pinyin was recognized internationally as the standard Romanization system of Chinese characters by the United Nations in $1986 .{ }^{50}$

\footnotetext{
48 John Rohsenow, "Fifty years of script and written language reform in the PRC: the genesis of the language law of 2001" in Language Policy in the People's Republic of China: Theory and Practice Since 1949, ed. Zhou Minglang and Sun Hongkai (Boston: Kluwer Academic Publisher, 1989), 23.

${ }^{49}$ Edith Terry. How Asia Got Rich: Japan, China and the Asian Miracle (Armonk, NY: M.E. Sharpe, 2002), 632.

${ }^{50}$ Margalit Fox, "Zhou Youguang, Who Made Writing Chinese as Simple as ABC" in The New York Times (14 January 2017).
} 


\subsubsection{Wade-Giles}

The Wade-Giles Romanization system for Chinese characters was developed by Thomas Francis Wade, a scholar of Chinese and a British ambassador in China who was the first professor of Chinese at Cambridge University. The system was completed by a British diplomat, Herbert A. Giles, in his Chinese-English Dictionary of 1892, and was further refined in 1912 by Herbert Giles' son, Lionel Giles. Taiwan has used Wade-Giles as the de facto standard for decades, and it has continued to exist in Taiwan even after being officially replaced by several other Romanization systems in succession, namely, Gwoyeu Romatzyh (1928), Mandarin Phonetic Symbols II (1986), and Tongyong Pinyin (2000). With the election of the Kuomintang Party in Taiwan in 2008, Taiwan officially

switched to Hanyu Pinyin. However, many people in Taiwan, both native Taiwanese and foreigners, still use or transcribe their legal names using the Wade-Giles system as well as the other aforementioned systems. As early Chinese emigration to the U.S. was mostly from Taiwan and Cantonese areas, Tongyong Pinyin or the Wade-Giles system has continued to be popular in the U.S. to the present day.

\subsubsection{English Phonetic Spelling}

Initially appearing in Chinese language learning books for English speakers, English phonetic spelling was a supplementary pronunciation guide on top of standard Chinese Romanization such as Pinyin and Wade-Giles. For example, a website aiming to help English speakers learn the rules of Pinyin notes that "can" in Pinyin is pronounced as 
"tsahn" in English phonetic spelling. ${ }^{82}$ Little research has been done on this phonetic spelling system, and its origins remain obscure. This Romanization system is casual, with un-standardized choices of consonants and vowels to represent Chinese pronunciation and un-uniform rules for phonetic spellings.

Since the purpose of English phonetic spelling is to aid pronunciation, this unstandardized Chinese Romanization system should not be used by itself to substitute any standardized Chinese Romanization system or Chinese characters. The similarities between Wade-Giles and some English phonetic spellings (Pinyin is quite different) may cause confusion among those who are unaware of these different systems of Chinese Romanization. In some cases, these two Romanization systems are used together and forge new inventions in Chinese Romanization that do not conform to rules in any standardized system. These new inventions are all categorized as English phonetic spellings in the data analysis. The table below provides examples to demonstrate the differences between the three Romanization systems (Table 4).

Table 3: Comparison of Chinese Romanization Systems and IPA

\begin{tabular}{|c|c|c|c|c|}
\hline $\begin{array}{l}\text { Chinese } \\
\text { Characters }\end{array}$ & Pinyin & Wade-Giles & $\begin{array}{l}\text { Phonetic Spelling } \\
\text { (unstandardized) }\end{array}$ & IPA \\
\hline 青 & qing & ching & cheeng & t $6^{\mathrm{h}} \bar{\partial} \mathrm{y}$ \\
\hline 阵 & zhen & chen & jehn & tş̀n \\
\hline 行 & xing & hsing & Sheeng & cán \\
\hline 菜 & cai & tsai & tsai & $\underline{\text { ts }}^{\mathrm{h}} \mathrm{ai}$ \\
\hline
\end{tabular}

${ }^{82}$ Xiaojin Zhou, "How to Pronounce Chinese Names," last modified April 13, 2005, http://www.cs.cmu.edu/ zhuxj/readpinyin.html. 


\subsubsection{The Complex Situation of Chinese Romanization}

Within the 88 collected Chinese songs from the music textbooks surveyed, 23\% display Chinese Pinyin in their lyrics, 10\% display Wade-Giles Romanization, 7\% display English phonetic spelling, and 14\% display Chinese characters. There is overlap between these categories since there are usually multiple lines of lyrics that use different representative systems under the music staves. In the U.S., for historical reasons, all these romanization systems co-exist among different Chinese-American communities. People from the mainland are more inclined to use Pinyin, people from Taiwan tend to use Tongyong, and people who emigrated before the invention of Pinyin may be more familiar with Wade-Giles. In music classrooms, it may be difficult for the teacher to decide which Romanization system should be used as no single system can speak to all Chinese people in the U.S. It is very challenging to create a uniform spelling system in a short period of time; thus it is necessary to include the actual Chinese characters for the clarity of lyrical content.

All the aforementioned Romanization systems were designed for Mandarin Chinese, the official language of China; however, Mandarin is only one of hundreds of languages and dialects spoken by Chinese people. For example, Cantonese and Taiwanese, the two most important Chinese languages besides Mandarin, both have their own standardized Romanization systems. The Miao and Dong songs collected in this study are sung in their local languages and are written in their own Romanized alphabets. The languages of Miao and Dong as well as their romanization systems will be discussed in chapters three and four. When teaching World Music, teachers will inevitably encounter the challenges 
of pronouncing different languages and presenting languages as close to their original form as possible. This can also be viewed as an exciting opportunity for teachers and students to explore new modes of thinking, new meanings in new contexts, and new ways of encoding our emotions.

\subsection{Reflections}

There are limitations to this study. First of all, textbooks are an optional reference material, not a requirement, for music classes in U.S. elementary schools, and many music teachers seek class materials from external sources, conferences, and workshops that are not included in the scope of this study. Teachers are granted a high degree of autonomy in choosing the music literature used in their classrooms and make these choices according to the actual class situation and their own musical background. Second, the music textbook collection in the SJSU music education library provides a solid foundation for this quantitative study but display uneven distribution in terms of the year of publication and publishing companies, which may lead to a degree of bias in the data analysis. Finally, the representation of Chinese folk songs in U.S. music textbooks is a challenging topic for quantitative reserach, as there are many un-quantifiable dimensions and corner cases. The observations drawn from the data analysis are nonetheless able to reflect the general situation and problems with the Chinese folk music included in elementary music textbooks.

The Chinese music culture presented in U.S. elementary music textbooks is misrepresentative of the actual music culture of China due to its lack of variety and diversity in styles and genres, as well as its disjointed lyrical content. Among the 88 
Chinese folk songs that appear in the sample textbooks, 39 distinct songs were all from the urban Han tradition, including three songs from the Cantonese tradition and two from the Taiwanese tradition. No other music culture was mentioned in any of the music textbooks. As music educators are encouraging the fostering of awareness of global cultural diversity among their students, a variety of Chinese folk music should be taught.

When Chinese folk songs are sung in English, this can act as a barrier to learning about Chinese culture. Language and culture are so intertwined with the historical experience of people that "to reject their words is to turn away from their habits and customs, their daily rhythms, their attitudes and values, the very substance one wants to observe and absorb." ${ }^{\prime 3}$ The misuse of Chinese Romanization systems and not displaying Chinese characters further weaken the connection between the presented and actual Chinese folk songs. Looking at all data collected in this study, $41 \%$ of Chinese folk songs contain Chinese Romanization in their lyrics with 19\% displaying Chinese characters. Recognizing the need to include Chinese characters in textbooks, the inclusiveness of Chinese Romanization and Chinese characters in Chinese folk songs has greatly improved, increasing to $81 \%$ and $44 \%$ respectively in textbooks published after 2000 . As more and more music educators advocate for multicultural music education in the original language, significant improvements in language representation are observed in more recent textbooks and teacher training. Nonetheless, the multicultural aspect of

${ }^{83}$ Palmer, "World Musics in Music Education," 35. 
Chinese folk music is lagging behind an is waiting for music educators along with ethnomusicologists to address and enrich music textbooks and teaching resources. 


\section{The Cultural Context of the Dong and Miao Ethnic Groups}

The folk music of the Miao and Dong is intimately related to their living environment and historical traditions. As Catherine Ingram wrote, "the echoes of the environment in Kam (Dong) big song and other song genres mean that the songs are not interpretable without detailed, lived knowledge of the surrounding environment." ${ }^{\circledR 4}$ If we listen to a piece of folk music from an unfamiliar culture without being informed of the context in which this folk music existed, we could easily judge the music based on our own culture and experience. This inclination will hamper our ability to fully appreciate and understand other peoples' music and cultures, sometimes even prompting us to ridicule and belittle folk music from unfamiliar cultures.

The following two chapters provide a detailed picture of the Miao and Dong context and living environment as well as of their history and culture to help music educators develop their own lesson plans in actual classrooms.

\subsection{The Miao Ethnic Group}

\subsubsection{History of the Miao}

The history of the Miao people has rarely been recorded in writing throughout Chinese history; however, in recent decades, it has been re-discovered through Miao songs, the study of Miao languages, the decorative patterns and symbols of traditional Miao embroideries (Figure 11), and occasional mentions of the Miao in the personal writings of the ancient Chinese literati. Celebrating themselves as descendants of the

\footnotetext{
${ }^{84}$ Catherine Ingram, "Echoing the Environment in Kam Big Song," Asian Studies Review 35, no. 4 (2011): 451.
} 
ancient king Chi You (虫尤, 2600 B.C.E.), many Miao people believe that their history can be traced back to around five thousand years ago. Martin Norins, one of the first Western scholars to study Chinese ethnic minority groups, described the Miao in Pacific Affairs (1939) in the following terms, "Wedged mostly in the hill country of the Southwest, there are thousands of tribesmen in China who, since the twilight of days when they themselves were powerful on the Asiatic continent, regularly have been shoved about by stronger neighbors. ${ }^{"} 85$

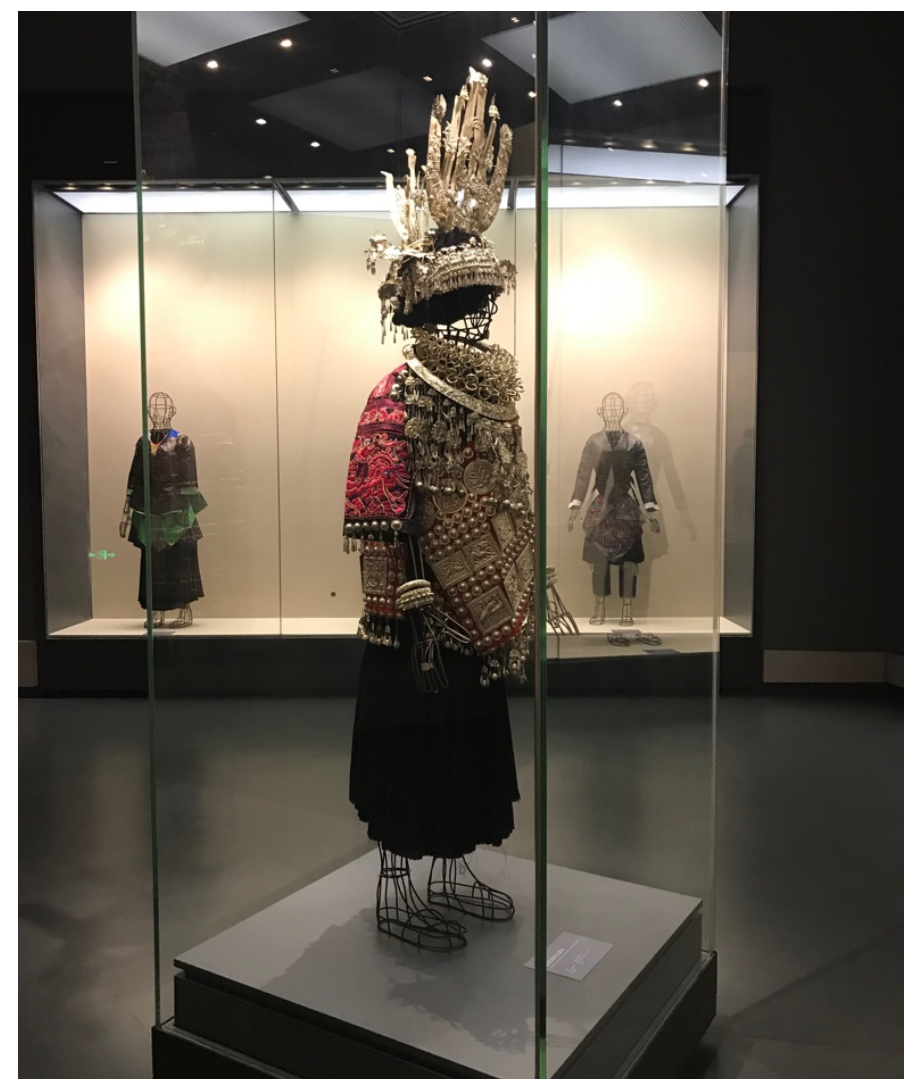

Figure 11: Traditional Miao costume display in Guizhou Provincial Museum. Photo by Ke Guo (2018).

${ }^{85}$ Martin R. Norins, "Reviewed Work: Stone-Gateway and the Flowery Miao. By Will H. Hudspeth," ed. Will H. Hudspeth, Pacific Affairs 12, no. 3 (1939): 340-42. 
Some evidence supports the possible connection between the Miao people and King Chi You. The classic Chinese mythology text Classic of Mountains and Seas (Shang Hai Jing 山海经, fourth century B.C.E.), includes accounts of Chi You being defeated by King Huang (黄帝) and becoming a maple tree. In their people's historical songs, the maple tree is used to symbolize the Miao's ancestors. Cao's study on Miao language also finds that the word "ancestor" in Miao languages shares similar pronunciation to and origins with the words "maple tree." ${ }^{86}$ Furthermore, scholars have found that some vocabulary in Miao languages share features of their pronunciation with the official Chinese language used in the Tang Dynasty, ${ }^{87}$ indicating communication between Han Chinese and the Miao thousands of years ago. ${ }^{88}$

The extensive distribution of Miao people around the globe substantiates their long history of migration. Currently, almost half of the Chinese Miao population resides in Guizhou province, while the rest scattered across Hunan, Yunan, Sichuan, Guangxi, Hubei, and Hainan provinces. In Southeast Asia, the Miao population mainly spread to Laos and Thailand. There is also a significant population of Miao people in Europe, United States, and Australia.

\footnotetext{
${ }^{86}$ Cao Cuiyun (曹翠云), “Tracing the History of Miao from Miao Language” (cong miao yuk an gu dai miao zu li shi wen hua heng ji 从苗语看古代苗族历史文化痕迹), Journal of Minzu University of China (Zhong yang min zu da xue xue bao 中央民族大学 学报) no. 1 (1982): 12-17.

${ }^{87}$ This stage of ancient Chinese language is called "Middle Chinese." It is the historical variety of Chinese recorded in the Qieyun, a rhyme dictionary first published in 601.

${ }^{88}$ Cuiyun, "Tracing the History of Miao from Miao Language," 13.
} 
Several historical periods of large-scale migration have contributed to the wide distribution of the Miao population across the world. Originating in the land between the Yellow River (downstream) and Yangtze River in Eastern China, Wu Xinfu identifies and describes four large-scale Miao migration events as follows:

1. Migration to midstream Yangtze River after their ancestor Chi You (虫尤) is defeated by the ancient kings Yan and Huang (炎黄二帝, 2600 B.C.E.)

2. Migration to upstream Yangtze River and mountain area after being attacked by the Han people during the Zhou Dynasty ( 1000 B.C.E.)

3. Migration further south west into the mountain areas of Sichuan, Guizhou, Yunnan, Guangxi provinces during the Tang and Song Dynasties ( $600-1200$ C.E.)

4. Migration to Southeast Asia after being expelled by the Ming and Qing Royal Courts $(\sim 1400-1900$ C.E. $){ }^{89}$

Shi Caojiang and other scholars later added a fifth migration event when hundreds of thousands of Miao refugees moved to the U.S., France, and other countries after the Lao People's Democratic Republic was established in $1975 .{ }^{90}$ Jeremy Hein argues that the global Miao diaspora that resulted from refugee migration from Laos in 1975 constitutes a "double diaspora" phenomenon. ${ }^{91}$

\footnotetext{
${ }^{89} \mathrm{Wu}$ Xinfu (伍新福), “The Four Major Migration in Miao's History” (lun miao zu li shi shang de si ci da qian xi 论苗族历史上的四次大迁徙), Ethno National Studies (min zu yan jiu 民族研究) no. 6 (1990):103-110.

${ }^{90}$ Shi Chaojiang (石潮江), The History of Miao Migration (shi jie miao zu qian xi shi 世 界苗族迁徙史) (Guizhou: Guizhou People's Publishing House 贵州人民出版社, 2006).

${ }^{91}$ Jeremy Hein, "The Double Diaspora”, Diversity in Diaspora: Hmong Americans in the Twenty-First Century. Edited by Mark E. Pfeifer et al. (Hawaii: University of Hawaii Press, 2013), 209-229.
} 
During each of these large-scale migrations, a considerable number of Miao people chose not to leave, some of whom had assimilated with the Han people while others had developed their own Miao communities in the area. Despite their widespread population and reclusive residential locations, most Miao traditions remain intact with Miao communities worldwide sharing similar rituals in their worship of ancestors, similar clothing, and similar languages.

\subsubsection{A Portrait of Miao Life}

In the summer of 2018, I visited the Qiandongnan Miao and Dong Autonomous Prefecture (黔东南苗族侗族自治州) in Guizhou province. Infrastructure in Guizhou province has improved significantly over the past decade. The construction of high-speed railways and highways has transformed what used to be incredibly grueling travel conditions, allowing people to travel in and out of the mountain area with ease. I arrived at Kaili (凯里), the largest city in Qiandongnan Prefecture and rented a car. Two hours of driving brought me to Taijiang county (台江县), one of the largest Miao residential areas in Guizhou. From Taijiang county, we drove further south on a narrow and rugged road to Fanpai village (反排村) where I was able to interview two revered Miao musicians and record them singing, dancing, and drumming.

Along the road, which meandered through the mountains, we drove past tall, empty wooden racks that are used to sun-dry the rice bundles in the autumn, clusters of wooden houses with dark tiled roofs, and neatly terraced rice paddies on the mountain slopes. Since Miao houses are typically constructed on steep slopes, exposed wooden pillars are placed under the houses for support, which has led to these houses being called "hanging- 
feet houses” (吊脚楼). These buildings usually have three to four stories with the first floor for tool storage, compost, and domestic animals, the middle floors for living space, and the top floor for food storage. These "hanging-feet houses" are built wall to wall, if not directly attached to each other. People in a village enjoy close with bonds each other, forming a large family beyond the individual household. In every village, there is a central plaza where people congregate to spend time with others, where events take place during important festivals, and where we, visitors, can find information.

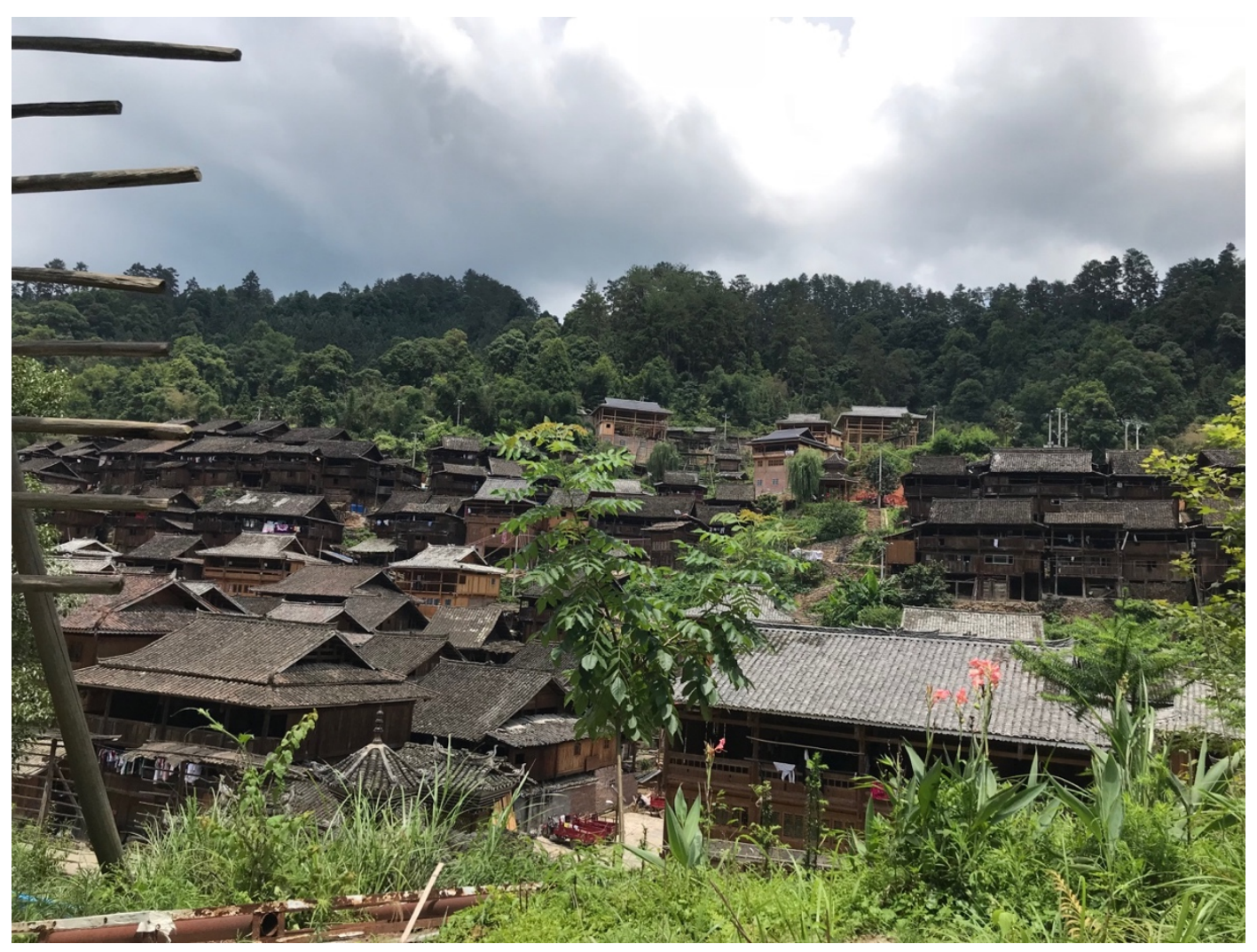

Figure 12: Fanpai Miao village in Guizhou. Photo by Ke Guo (2018).

When I visited Fanpai village in July 2018, it was quiet and calm. The elderly people were doing housework and the children were playing and giggling softly. In the last ten 
years, as transportation to metropolitan cities has opened up new economic opportunities, very few young people have chosen to stay in the village, preferring instead to explore the outside world. The selection of food in the small grocery shop in the central plaza are not local products, and the items are not very different from what we see in the cities. Villagers have cell phones and can quickly get access to the internet. The boundaries that used to separate Miao villages from more economically advanced towns and cities have been rapidly disappearing in recent years. However, the Miao has never stopped practicing their music; even when the younger generations leave home for the city, they come back to the villages to sing and dance at key festivals.

\subsubsection{Miao Languages}

The broad concept of "Chinese languages" covers an astonishing number of languages and dialects, many from different language families. Furthermore, over time, these languages have changed and evolved under the influence of other cultures. The Mandarin that we hear today became an official language after the establishment of the P.R.C. Looking back, the official language used by Chinese royal courts and governments has changed again and again as different dynasties have come and gone. Compared with the ever-changing official language of China, the evolution of the languages of ethnic minorities has been much slower. Some of the languages of these groups still preserve pronunciation characteristics of the ancient Chinese that was spoken hundreds of years ago. The Dong and Miao languages branched off from Han languages very early on and thus their languages differ significantly from present-day Mandarin. 
Miao languages fall under the Miao-Yao language family (also known as HmongMien), which is mainly spoken in Southern China and northern Southeast Asia. The various Miao dialects may not be mutually intelligible even among Miao people who live in nearby villages, thus scholars have suggested calling these vernaculars "Miao languages" instead of "Miao dialects." Due to difficulties in transportation and communication in the past, these Miao dialects may vary even between villages located on two sides of the same mountain. Chinese scholars, such as Du Yaxiong and Deng Jun, have agreed on the classification of three main Miao dialects based on geographic distribution: the eastern dialect, the central dialect, and the western dialect. ${ }^{92,93}$ In Western publications, the classification of Miao languages and dialects has not reached a consensus. Ratliff asserts that the main dialect spoken by most Chinese Miao is the Chuanqiandian dialect (川黔滇方言), named after the broad geographic region that includes Sichuan, Guizhou, and Yunnan province and which is similar to the western dialect. ${ }^{94}$ However, this is controversial as the Chuanqiandian dialect classification might over-generalize and ignore language diversity. The main argument is that the two main

\footnotetext{
${ }^{92}$ Du Yaxiong (杜亚雄), Chinese Folk Song Map: Southern China (Zhong guo min ge di tu: nan fang juan 中国民歌地图南方卷) (Time Publishing and Media Company, 2013), 242.

${ }^{93}$ Deng Jun (邓钧), “Cultural Context of Miao's Lusheng Music” (miao zu lu sheng de ying yong chuan tong ji qi wen hua nei han 苗族芦笙的应用传统及其文化内涵, Musicology in China, no. 3 (1999): 116.

${ }^{94}$ Martha Ratliff, Meaningful Tone: A Study of Tonal Morphology in Compounds, Form Classes, and Expressive Phrases in White Hmong (Illinois: Center for Southeast Asian Studies, Northern Illinois University, 1992).
} 
sub-dialects of the Chuanqiandian dialect are vastly different from each other and can even be considered two separate languages. ${ }^{95}$

The development and classification of Miao languages was further complicated after the migration of Miao into Southeast Asian countries, such as Laos, and Western countries such as the United States. In the U.S., Miao languages are usually called "Hmong" or "Mong" and were developed from the Miao dialects in Laos. The Hmong Culture website, introduces the Miao dialect in the U.S. as follows: "In the U.S., the dialects are known as Blue Mong and Mong Njua; sometimes this is referred to as White Hmong. Many of the vowel sounds are quite a bit different in these dialects compared to some of the Asian ones". ${ }^{96}$

Miao languages have no written form, at least no written form that has survived to the modern day, and thus these languages adopt a Romanization system called "Ntawv Hmoob" based on the work of two Western missionaries who lived in Laos in the 1950s. This Romanization system requires a considerable amount of training for non-Miao language speakers. Table 5 shows two examples of Ntawv Hmoob writing.

Table 4: Examples of the Miao Written Language Ntawv Hmoob

\begin{tabular}{|c|c|}
\hline Ntawv Hmoob & English \\
\hline Kuv now mov. & I am eating. \\
\hline Kuv tsis xav mus lub tsev kawm ntawv. & I don't want to go to school! \\
\hline
\end{tabular}

95 “Hmong Language," Hmong Culture, accessed on January 22, 2019, http://www.hmongculture.net/hmong-language. ${ }^{96}$ Ibid. 
For the purposes of this paper, I will not notate the lyrics of songs in the Ntawv Hmoob Romanization system due to its complexity for non-Miao language speakers. Instead, I will phonetically transcribe the Miao language based on English pronunciation of the Roman alphabet. The pronunciation of Miao lyrics will be according to the Fanpai accent as I recorded Miao songs in the Guizhou village of Fanpai, the language of which falls within the Chuanqiandian dialect category.

\subsubsection{Community Life}

From their long history of conflict with other ethnic groups such as the Han and several migrations into the mountains, the Miao have developed unique ideologies. First, the Miao has an idealized concept of a golden age prior to their forced migration. The Miao's oral history and narrative songs often recall a mythic past. According to Tapp, "a culture hero would periodically arise to unify the clans and establish hegemony over the land." ${ }^{\prime 97}$ The Miao thus worship their heroic ancestors and through this express their wish to revive a bygone golden age. Second, the Miao have a strong ethnic boundary that separates the in-group from out-groups. As Lo writes, "The Hmong [Miao] view the world as 'us and them.' This means that from the larger perspective, 'us' represents the Hmong [Miao] and 'them' represents the non-Hmong."98 Third, the Miao have a collective memory of dispersal from a homeland that sensitizes each new generation to the importance of the past. Schein identifies this characteristic from collections of oral

\footnotetext{
${ }^{97}$ Nicholas Tapp, "Hmong Religion," Asian Folklore Studies 48, (1989a): 59-94.

${ }^{98}$ Fungchatou T. Lo, The Promised Land: Socioeconomic Reality of the Hmong People in Urban America (1976-2000) (Lima, OH: Wyndham Hall Press, 2001), 21.
} 
histories in his study of Miao communities overseas stating, "Everywhere the Hmong [Miao] reside they refer to China as a homeland." 99

The Miao culture, as the manifestation of these ideologies, has always focused on community building. The community is the enlargement of the family and has held the Miao people together throughout their long history of fleeing and migrating. The bond within the community has given Miao people the strength to survive and has helped them to find joy in their lives; on the flip side, the Miao people are less inclined to mix with people outside of their community. Thus, the Miao people have come up with ways to establish an identity as a community and differentiate themselves from others through language and clothing as well as music and dance.

Almost every Miao community speaks differently, whether it is the use of unique vocabulary and accents or completely different dialects and languages. In addition to this language difference, clothing styles also allow the Miao people to express their identity. For example, the White Miao's clothing is predominantly white in color, the Blue Miao typically wear blue-colored clothes, the Flower Miao women enjoy putting a flower in their hair, and the Horn Miao women prefer to weave their hair into horn-shaped buns. Moreover, the patterns on women's clothes are usually unique to individual communities, as the symbolic meanings of these patterns often denote the history of the community.

Nonetheless, music and dance are the most important ways for the Miao people to express not only their emotions but also their identity as a community. Each community

\footnotetext{
${ }^{99}$ Louisa Schein, "Hmong/Miao Transnationality: Identity Beyond Culture," in Hmong/Miao in Asia. Edited by Nicholas Tapp, Jean Michaud, Christian Culas, and Gary Y. Lee (Chiang May, Thailand: Silk-worm Books, 2004), 273.
} 
has their own celebrations and specific music and dances to accompany them. Fanpai village, for example, is famous for their "Wooden Drum Dance" performed during the Guzang Festival, which occurs every thirteen years. This dance, however, is not part of the traditions of the Miao people in Wujiaonan village, which is just 10 miles from Fanpai village. The Miao people value their traditions more than innovation in music and dance as they feel responsible for protecting the spirit of their community.

\subsubsection{Music Traditions}

The Miao people have different songs for different occasions. For example, "flying songs" are to be sung in the mountains, "love songs" are for courtship events, "drinking songs" are for banquets, and "long songs" narrate historical events and heroic stories. ${ }^{100}$ Apart from vocal music, the Miao people also have rich instrumental music traditions, which mainly involve the bamboo pipe instrument the "Lusheng" (or "Qeej") and drums. In Miao tradition, playing musical instruments and singing in worship-related ceremonies is for men only. ${ }^{101}$ By playing music, men and women can acquire knowledge of their culture, history, religious beliefs, and communicate conventions and can authenticate themselves as part of the community.

In my interview with the singing master Tang Wengweng in Fanpai village in 2018, she told me about her experience of singing with people from other villages:

When I was young and unmarried, I used to attend singing events quite frequently. Sometimes they were in our village, sometimes they were in the other villages, while other times they were in the town [Taijiang county]. I had an excellent voice back then, piercing through the valley. Then I became a singer, and I learned all the flying songs, drinking songs, love songs, and songs from

${ }^{100}$ Du, Chinese Folk Song Map, 244.

${ }^{101}$ Deng, "Miao's Lusheng Music," 116-130. 
other villages too. We took turns to sing for each other, and we could sing continuously for days! They [people from other villages] sang different songs that I had not heard before, and sometimes spoke languages that I could not fully understand. ${ }^{102}$

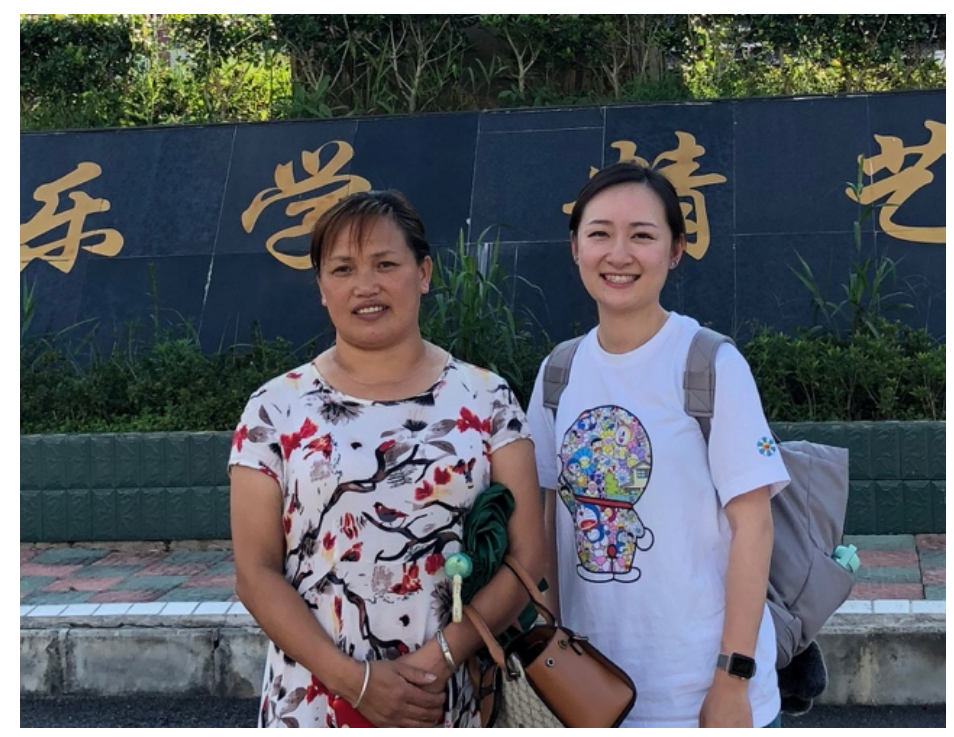

Figure 13: Tang Wengweng and author. Photo by Ke Guo (2018).

Despite individual differences in music across Miao communities, there are styles and characteristics that are commonly seen in all communities. The Chinese “Gong” key (宫 调) is the most important key in Miao songs, with "Do-Re-Mi-Sol-La" as the primary scale for melodies. The melodies of Miao songs often involve disjunct motions that jump between the third, fifth, eighth, or even bigger intervals. ${ }^{103}$ Most Miao songs are monophonic, while polyphonic (usually in two parts) songs also exist in a few locations such as Fanpai village. ${ }^{104}$ Traditionally, vocal music and instrumental music are performed separately and do not accompany each other.

\footnotetext{
102 Tang Wengweng (唐翁翁), personal interview with author, July 15, 2018.

103 Du, Chinese Folk Song Map, 242-246.

${ }^{104} \mathrm{Yu}$ Weiren (余未人), "Polyphonic Miao Folk Songs" (miao zu duo sheng bu min ge 苗族多声部民歌), Colorful Guizhou (duo cai gui zhou 多彩贵州) April, no. 8 (2010): 57.
} 


\subsection{6 "Wooden Drum Dance"}

Wan Zhengwen (万政文), the only Miao wooden drum player and dancer who holds a certificate of "Intangible Cultural Heritage Inheritor" from the Chinese government (Figure 14) was watching over his cows grazing in the mountains when I asked the village officer if I could meet with him. He had a cell phone and quickly came down on a motorcycle. He was in his 70s but showed no signs of slowing down and offered to show me the "Wooden Drum Dance." His drumming (Figure 15) soon attracted a small crowd of women who continued their sewing or other manual work while watching us and children who quietly sneaked into the performance hall.

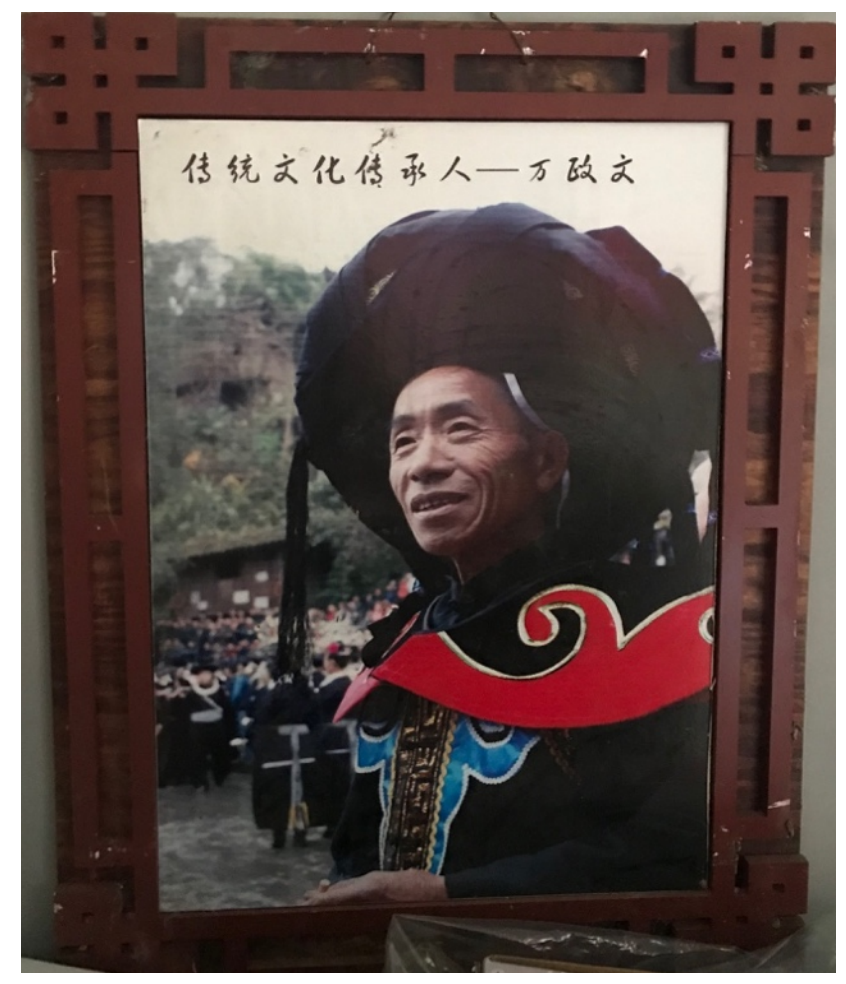

Figure 14: A photo of Wan Zhengwen on the wall in Fanpai Village Event Center. Photo by Ke Guo (2018). 


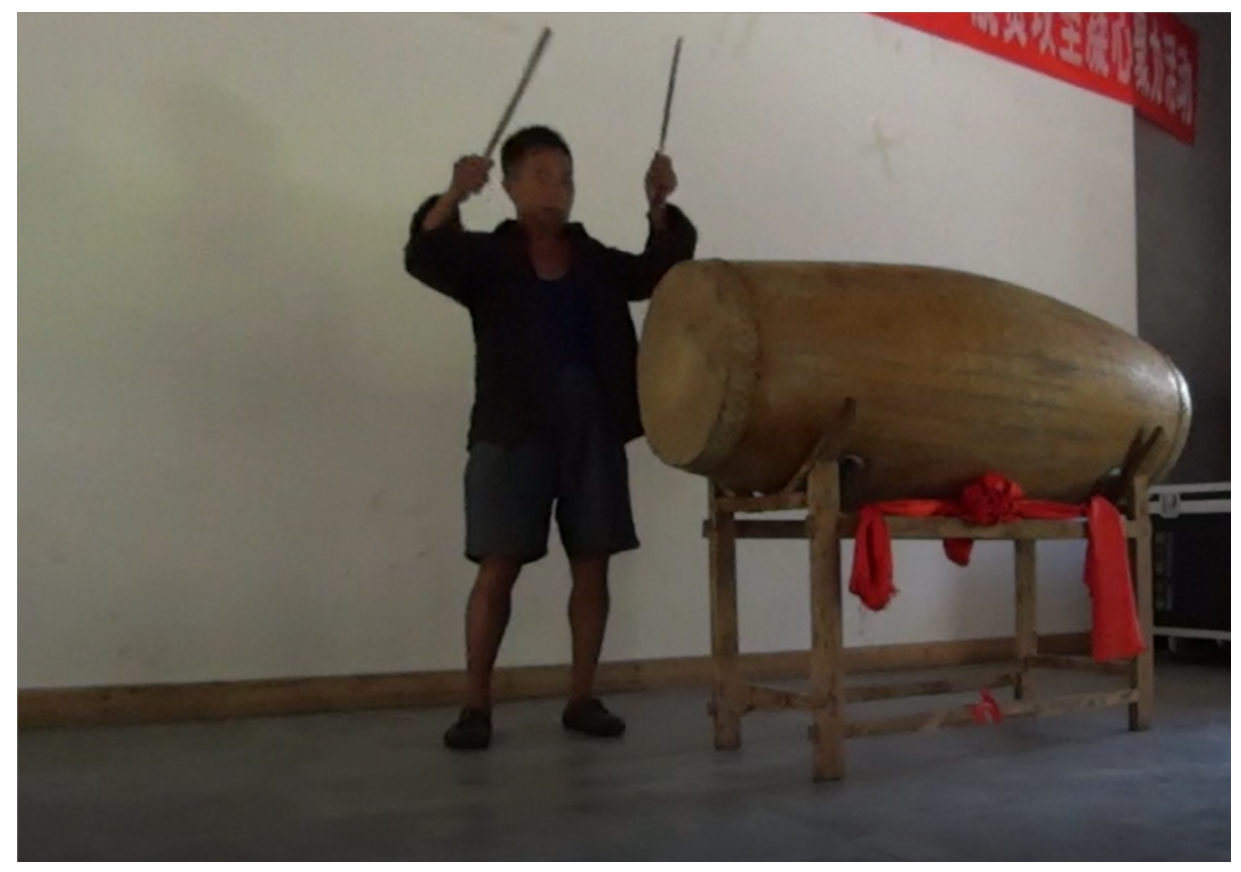

Figure 15: Wan Zhengwen playing the wooden drum. Photo by Ke Guo (2018).

Wan told me that when he was young, everyone in the village knew how to play the "Wooden Drum Dance," and all the men would play it together at the Guzang Festival (牯藏节), which, as previously stated, is held every thirteen years (although the frequency may vary in different places) and lasts for the whole year. The legend told by the elders states that the spirit of the Miao ancestor King Chi You (虫尤) has lived in a maple tree since his death; thus people would create a giant drum using the maple tree bark to worship Chi You. The thundering sound of drumming resembles the supernatural force that Miao believe will bring them a good harvest and life.

The "Wooden Drum Dance" consists of five chapters of drumming patterns and dance moves: 
1. Out of the door

This chapter demonstrates the determination to migrate when the early people of Miao moved from the eastern Chinese plain to the Guizhou mountain area.

2. Showing the knives

This chapter tells the story of the tough journey from the east of China to Guizhou, during which the brave Miao fighters had to use long knifes to create paths through the forests and over mountains.

3. Stepping on the bugs

When people died on the journey, others would step on the bugs to protect their bodies.

4. Planting seeds

When the Miao's ancestors finally arrived at Guizhou, they found it was an ideal place to live and settle down. This chapter shows the activity of planting rice seeds in their new home.

5. Celebration thirteen years later

Thirteen years after they settled down in their new home, the Miao people look back on their journey and celebrate their achievements with drumming and dancing, as well as sacrificing cows for their ancestors.

The "Wooden Drum Dance" in Fanpai village is a long-lasting tradition. Through teaching the "Wooden Drum Dance" to children, the Miao people pass down their history, their belief in ancestor worship, their culture, and their music to the next 
generation. Worshipping one's ancestors reminds children is to remain humble, be thankful for everything they have, and always remember their roots.

\subsection{The Dong Ethnic Group}

\subsubsection{A History of the Dong}

The Dong ethnic minority group is one of the 55 officially recognized nationalities in southwest China. In the process of "categorizing ethnic minority groups" (minzu shibie 民族识别), which lasted for over 30 years after the establishment of the P.R.C., many Dong people living in the mountainous areas of Guizhou, Hunan, and Guangxi provinces were grouped under the name due to their similar languages and cultures. Whether the Dong people are native or migrants to their current region of residence is unclear. Although scholars have not reached an agreement on the origins of the Dong ethnic group, Dong legends claim that the ancestors of the Dong migrated from the eastern plain of China.

The Dong have many names in Chinese historical records. Analyses of the Dong's oral history and myths suggest connections between the current Dong people and the ancient Baiyue (百越) ethnic group, a group first recorded in the Warring States period ( 400-200 B.C.E.). The Baiyue people followed the Duliu river and migrated from Southeast China to the southwest mountain area. ${ }^{105}$ The Dong are thought to be the modern-day descendants of the ancient Liáo (僚), one of the branches of the Baiyue

\footnotetext{
${ }^{105}$ Zhang Min (张民), "An exploration of the formation of the Dong nationality" (shi tan dong zu xing cheng 试探侗族形成), Guizhou Ethno Studies (gui zhou min zu yan jiu 贵 州民族研究) 58 (1998): 95-104.
} 
group. ${ }^{106}$ The earliest written record of the Dong people can be traced back to the Song Dynasty (960-1297), when the ethnic group was called “Geling” (仡伶). ${ }^{107}$ More detailed records using the name "Dong" (峒 $)^{108}$ appear later in the Ming (1368-1644) and Qing Dynasties (1636-1912). ${ }^{109}$

In Guizhou province, the Dong people mainly reside in the southeastern region, called the Qiandongnan Dong and Miao Autonomous Prefecture (黔东南苗族侗族自治州), which borders Hunan and Guangxi provinces (Figure 16). According to 2010 data released by the National Bureau of Statistics of China, the 2.88 million Dong population accounts for $0.22 \%$ of China's total population, and around half of the Dong population lives in Guizhou (49.7\%), around one-third lives in Hunan (29.7\%), and around one-tenth lives in Guangxi (10.6\%).

${ }^{106}$ D. Norman Geary, Ruth B. Geary, Ou Chaoquan, Long Yaohong, Jiang Daren, Wang Jiying, The Kam People of China: Turning Nineteen (London/New York: Routledge Curzon, 2003).

${ }^{107}$ In current Dong language, the Dong people refer to themselves as "Geaml" or "Kam." ${ }^{108}$ This character “峒” is different from the standard name “侗," although they are pronounced the same in Mandarin Chinese. The first character indicates people living in the mountains, whereas the second character refers uniquely to this ethnic group. ${ }^{109}$ Zhang Guihua (张贵华) and Deng Guanghua (邓光华), The Dong's Big Song (dong zu da ge gai lun 侗族大歌概论) (Beijing: Higher Education Publishing House, 2016), 8. 


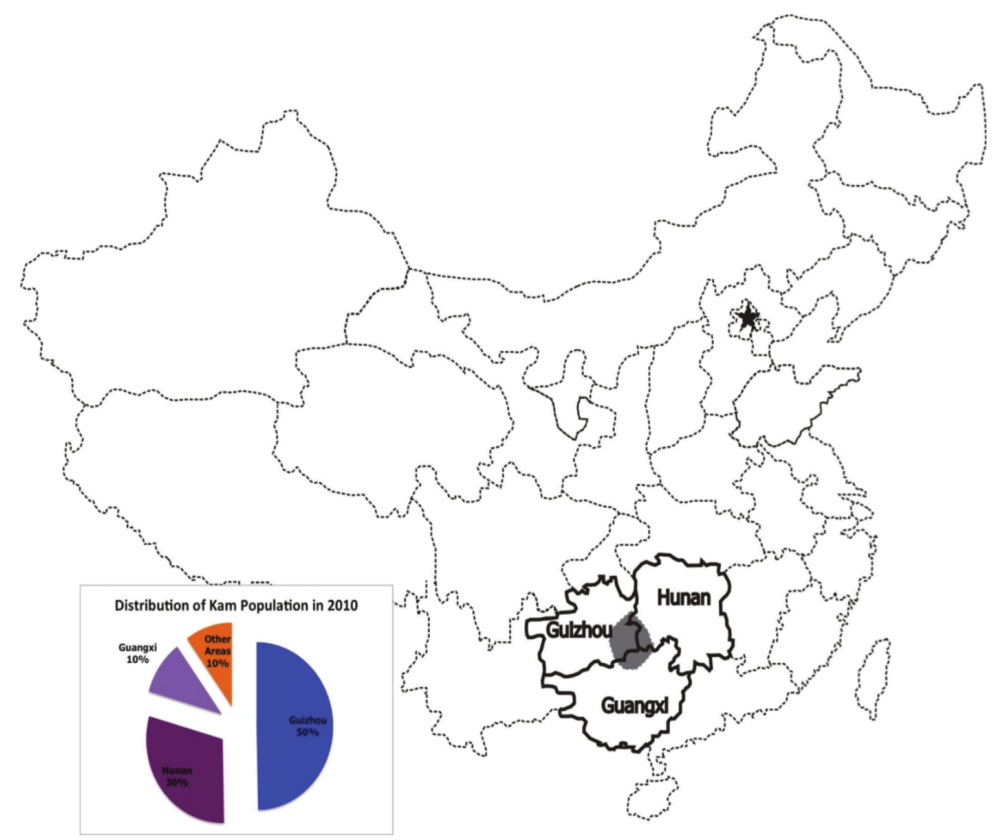

Figure 16: Distribution of Dong (Kam) population in $2010 .^{110}$

The Dong ethnic group exists almost exclusively in China, with a very few populations residing in Vietnam. There are two main branches of the Dong people: the northern Dong and the southern Dong. The northern Dong are more influenced by the culture of the Han people and practice little music or dance, whereas the southern Dong have preserved more of their historical traditions and enjoy frequent musical activities in their communities.

${ }^{110}$ Catherine Ingram, and Wu Jiaping, "Research, Cultural Heritage, and Ethnic Identity: Evaluating the Influence of Kam Big Song Research of the 1950s," Asian Ethnology 76, no. 1 (2017): 65-93. 


\subsubsection{A Portrait of Dong Life}

A Dong proverb says, "Not three feet of flat land, not three days without rain, not a family with three silver coins." ${ }^{111}$ In this warm and humid mountainous region of altitudes between 25 to 31 degrees and elevations between $500 \mathrm{~m}$ to $1 \mathrm{~km}$, the weather conditions provide an ideal natural environment for agriculture and forests. Dong villages are usually built along the rivers in the valley, with plentiful food resources from the rivers and abundant water for rice irrigation. Their agricultural lifestyle, however, did not bring Dong villages economic prosperity, thus the proverb's conclusion "not a family with three silver coins.” The Dong people lived a self-sufficient lifestyle for a long time; however, recent economic growth in other regions of China have drawn the younger generations out of the mountains.

It is a four-hour drive from the closest city of Kaili to Xiaohuang Dong village in Congjiang county thanks to the rapid construction of highways in Guizhou. Driving to Xiaohuang, we passed several Dong villages of various size (ranging from dozens to thousands of families) all with a similar outlook but not as famous as Xiaohuang village in terms of the Dong people's "big song." From the 1950s, domestic and international ethnomusicologists have been coming to Xiaohuang village to study big song. In 1986, singers from Xiaohuang village performed at the $15^{\text {th }}$ Autumn Festival in Paris and introduced Dong choral music to an international audience.

The grand Bridge of Wind and Rain (Feng Yu Qiao 风雨桥) (Figure 17) arching over a river told us that we had arrived at the entrance of Xiaohuang village. This type of

111 Original proverb: “地无三尺平, 天无三日晴, 人无三分银.” 
bridge covered with a multi-story roof is unique to Dong villages; it is a pavilion sitting on the river that symbolizes and protects the Dong village while providing shelter for people in rainy weather. A narrow and winding path from the entrance gateway led us to the residential buildings in the village. Afar on the mountain slopes, long corridors of roofs connect the residential buildings, allowing people to walk through the village without getting wet in the rain. The several "drum towers" scattered around the village are places where the Dong people hold communal events, which usually involve singing and dancing. These carefully designed and meticulously built drum towers are open towers with a fire pit in the center and covered with a multi-story roof similar to that of the pavilion bridge but much taller and consisting of more layers. 


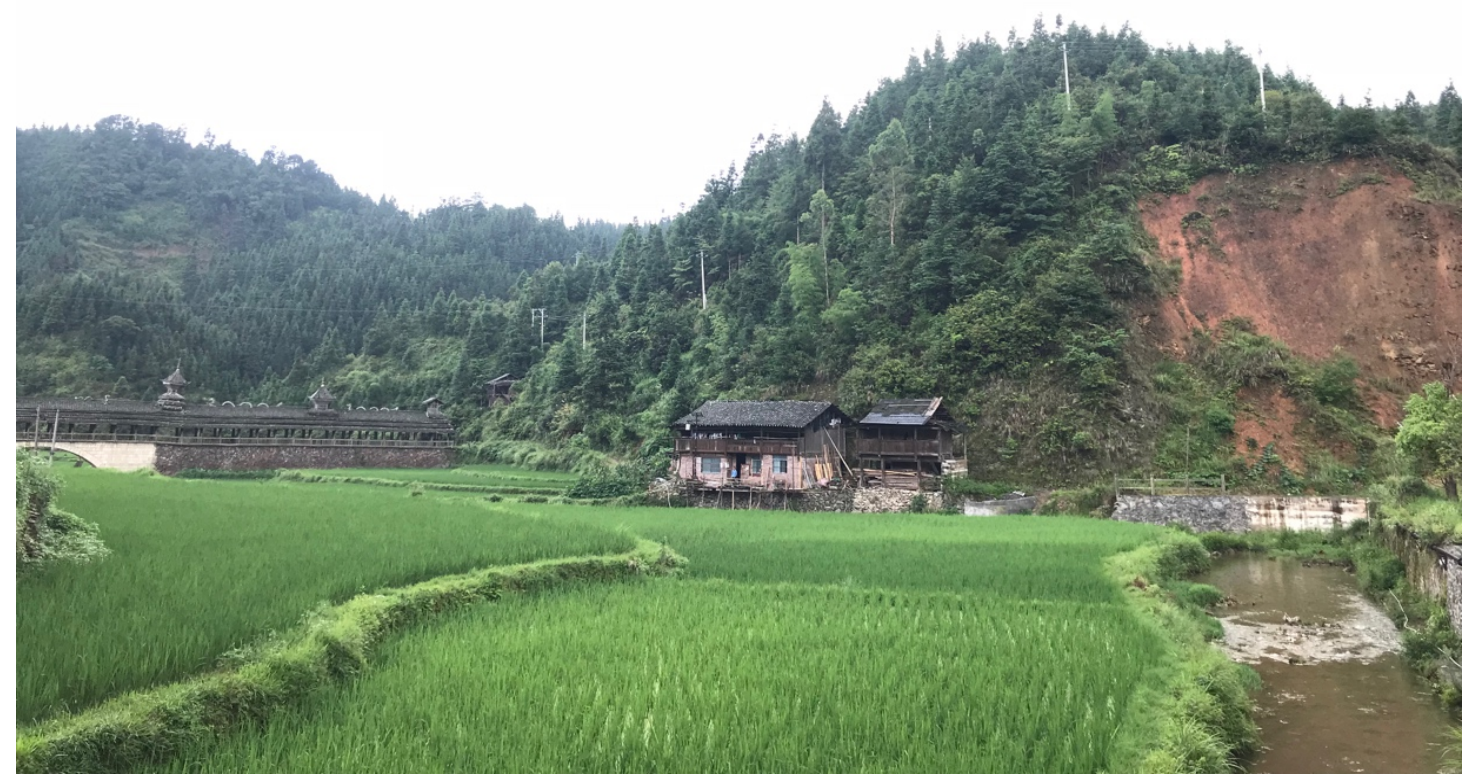

Figure 17: Dong residential buildings and the Grand Bridge of Wind and Rain (Feng Yu Qiao 风雨桥). Photo by Ke Guo (2018).

Convenient transportation has brought many tourists to Xiaohuang village. Although a large proportion of the young men in the village have gone to work in other more economically advanced areas, more and more young people are choosing to stay in the village because of its promising tourism industry. Choir performances of big song are given daily at the largest drum tower in the village, which was built specifically for concerts aimed at tourists. The female choir members wear uniforms of a traditional Dong style with layers of silver accessories from their heads to their aprons (Figure 18), while the male choir members wear white shirts, purple pants, and a check-pattern turban. The purple fabric in traditional Dong clothing is called "Dong Bu" ("Bu" means fabric), which is a shiny and water-proof textile made by repeatedly rubbing egg whites into cotton. Dong $\mathrm{Bu}$ is exceptionally durable and functional in rainy weather. At the end of 
each concert, the choir invites the audience to dance with them in a large circle. Local children like to hang out by the drum tower to listen to the music, and they gladly join the dancing circle with guests after each concert.

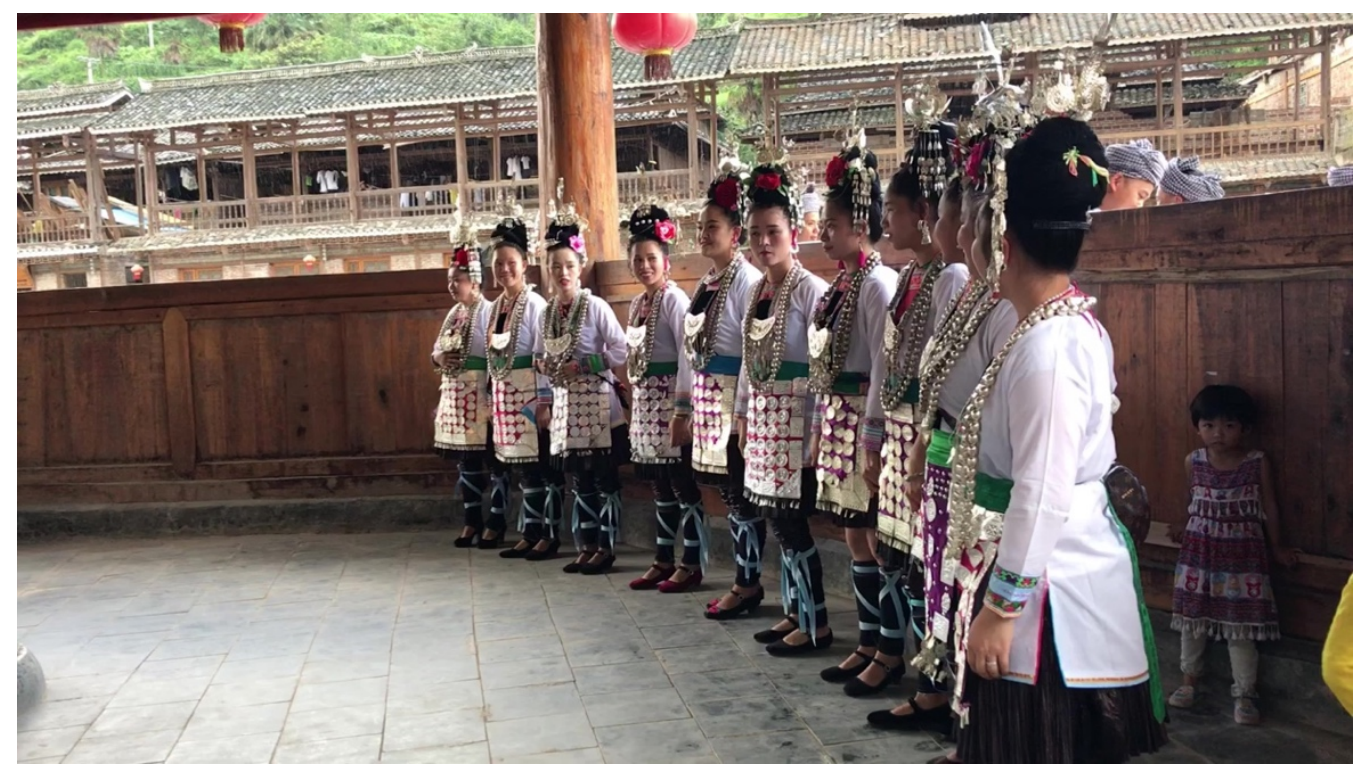

Figure 18: The Xiaohuang Village Choir performing at the Drum Tower in traditional clothing. Photo by Ke Guo (2018).

The chef at the restaurant where I had my lunch happened to be a renowned singer in the village (Figure 19). He quickly changed his outfit from a chef's apron into traditional Dong festive clothing, grabbed his two-string-lute, called a "Cow's leg lute“ (Niu Tui Qin 牛腿琴), and led the way to the drum tower. He gladly accepted my request for an interview following the concert and shared his understanding of big song as well as explaining some lyrics in details. He told me that in Xiaohuang village, people who can sing lots of songs are considered to be knowledgeable and educated because the Dong people pass down their history and culture through music. Men who cannot sing will have a difficult time finding a date! 


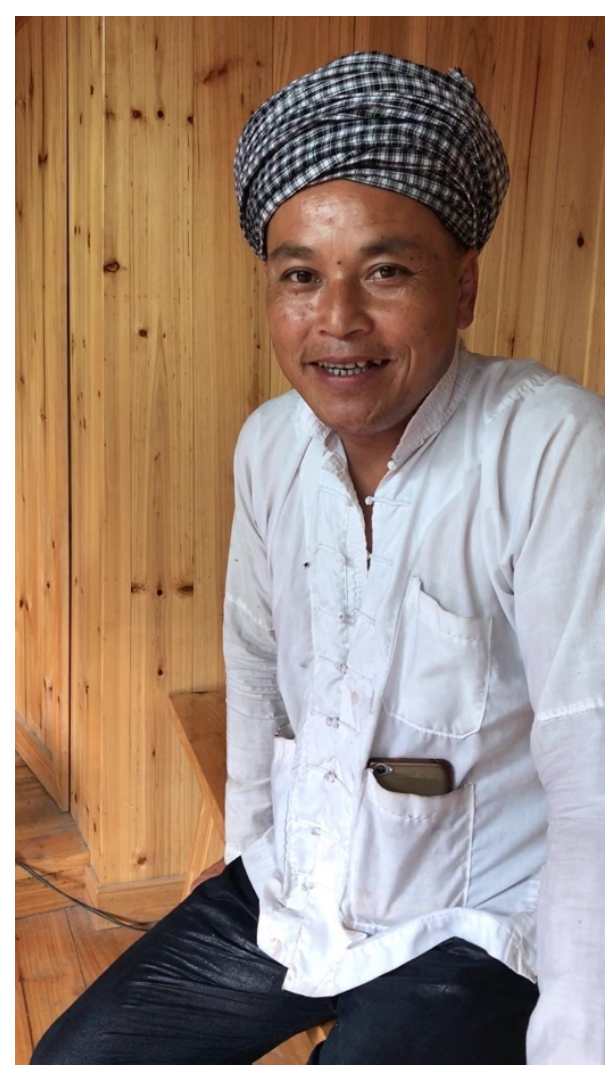

Figure 19: Wu Rongde, a chef and a singing master in Xiaohuang Village. Photo by Ke Guo (2018).

\subsubsection{Dong Languages}

The Dong language (also called Kam by Western scholars) is part of the ZhuangDong (also called Tai-Kadai or Kra-Dai) language family, in which all languages are tonal. While Thai and Lao are the main languages in this family, Zhuang-Dong languages are found in in many places in Asia, such as Southern China, Southeast Asia, and Northeast India. Ethnologue distinguishes between two Dong languages, the Northern Dong and the Southern Dong languages. ${ }^{112}$ The Dong people who live in the northern

112 David M. Eberhard, Gary F. Simons, and Charles D. Fennig (eds.), Ethnologue: Languages of the World, Twenty-second Ed. (Dallas, Texas: SIL International, 2019). 
region are more assimilated to Han culture; therefore, the Northern Dong language has gradually evolved to resemble the Han people's language by adopting key characteristics in pronunciation and vocabulary. Traditional music practices are less important in their daily lives compared with those of the Dong people living in the southern regions. Due to natural geographic barriers in the southern mountainous region, the Southern Dong language is less influenced by other cultures and can be considered more "authentic" and closer to the old Dong languages.

No written form of Dong languages exists. From the Ming Dynasty (1368-1644), the Han culture was introduced into the Dong region, and there are records of Dong people using Chinese characters to notate their language phonetically. However, the Dong people were only borrowing the sound of Chinese characters, not the meaning of the words. From the 1950s, there was an effort to use the Roman alphabet to notate the Dong language, but this Romanization system was not widespread and most Dong people still prefer to use Chinese characters. Thus, Chinese characters are the only phonetic symbols used by Dong people, which have no semantic meanings and usually cannot be understood by non-Dong speakers. Table 6 compares the Dong written language and the English translation of two sentences.

Table 5: Comparison of Dong Written Language and English

\begin{tabular}{|c|c|}
\hline Romanized Dong Written Language & English Translation \\
\hline janl oux mix? & Have you eaten yet? \\
\hline yaoc meec wox maoh jangs nouc & I don't know who he is. \\
\hline
\end{tabular}




\subsubsection{Dong Big Song}

Music is a critical component of festivals, celebrations, guest welcome events, and courtship activities in Dong culture. A Dong proverb says, "Plant wheat in the dry land, plant rice in the wet land, and every Dong person knows how to sing." 113 Among various genres of vocal music in Dong tradition, "ga lao" in the local Dong language, "da ge" (大 歌) in Mandarin Chinese, or "Kam big song" in the Western media, is a unique form of polyphonic group singing that has been passed down orally for hundreds or even thousands of years. These songs have traditionally served as a medium for recording and transmitting history, philosophy, and other local knowledge, including that concerning the environment, and is the only genre to be taught by village "song experts" in a relatively formal context. It was recognized as a form of National Intangible Cultural Heritage (ICH) in 2006 and was included on UNESCO's Representative List of the ICH of Humanity in 2009. ${ }^{114}$

In this paper, I will use the term "big song" to represent this form of polyphonic choral music in Dong culture in Guizhou. Although the nomenclature may differ for the Dong people in different geographic locations, and there is still disagreement among scholars, a widely accepted categorization of big song is summarized as follows:

113 Original proverb: “旱田种谷, 水田种禾, 侗家人人会唱歌.” ${ }^{114}$ Ingram, “Echoing the Environment in Kam Big Song," 439. 
Ga lao (big song) $\left\{\begin{array}{l}\text { Ga lao: normal big song } \\ \text { Ga so: minimal lyrics, mainly vocables to produce sound } \\ \text { effects } \\ \text { Ga jinlao: narrative content } \\ \text { Ga lawen: children's choral songs } \\ \text { Ga shakun: guest-welcoming songs } \\ \text { Ga ye: ancestor-worship songs } \\ \text { Dong opera songs }\end{array}\right.$

Within the village context, public performances of these songs usually take the form of a sung exchange between a female singing group and a male singing group as they sit opposite each other around the fire pit of a drum tower. ${ }^{115}$ When important guests come to the village, the Dong sing the ga shakun, the guest-welcoming songs, in front of the village. During ancestor-worship ceremonies, the Dong sing ga ye, ancestor-worship songs, while dancing in a large circle holding hands. The children's songs, ga lawen, can be performed in any scenario, usually for an educational purpose.

As Catherine Ingram states in her study of Dong music, one of the most intriguing characteristics of big song is the vocal imitation of the natural environment. In "Cicada Song," 116 two or three lines of melody are sung concurrently with the vocable "neng" to capture the sound of a cicada singing in the forest. In "Frog Song", a children's song popular in Xiaohuang village, every line of lyrics ends in "gab gab," imitating frogs in

\footnotetext{
115 Ibid, 441.

116 There are multiple versions of "Cicada Song" in different regions, with similar lyrics but fairly different melodies.
} 
ponds. In another children's song, "Song of Goat," performers sing "mie mie" to each other in a lively imitation of goats calling each other. Ingram compares the imitation of natural sounds in Dong big song to many other singing traditions that also feature sounds derived from the natural environment in vastly disparate regions worldwide. These traditions include certain song genres of the Navajo and other American Indian groups, ${ }^{117}$ the singing of the Kaluli people in Papua New Guinea, and others. Steven Feld connects the vocal imitation of bird calls by the Kaluli people to "a metaphoric human society, and their sounds come to stand for particular forms of sentiment and ethos," 118 which may be relevant to Dong big song.

The basic Chinese music scale of the "Yu" key, "La-Do-Re-Mi-Sol," is the most common key used in Dong music. In two-part polyphonic big song, the lower voice part usually sings stable notes that are sustained for a relatively long time while the upper voice part sings the main melody of the song. The intervals between the two voice parts do not exceed one octave, and are usually at third, fourth, or fifth intervals. In three-part polyphonic big song, a decorative high voice part is added on top of the two-part harmony. This third voice part is usually sung by one or two of the best female singers who are skilled in improvisation. The intervals between voice parts can be increased to two octaves in three-part choral songs. The choir has no conductor, and the tempo of big song is a relatively stable tempo in every song.

${ }^{117}$ Charlotte J. Frisbee, "Vocables in Navajo Ceremonial Music," Ethnomusicology 24, no. 3 (1980): 347-392.

118 Steven Feld, Sound and Sentiment: Birds, Weeping, Poetics, and Song in Kaluli Expression, 2nd ed. (Philadelphia: University of Pennsylvania Press, 1990), 30. 


\subsubsection{Music Education for Children}

In Dong villages, most children start to study music at the age of five. Music education was the most important, if not the only part of children's early education until the Chinese national school system was introduced in Dong villages in recent decades. The Dong people believe that "rice can nourish our body and singing can nourish our heart." ${ }^{119}$ Senior masters, called "sangh gal" in the Dong language (masters in singing), set up classes to teach children history, culture, moral values, and even science and agricultural techniques through songs. Dong songs have been described as the encyclopedia of Dong life.

Senior masters usually hold daily singing classes at their own homes by the fire pit or on a balcony. Children aged five to six enter the choir as reserve singers and sit at the far end of the choir during performances or singing competitions. When they grow up and get married, they will leave the choir. However, the best singer and the one who can remember the most songs will stay and help the senior masters with their teaching and will assume the responsibility to become a master in the future. ${ }^{120}$

Children's songs are called "ga lawen" in Dong language, with "lawen" meaning children. The lyrical content of ga lawen almost exclusively concern nature, such as animals, plants, and food. Songs about animals teach children the habits of animals as

119 Original proverb: “饭养身, 歌养心.”

${ }^{120}$ Chen Fang (陈芳) and Zhang Kai (张凯), "Discussing the History and the Role of Singing in Children's Education in Dong Societies" (lun gui zhou dong zu 'yi ge ti shu' min jian er tong jiao yu chuan tong de xing cheng 论贵州侗族“以歌替书”民间儿童教 育传统的形成) Northern Music (bei fang yin yue 北方音乐), no. 12 (2017): 114. 
well as the Dong rituals that are related to those animals. For example, "Song of Goat" includes the lyrics:

Little goat, runs around the hill, Little goat, feeling hungry.

Can't find its mother, calling "nay nay,"

Found its mother and happily sucking her breast. ${ }^{121}$

Some songs also teach children simple agricultural techniques, such as how to build ridges in rice paddies, sun-dry rice plants, and pick fern plants. For example, "Frog Song" goes:

On the third day of March the frogs sing "gab gab," Loud and soft sound calling people to plow in the spring. Sun and Moon will leave us every day and never come back, After a few months, the rice field will be golden yellow. ${ }^{122}$

121 Zhang and Deng, The Dong's Big Song, 173.

${ }^{122}$ As sung by Wu Rongde, July 2018. 


\section{Designing the Classroom Experience}

\subsection{The Orff Schulwerk Approach}

\subsubsection{Introduction to Orff Schulwerk}

Orff Schulwerk, which translates as "Orff school work" in English, is a method of teaching music to children. It was developed by the German composer and music educator Carl Orff (1895-1982) during the 1920s and was introduced to the U.S. in the 1960s. Growing out of Carl Orff's experiments with musicians, dancers, and actors, he and the dancer Dorothee Gunther established an experimental school called Guntherschule in Munich for the integration of the performing arts. However, the Guntherschule was destroyed during World War II. Orff then collaborated with a music teacher named Guild Keetman to advocate for children's music education as an integrated art form. Together Orff and Keetman published five volumes of chants, songs, and instrumental pieces called Music Für Kinder, which were later widely used in Orff Schulwerk music education around the globe.

Orff Schulwerk addresses the natural behaviors of childhood, specifically, singing, speaking, dancing, playing, improvising, and creating. Campbell describes the elemental music of Orff Schulwerk as "pre-intellectual and exploratory, with music, movement, and speech interrelated and overlapping." 123 While the use of specially made Orff instruments, wood xylophones, metal glockenspiels, and metallophones is suggested in Orff Schulwerk music classrooms, other instruments such as drums and recorders are also frequently used. The construction of Orff instruments allows teachers and students to

${ }^{123}$ Campbell and Scott-Kassner, Music in Childhood, 56. 
easily remove and change the bars to play in different keys and scales. To complement the Orff Schulwerk methodology, folk songs that include the pentatonic scale, ostinato patterns, and pedal tones are often used in the classroom. Carl Orff emphasized music and movement as "elemental" parts of music education:

What is elemental? The Latin term "elementarius" means "belonging to the elements," that is, to the origins, the beginnings, appropriate to first principles. Further, what is elemental music? It is never music alone; it is bound together with movement, dance and speech; it is a music that one must make himself, into which one is drawn in not as listener, but as participant. It is unsophisticated, knows no large forms or grand structures; instead it consists of small series forms, ostinatos, and small rondo forms. Elemental music is near the earth, natural, physical, to be learned and experienced by everyone, suitable to the child. ${ }^{124}$

In Orff music and movement, speech is the first step for children to understand rhythm. Words and chants are spoken in rhymes and then further combined and parsed to form a regulated rhythm. Speech is combined with movement such as clapping and stamping. The San Francisco Orff School instructor Janet Greene encourages her student teachers to turn words and rhythm into a song, the song into a dance, and then an actedout story. Finally, instrumental accompaniments are added. This natural development of musical activity creates an atmosphere of experimentation and spontaneity. The essence of the Orff approach is the integration of music, movement, speech, and song, which are often inseparable in many cultures around the world, but rarely in our daily life. In Orff Schulwerk classrooms, an environment of integrated artforms is created for students to practice, enjoy, and create music as a community.

${ }^{124}$ Orff, Orff Schulwerk, Past and Future, 5. 


\subsubsection{An Orff Classroom Observation}

Tiffany Barry is a teacher at the Steindorf Steam School in the Cambrian School District of North California. She teaches students from kindergarten to eighth grade. Ms. Barry is a certified Orff Schulwerk teacher who has not only completed three levels of training but also offers workshops for other teachers who are interested in the Orff approach in music classrooms. She often uses Philippine folk songs as well as music from different cultures in her Orff Schulwerk classrooms and workshops, bringing knowledge from her Philippine heritage while acknowledging the cultural diversity of her classes.

I attended an Orff teaching workshop on March $25^{\text {th }} 2018$, in which Tiffany Barry demonstrated to music educators and scholars the teaching process for two Philippine folk songs of different difficulty levels using Orff approaches. She transcribed the folk songs from memory and other primary sources. Before she introduced the two Philippine folk songs, Ms. Barry started the class with a greeting song from a music textbook called “How Do You Say Hello?"125

\section{a. Pen Pen De Sarapen}

This is a solo voice Philippine children's rhyme arranged by Tiffany Barry. The lyrics are in Tagalog (a language spoken in the Philippines) without English translation. The song was entirely taught by rote to the students, phrase by phrase, without referring to any form of printed material. Ms. Barry adopted the simple teacher-sing-student-echo format, gradually increasing the lengths of the phrases the students were echoing.

${ }^{125}$ Note from Tiffany Barry: Melody from “Music for Children,” vol. 1, 91. 
After the students had become familiar with the song, Ms. Barry introduced a singing game where the students were asked to repeat the song many times while playing the game. First, the students sat in a circle and joined hands. Then, the students clapped hands with their neighbor one by one, passing the clap around the circle while singing the song. On the last note of the song, the student about to receive a clap needed to avoid being this clap or they would be eliminated from the game. After being eliminated, the student can choose a percussion instrument to accompany the song as they wish. As the game went on, more and more students were eliminated and moved on to play percussion instruments and the circle became smaller and smaller until there was one final winner. After singing the song many times in the singing game, the students had become extremely familiar with the folk song.

\section{b. Planting Rice Song}

This is a Philippine folk song arranged for a solo voice and drum parts by Tiffany Barry. Originally sung by Filipinos in both English and Tagalog, this song can be taught in both languages. In Ms. Barry's demonstration, she taught the song using similar methods to those using when teaching "Pen Pen De Sarapen." Through listening and memorizing, the students echoed the teacher's singing phrase by phrase and eventually connected the entire song together.

When the students were familiar with the song after a few repetitions, Ms. Barry introduced dance movements to accompany the singing. The dance movements simulated the action of planting rice. The students bent down from the waist, walking backward with two hands putting "rice seedlings" on the floor in alternative motions. Initially, the 
students found it entertaining and laughed when imitating Ms. Barry's movements. Then Ms. Barry stopped and explained the reason why rice planters bend down from the waist and walk backward, which is to keep their clothes dry and avoid stepping on the seedlings. The students were then able to understand what they were doing and were willing to dance. Ms. Barry continued to talk about the connection between the local environment and culture, exploring further the land of the Philippines.

The last activity asked the students to design their own choreography for the chorus of the song. The students were divided into groups of six and were given ten minutes to discuss their choreography. They were actively engaged in singing the song, remembering the previously taught dance movements, and recollecting knowledge about Philippine cultures. Finally, each group performed their choreography in front of the class and received compliments and feedback from their classmates.

This model class demonstrated by Tiffany Barry provides a viable way for teachers to adapt folk songs from unfamiliar cultures for use in classrooms. Some of the most effective approaches in her classrooms include using call and response techniques to teach folk songs phrase by phrase, adding dance movements to the music, introducing singing games, allowing students to freely accompany singing with percussion instruments, and creating their own choreography.

\subsection{Synergy between Orff Schulwerk and Cultural Music}

The above class observation offers valuable insights into designing classes that involve folk music from unfamiliar cultures. The Orff Schulwerk approach does, in fact, share many similarities with traditional music education in many other cultures. Below 
are some of the parallels between the philosophies and methodologies of Orff Schulwerk and Dong and Miao music practices:

- Music practices and music education are not strictly separated. Casual performances are also music classrooms, and can arise at any time. Besides their educational function, music lessons also serve the purpose of entertainment, social activities, and communication. Thus, performance skills such as singing, moving, and playing are emphasized from the beginning rather than being an end product.

- Music practices are multi-sensory experiences. Singing, dancing, instrument playing, rhythmic speech, and dramatic elements are all integrated to trigger the aural, kinesthetic, and visual modes that greatly enhance students' learning process.

- An inclusive environment nurtures the sense of community among people. In most Dong and Miao music activities, everyone is part of the ensemble, whether they are singing, dancing, or playing instruments. Performers are also observers and the audience. In Orff classrooms, teachers and students participate together without being separated by any hierarchies.

- Creativity is encouraged through improvisation in Dong and Miao music practices as well as in Orff Schulwerk classrooms. In Dong and Miao traditions, one of the most important abilities of musicians is to improvise according to the occasion and music genre. In Orff approaches, students are strongly encouraged to improvise with given instruments, scales, or music styles. Improvisation is also transferable from vocal speech and music to instrumental music, expanding the possibilities of music making. 
These similarities in teaching methodologies and philosophies between Orff Schulwerk and traditional Dong and Miao music education confirm the benefit of these music education approaches. Furthermore, music educators are able to create a close-toauthentic cultural environment in their elementary classrooms through the Orff approach.

\subsubsection{Adaptation in Teaching Dong and Miao Ethnic Music}

There may be as many methods of teaching as there are music teachers. Although there are methodologies to help teachers accomplish their goals, every teacher finds his or her own way to address their specific environment and needs in the classroom effectively, and to guide children toward the development of musical skills and understanding. Depending on the teacher's cultural background, musical training, and personal experiences, a unique approach is employed to fulfill instructional goals, to speak to the culturally diverse communities, and to address the interests of students with the resources on hand.

In the following chapter of this study, suggestions and contexts are provided for teachers to develop their own lesson plans in the classrooms, including two folk songs, one each from the Dong and Miao ethnic groups, as well as one percussion ensemble piece from the Miao tradition. I recorded all of the music personally during my trip to Guizhou in the summer of 2018, and I have received permission to use these materials in this study.

Trying my best to stay true to the original recordings, I have nonetheless made necessary adjustments when writing the music, such as eliminating microtones that do not correspond with standard pitches on a piano, simplifying grace notes and vocal 
ornamentations, adjusting note values to fit certain rhythms, and so on. Since Dong and Miao music is part of these communities' oral traditions, the nuances in vocal techniques and singing styles are extremely difficult to capture when using Western music notation. Even if these nuances and details are addressed and displayed in the score, they would be immensely difficult for teachers to use or for students to learn in elementary classrooms. The goal is to open a door for students to develop respect and interest in music from Dong and Miao ethnic groups; thus the threshold of learning should be kept at a reasonable level and in line with students' developmental stages. The teacher should recognize these issues and share them with the students, to avoid students accepting the simplicity of the music as entirely authentic.

The lyrics of the two folk songs are sung in local dialects of Dong and Miao languages. Dong and Miao languages do not traditionally have a written form; however, in recent decades, Romanized spelling systems such as Ntawv Hmoob (see chapter three) that are similar to Vietnamese were developed for educational purposes. These Romanization systems have developed with help from Western missionaries (mainly French) and linguists and are difficult to read and pronounce for people without substantial training. The vowels and consonants are pronounced differently than those in English, and the additional ending consonants that represent the tonal deflections only add more complexity to these systems. Due to their remote residential locations, many Dong and Miao people traditionally did not have access to education and could not read the Roman alphabet. Thus, the international Romanization systems of Dong and Miao languages are rarely seen in Chinese Dong and Miao residential regions. 
While these Romanization systems of Dong and Miao languages are internationally recognized, the local Chinese Dong and Miao use Chinese characters to record the pronunciation of their songs' lyrics. However, the Chinese characters are used solely to reflect the pronunciation of words, not their meaning. Therefore, the random assembly of Chinese characters in lyrics does not have any semantic meaning and is only intended to guide pronunciation.

Considering the impracticality of both writing systems of Dong and Miao languages, they are not included in the transcriptions of the two folk songs in this study. Another system that is frequently used by professionals when learning lyrics in unfamiliar languages is the International Phonetic Alphabet (IPA). Although the IPA may provide the most accurate guidance regarding pronunciation, this system also requires substantial training before people can accurately read the phonetic symbols. Therefore, I transcribed the lyrics of the two folk songs using an English phonetic spelling based on English pronunciation rules. This is not a standard phonetic spelling system; however, it can provide an accessible way for teachers and students to sing the lyrics of songs in unfamiliar languages. Teachers should acknowledge that these phonetic spellings provide a close simulation of local Dong and Miao dialects but not the original form of the languages.

Using English phonetic spelling, all the vowels should be pronounced as rounded vowels, similar to that heard in Italian or British English. The pronunciation guide is illustrated in Table 7. 
Table 6: Pronunciation Guide for Transcribed Lyrics

\begin{tabular}{|c|c|}
\hline $\begin{array}{c}\text { Vowels and Consonants } \\
\text { in Lyrics Transcriptions }\end{array}$ & Pronunciation Guide \\
\hline $\mathrm{a}$ & ah, rounded vowel \\
\hline $\mathrm{i}$ & ee, as in "sheep" \\
\hline $\mathrm{o}$ & or, but without curling of the tongue \\
\hline $\mathrm{e}$ & eh, as in "bless" \\
\hline $\mathrm{u}$ & oo, as in "wood" \\
\hline $\mathrm{j}$ & gi, as in "giraffe" \\
\hline
\end{tabular}

\subsubsection{Crafting the Cultural Experience}

In contemporary elementary music classrooms, many teachers have incorporated music from unfamiliar cultures into their repertoires. The focus, however, has mostly remained on the sonic aspect of the music, overlooking other essential elements. ${ }^{126}$ Although in European classical instrumental music, music is an abstract, socially autonomous artform, music of many other genres or cultures around the world is often associated with social occasions and experiences. Thus, the context of cultural music is critical for children to understand the diversity of global musical culture. Studying expressive cultural practices such as music and dance from different societies is vital for children to avoid presumptions that can blind them to our common humanity. To craft an effective cultural experience for children in music classrooms, music teachers should look beyond the sonic aspect of music practices.

${ }^{126}$ Juliana Vita, "Promoting Cultural Understanding Through Orff Schulwerk: Embracing Music in and as Culture," The Orff Echo 50, no. 2 (2018): 42. 
First, in Western music education, a standard notation system is employed for all types of music, including music from unfamiliar cultures. Often, music from nonWestern traditions loses some degree of authenticity and expressiveness when notated in staves. Then, when singers and players reproduce this music solely by reading musical scores, the music may sound significantly different than the original. Without contextual information, students may be at risk of learning what is essentially a new form of music, one that belongs to neither the student's culture nor the music's original culture. For example, Chinese Guqin music is traditionally notated in Chinese characters that provide instruction only on hand movements without indications on tempo, dynamics, phrasing, and other parameters. The essence of Guqin music is to express one's inner state of mind and to depict the environment in an abstract manner. Performers of Guqin music are given a large degree of freedom in interpreting the score. If a Guqin piece is notated in standard staves with bar lines, absolute pitches, and rhythms, students may find it difficult to make sense of the piece without any contextual information. One of the possible results if this will be to judge Guqin music from one's own cultural perspective and to thus undervalue or misunderstand the meaning of Guqin music. The standard notation system can only provide instruction on music performance, while the addition of contextual information can help students to develop an aesthetic understanding of music and to appreciate music from unfamiliar cultures.

Second, music making is always closely associated with human societies and activities. In many cultures, music not only provides entertainment, but also displays specific functionalities such as to worship ancestors, to record history, to perform 
religious rituals, and much more. As Turino wrote, "music is not a unitary art form, but rather this term refers to fundamentally distinct types of activities that fulfill different needs and ways of being human." ${ }^{27}$ Music contains a culturally-specific connection between a sign and what it stands for through resemblance, the "icon" as Peirce puts it. ${ }^{128}$ Understanding these cultural icons in the context of music will improve our ability to appreciate music in its own cultural environment. For example, the sound of the wooden drum can evoke the sound of thunder, which further resembles the sound of a natural force beyond human capabilities, and thus can lead to its presence in ancestor worship activities in Miao societies. From this perspective, the sound of the wooden drum is not simply "noise" or chaotic strikes, instead, we feel the reverberations in our body transmitted from the sound of the wooden drum. The Miao people believe that this primary form of resonance between our body and a musical object can connect us with our ancestors through the force of nature and grant us energy and courage to live for the future. To understand music according to its original cultural environment can help children develop compassion and empathy for the diverse cultures around them.

Lastly, it is necessary for children to hear and sing folk songs from other cultures in their original languages. In current music textbooks and songbooks, many folk songs are translated out of their original language or simply given new English lyrics. Although this may simplify the teaching process and shorten courses, the authenticity of cultural music is lost. Language and culture are so closely intertwined with the historical experience of a

${ }^{127}$ Thomas Turino, Music as Social Life (Chicago: University of Chicago Press, 2008), 1. ${ }^{128}$ Charles S. Peirce, Philosophical Writings of Peirce, ed. Justus Buchler (New York: Dover, 1955). 
people that to reject their words is to turn away from their habits and customs, their daily lives, their attitudes and values, the very substance one is trying to observe and absorb in learning about them. When foreign language lyrics are replaced by English words, students tend to make presumptions about a song based on their understanding of English songs. Often, folk songs from foreign cultures do not sound natural when sung using English words, and this will may greatly affect students' interest in learning the song. Even if the foreign song does sound natural with English lyrics, students will likely regard it as just another "English song" and will tend to ignore the cultural aspect of the music. Furthermore, some languages are tonal and tonal inflections of the lyrics are connected with its melodic contours. ${ }^{129}$ In fact, Schellenberg's study demonstrates that in some tonal languages, including Cantonese ${ }^{130}$ and Zulu, ${ }^{131}$ language tones largely determine the melody of vocal music. The melody of speech and the melody of sung lyrics are closely connected in tonal languages, adding subtle nuances to melodies that cannot be transcribed using standard notation. Singing in a foreign language is difficult for young children, but it opens up their curiosity about the mysterious sounds and symbols of unfamiliar cultures. Children will immediately abandon their presumptions and stereotypes and adopt a real curiosity about foreign cultures, and it will be these unfamiliar vowels and consonants that carry children's imagination to foreign lands.

${ }^{129}$ Murray Schellenberg, "Does Language Determine Music in Tone Languages?" Ethnomusicology: Journal of the society for Ethnomusicology 56, no. 2 (2012): 269-270. ${ }^{130}$ Patrick Wong and Randy Diehl, "How Can the Lyrics of a Song in a Tone Language be Understood?" Psychology of Music 30, no. 2 (2002): 202-09.

${ }^{131}$ David Rycroft, "The Relationship between Speech-Tone and Melody in Southern African Music," in South African Music Encyclopedia, vol. 2, edited by J.P. Malan, (1979), 301-14. 
As the classroom is removed from the original context in which a piece of World Music is performed, it is often a challenge for teachers to adopt World Music in classrooms. As Palmer posits,

At best, understandings can be put to the test by exploring questions of authenticity, a matter of no small importance. At worst, a classroom experience can also misrepresent a music tradition so its musical values are seen as boring or uninteresting, or poor quality in substance or performance, incoherent in structure, simple-minded because of didactic simplifications, lacking in cultural values, and laughable in its pretence of being 'music'. ${ }^{132}$

Today's substantial multi-media resources and diverse community members can significantly support the teaching of World Music to young children. By carefully presenting cultural contexts and background information, crafting cultural experiences in singing and dancing, and encouraging children to explore World Music in its original language and according to its original function, music teachers can nurture children's understanding and empathy for the diverse cultures in our world.

${ }^{132}$ Palmer, "Authenticity," 39. 


\section{Classroom Teaching Strategies}

In this chapter, I present a collection of teaching strategies using an Orff-inspired methodology for the three pieces of folk music from the Dong and Miao, and provide essential cultural context for each of these pieces and ethnic groups. It is necessary to acknowledge that the presentation of ethnic languages is adapted for accessibility in elementary music classrooms, which may not accurately represent the native speaker's pronunciation. The three pieces of folk music collected in this study may have alternative versions in other publications or media due to the fluid nature of orally transmitted folk music. My arranged versions of these folk music are also adapted for the purpose of elementary music education, which may not accurately represent the nuance in native musicians' performances. It is vital for the teachers to provide the cultural context for the students, and thus developing a sense of respect for these cultures and fostering interests in students' future explorations. 


\section{1 "Song of Goat"}

Please see Appendix A for the full arranged score.

\section{Cultural Context:}

- China's multicultural environment:

O There are 56 officially recognized ethnic groups in China.

- The Dong ethnic group:

They are located in the southwest mountain region of China.

They speak their own language, which is very different from Mandarin Chinese. They have no written form of language.

They wear cultural clothing in daily life. (Refer to Figure 18 in chapter three.)

They pass down their history and culture through singing and music education.

O Suggested video: "Grand song of the Dong ethnic group" by UNESCO (https://www.youtube.com/watch?v=iaHRfLb2oOk)

- "Song of Goat":

This is a children's big song from the Dong ethnic group.

This song has simple lyrics, mainly imitating the sound of goats on the hills, while the accurate pronunciation of the lyrics in the Dong language is of less importance.

This song starts with a solo line, then the choir join in the two-part harmony and the song ends with the choir singing the word "ei-jiu" in unison 


\section{Suggested teaching strategies:}

- Introductory:

O Start by asking students what they had for lunch/dinner and connect meals to the rice paddies in southwest China. Rice is not only the most important food for Dong people, but also an important economic product for them.

O Start by asking students what animals sound like and connect this to "Song of Goat." There may be differences in how people imitate animal sounds in different countries.

\section{- Movement:}

Divide students into two groups and have them stand in opposite corners of the classroom facing each other. Use props or simply get students to imagine the two groups are standing on the top of two mountains that are far away from each other so students need to talk or sing loudly. Encourage students to use loud voices and to enjoy expressing their energy within a set timeframe.

O Have students move along to the recording of Dong big songs (doesn't need to be "Song of Goat") and describe their feelings. Encourage students to come up with their own interpretations of the movement that should accompany the music. Students may feel lost or confused when first listening to music from unfamiliar cultures. This feeling should be discussed within the class to acknowledge the cultural diversity in our society. 
- Explore Dong culture:

Show students pictures of Dong people's clothing, houses, faces, and living environments, and encourage respectful discussions.

O Suggested video: "Grand song of the Dong ethnic group" by UNESCO

(https://www.youtube.com/watch?v=iaHRfLb2oOk)

- Music making:

Invite one musically advanced student to be the soloist. Rehearse the two-part song "Song of Goat" in class.

The instructor can be the soloist, making it easier for students to learn the lyrics. In this case, divide students into two groups and rehearse the song. 


\section{2 "Welcome! Our Guest!"}

Please see Appendix B for the full arranged score.

\section{Cultural Context:}

- China's multicultural environment:

There are 56 officially recognized ethnic groups in China.

- Miao/Hmong ethnic group:

O They were originally from the central plains of China and then migrated to the southwest mountain region of China, Southeast Asia, United States, and all over the world.

O There are a large population of Miao people in the U.S., mainly residing in California and Minnesota. The Miao people in U.S. call themselves Hmong, and they migrated from Laos in the 1980s.

They speak Miao languages, which vary from place to place. There's no written form of Miao languages.

They have beautiful traditional costumes that they wear in daily life and for festivals. (Refer to Figure 11 in chapter three.)

They pass down their history and culture through singing and music education.

O Suggested video: "Xijiang: The Miao Village of a 1000 Households" by The Guizhou Tourism Board (https://www.youtube.com/watch?v=y5p34xrxGfE)

- “Welcome! Our Guest!”:

This song is usually performed by a small group of people singing in unison 
for their guests.

O This song was recorded in Fanpai village in Guizhou province.

The lyrics are in the local Miao dialect.

Suggested teaching strategies:

- Introductory:

O Start by asking students how they welcome their friends and family into their home. Encourage them to think of activities they could do to be hospitable to their guests besides saying "hi." Explore different acts of hospitality in different cultures around the world.

O Start by introducing China as a multi-ethnic and multicultural country where people from different ethnic backgrounds live together. Draw a connection to the world around us and encourage discussion on cultural diversity.

- Movement:

O Listen to the song "Welcome! Our Guest!" The instructor can introduce the concept of triple meter to students and explore triple meter dance movements from around the world.

Encourage students to come up with a short story. The story can be creative, but it should relate to the theme of guest-welcoming activities. Use the story to guide students to create a short piece of choreography to accompany the folk song. Students can work in small groups and share their dance with the rest of the class. 
- Explore Miao culture:

On a world map, identify the global diaspora of the Miao ethnic group. Miao culture may be different in different geographic locations. The instructor can further explore the cultural diversity within the Miao ethnic group by showing students pictures of Miao people from different regions.

O Suggested video: "Xijiang: The Miao Village of 1000 Households" by The Guizhou Tourism Board (https://www.youtube.com/watch?v=y5p34xrxGfE)

- Music making:

Teach the song phrase by phrase to students. It is suggested that the instructor teach the song in the Miao language from the beginning.

Teach students the melody of this song using Orff instruments to demonstrate. Students are encouraged to improvise on Orff instruments on the pentatonic scale starting at $\mathrm{A}$. 


\section{3 "Wooden Drum Dance"}

Please see Appendix C for the full arranged score.

\section{Cultural Context:}

- China's multicultural environment:

There are 56 officially recognized ethnic groups in China.

- Miao ethnic group:

O They were originally from the central plains of China and then migrated to the southwest mountain region of China, Southeast Asia, United States, and all over the world.

O There are a large population of Miao people in the U.S., mainly residing in California and Minnesota. The Miao people in the U.S. call themselves Hmong and they migrated from Laos in the 1980s.

They speak Miao languages, which vary from place to place. There's no written form of Miao languages.

$\bigcirc$ They pass down their history and culture through singing and music education.

- The Fanpai "Wooden Drum Dance":

O Since there are Miao communities across the world, it is necessary to specify that this dance was recorded in Fanpai village in Guizhou, China.

O This piece is usually performed by the Miao people during Guzang Festivals for celebration purposes.

O There are five movements in the Fanpai "Wooden Drum Dance," and this 
lesson only includes the first movement.

O The percussion pattern is traditionally played by one player on a large wooden drum. Considering the reality of elementary school settings, the score is arranged as a three-part percussion ensemble to reduce the level of difficulty.

O Suggested videos:

"Fanpai Miao Village" by Chinese Central Television (CCTV) (https://www.youtube.com/watch?v=B3vEHoFYQXk)

"Fanpai Wooden Drum Dance" by CCTV

(https://www.youtube.com/watch?v=KP1YsZxExps\&t)

\section{$\underline{\text { Suggested teaching strategies: }}$}

- Introductory:

Start by brainstorming different genres of percussion music and different types of drums around the world. The instructor can bring a few types of drums to compare, such as congas, snare drums, hand drums, etc.

Encourage students to come up with different ways to play the drums, such as with/without a stick, hitting on the center/edge, and more creative ways.

- Movement:

Listen to a few types of percussion music and encourage students to move or dance with the music. Ask students to describe their feelings and what they are trying to convey through their movements. Students may feel lost or confused when first listening to music from unfamiliar cultures. This feeling 
should be discussed within the class to acknowledge the cultural diversity in our society.

O Listen to the recording of the Fanpai "Wooden Drum Dance" and encourage students to come up with their own movements without watching the video.

After watching the video, compare the movements in the video and the movements students came up with. In small groups, get students to design a short dance based on the combination of these movements.

- Explore the culture of the Miao in Guizhou:

Show students pictures of Miao people's clothing, houses, faces, and living environments, and encourage respectful discussions.

O Suggested video: "Fanpai Wooden Drum Dance" by CCTV (https://www.youtube.com/watch?v=KP1YsZxExps\&t)

- Music making:

Divide students into two groups, each responsible of playing the percussion piece and dancing.

Have all students play the percussion score. Divide students into three groups and get each to play one of the three parts (drum, wooden block, and clave) in the percussion ensemble. 


\section{Conclusion}

Through this study, I aim to provide an accessible path for music educators to introduce folk music from the Miao and Dong ethnic groups into elementary music classrooms. Prior to exploring Miao and Dong folk music, I examined how Chinese folk music is currently being represented in U.S. elementary music textbooks and the original sources of the folk music taught. By highlighting the limited diversity of Chinese folk music selections and the prevailing use of English lyrics in Chinese folk songs, I argue that there is enormous potential to improve music education by increasing the diversity of Chinese folk music selections and teaching folk songs in their original languages. Therefore, I hope to introduce folk music from Chinese ethnic minority groups as a resource for elementary music educators.

In the process of searching for an accessible path for working teachers to introduce Miao and Dong folk music into practical classroom settings, I discovered many shared visions and methodologies between Orff Schulwerk and the approaches to music education in Miao and Dong traditions. The focus on natural learning, the integration of movement and dance in music practice, and the emphasis on improvisation in Orff Schulwerk give students a similar experience to Miao and Dong children and how they learn music. Teachers are often hesitant to adopt music from unfamiliar cultures in the classroom as it is extremely difficult for both teachers and students to learn "authentic" folk music from other cultures. Teachers, however, should recognize the difficulty in achieving authenticity in folk music teaching in classroom settings and should encourage students to further explore this folk music outside the classroom. 
As discussed in this study, Chinese folk music is extremely diverse and contains an abundance of different genres and styles. One of the difficulties of teaching Chinese folk music to non-native Chinese speakers is the language barrier. The numerous languages and dialects that fall under the broad categorization of "Chinese language" present enormous challenges in practical teaching. In future studies, I hope to conduct field research to explore the optimal approach to teaching and learning folk music in its native language. This exploration of introducing Miao and Dong folk music into elementary music classrooms using the Orff Schulwerk approach is only the first step in expanding educational resources on Chinese folk music. There is enormous potential for future studies to improve not only the diversity of Chinese folk music in music education resources, but also the quality and authenticity of these educational resources. 


\section{Reference}

\section{English Sources}

Ashbrook, William and Powers, Harold. Puccini's Turandot: The End of the Great Tradition. Princeton, New Jersey: Princeton University Press, 1991.

Banks, J. A. and Banks, C. M. Handbook of Research in Multicultural Education. New York: Macmillan, 2004.

Bender, Mark. "Hunting Nets and Butterflies: Ethnic Minority Songs from Southwest China." Manoa 12, no. 1 (2000): 80-86.

Blacking, John. How Musical Is Man? Seattle: University of Washington Press, 1973.

Britannica Academic, s.v. "Tai languages," accessed November 28, 2018, https://academic.eb.com/levels/collegiate/article/Tai-languages/109796.

Buckley Ebrey, Patricia. The Cambridge Illustrated History of China, 2nd ed. Cambridge: Cambridge University Press, 2010.

Campbell, Patricia Shehan and Scott-Kassner, Carol. Music in Childhood: From Preschool Through the Elementary Grades, 4th ed.. Boston: Shirmer, 2014.

Campbell, Patricia Shehan and Yung, Bell. "Bell Yung on Music of China: As Part of the "Music in Cultural Context" Series, this Interview with Bell Yung Focuses on the Music of China." Music Educators Journal 81, no. 5 (1995): 39-46.

Chen, Chin-Hsin Yao and Chen, Shih-Hsiang. The Flower Drum and Other Chinese Songs. New York: The John Day Company, 1943.

Dietz, Betty Warner and Park, Thomas Choonbai, Folk Songs of China Japan and Korea. New York: The John Day Company, 1964.

Eira, Christina. "Hmong and Hmong-Mien (Miao-Yao) Languages." In Routledge Encyclopedia of Linguistics, edited by Philipp Strasny. London: Routledge, 2005.

Elliot, D. "Key Concepts in Multicultural Music Education," International Journal of Music Education 13, no. 1 (1989).

Elliot, D. Music Matters; A New Philosophy of Music Education. New York: Oxford, 1995.

Feld, Steven. Sound and Sentiment: Birds, Weeping, Poetics, and Song in Kaluli Expression, 2nd ed. Philadelphia: University of Pennsylvania Press, 1990. 
Fox, Margalit. "Zhou Youguang, Who Made Writing Chinese as Simple as ABC". The New York Times (14 January 2017).

Frisbee, Charlotte J. "Vocables in Navajo Ceremonial Music." Ethnomusicology 24 no. 3 (1980): 347-392.

Geary, D. Norman, Geary Ruth B, Ou Chaoquan, Long Yaohong, Jiang Daren, and Wang Jiying. The Kam People of China: Turning Nineteen. London / New York: Routledge Curzon, 2003.

Google Map. Accessed March 27, 2019.

https://www.google.com/maps/place/Guizhou,+China/@34.6411191,89.195614,4.98z /data $=! 4 \mathrm{~m} 5 ! 3 \mathrm{~m} 4 ! 1 \mathrm{~s} 0 \times 36 \mathrm{bf67eaae} 6 \mathrm{dd} 399: 0 \times e c 9 \mathrm{c} 1 \mathrm{~d} 7600 \mathrm{abd} 55 \mathrm{e} ! 8 \mathrm{~m} 2 ! 3 \mathrm{~d} 26.8429645$ ! 4d107.2902839.

Hall, Ronald. T. Z. Koo: Chinese Christianity Speaks to the West. London: SCM Press, 1950.

Hawn, Michael C. "History of Hymns: "Rise to Greet the Sun," The United Methodist Church, accessed October 10, 2018, https://www.umcdiscipleship.org/resources/history-of-hymns-rise-to-greet-the-sun.

Hein, Jeremy. Diversity in Diaspora: Hmong Americans in the Twenty-First Century, ed. Mark E. Pfeifer, et al. Hawaii: University of Hawaii Press, 2013.

Heinrich, Lisa. "Promoting Culturally Responsive Music Experiences in an Orff Schulwerk Setting." Orff Echo 49, no. 4 (2017): 16-19.

Hetrick, Pam. "International Voices: An Introduction." Orff Echo 39, no. 2 (2007): 8.

Iafigliola, Beth. 2007. "From the AOSA Video Library: Chinese Children's Songs and Singing Games." Orff Echo 39, no. 2 (2007): 48.

Ingram, Catherine. "Echoing the Environment in Kam Big Song." Asian Studies Review 35, no. 4 (2011): 439-455.

Ingram, Catherine and $\mathrm{Wu}$, Jiaping. "Research, Cultural Heritage, and Ethnic Identity: Evaluating the Influence of Kam Big Song Research of the 1950s. (Essay)." Asian Ethnology 76, no. 1 (2017): 65.

Jahre Orff Institut. "Orff Institute Guidelines." Orff Schulwerk Informationen - "50 Jahre Orff-Institut”. (Jahre Orff-Institut, 2011), 85.

Johnson, N.B. "On the Relationship of Anthropology to Multicultural Teaching and Learning," Journal of Teacher Education 28, no. 3 (May/June 1977). 
Kaiyr, "Autonomies in Guizhou” in Wikipedia. Accessed March $27^{\text {th }} 2019$. https://en.wikipedia.org/wiki/Guizhou\#/media/File:Ethnic_minorities_areas_in_Guiz hou.png.

Kang, Sangmi. "The History of Multicultural Music Education and its Prospects: The Controversy of Music Universalism and its Application." Update: Applications of Research in Music Education 34, no. 2 (2016): 21-28.

Koo, Tz-Zeung, Folk-Songs From China. London: The Hon. Lady Cripps, 1943.

Lau, Frederick. Music in China. New York, Oxford University Press, 2008.

Lo, Fungchatou T. The Promised Land: Socioeconomic Reality of the Hmong People in Urban America (1976-2000). Lima, OH: Wyndham Hall Press, 2001.

Mark, Michael L. and Gray, Charles L. A History of American Music Education, 3rd ed. Lanham, MD: Rowman \& Littlefield Education, 2007.

Nettl, Bruno. "On the Question of Universal," The World of Music 19, (1977).

Nettl, Bruno. The Western Impact on World Music, Change, Adaptation, and Survival. New York: Schirmer Books, 1985.

Norins, Martin R. "Reviewed Work: Stone-Gateway and the Flowery Miao. By Will H. Hudspeth.” Edited by Will H. Hudspeth, Pacific Affairs 12, no. 3 (1939): 340-42.

Orff, Carl. "Orff-Schulwerk: Past and Future.” In Orff Re-Echoes. Edited by Isabel McNeill Carley. Cleveland, OH: American Orff-Schulwerk Association, 1977.

Orff, Carl. "The Schulwerk," in Carl Orff/Documentation: His Life and Works, vol. 3. Translated by Margaret Murray. Tatzing: Schott, 1976.

Orff, Carl. Orff Schulwerk, Past and Future. American Orff-Schulwerk Association, 1973.

Palmer, Anthony J. "World Musics in Music Education: The Matter of Authenticity." International Journal of Music Education 19, no. 1 (1992): 32-40.

Pegg, Carole. "Folk music." Grove Music Online. Last modified 2001, accessed November 27, 2018. https://doiorg.libaccess.sjlibrary.org/10.1093/gmo/9781561592630.article.09933.

Peirce, Charles S. Philosophical Writings of Peirce. Edited by Justus Buchler. New York: Dover, 1955. 
Pratte, R. Pluralism in Education: Conflict, Clarity and Commitment. Springfield, IL: Charles C. Thomas, 1979.

Rees, Helen. Echoes of History: Naxi Music in Modern China Book and CD-ROM. New York: Oxford University Press, 1989.

Rees, Helen. "Environmental Crisis, Culture Loss, and a New Musical Aesthetic: China's "Original Ecology Folksongs" in Theory and Practice." Ethnomusicology 60, no. 1 (2016): 53.

Robert, A.C., Charles, B.F., Charles, E.B., and Wersen, L.G., "The Tanglewood Symposium: Music in American Society," Music Educators Journal 54, no. 3 (1967): 49-80

Roberts, J. Christopher and Beegle, Amy C. World Music Pedagogy Vol. 2: Elementary Music Education. New York: Routledge, 2018.

Roberts, J. Christopher and Campbell, Patricia Shehan. "Multiculturalism and Social Justice." In The Oxford Handbook of Social Justice in Music Education. Edited by C. Benedict, et al. New York: Oxford University Press, 2015.

Rohsenow, John. "Fifty Years of Script and Written Language Reform in the PRC: the Genesis of the Language Law of 2001." Language Policy in the People's Republic of China: Theory and Practice Since 1949. Edited by Zhou Minglang and Sun Hongkai. Boston: Kluwer Academic Publisher, 1989.

Rycroft, David. "The Relationship between Speech-Tone and Melody in Southern African Music." In South African Music Encyclopedia. Edited by J.P. Malan, vol. 2, 1979, 301-14.

Schein, Louisa. "Hmong/Miao Transnationality: Identity Beyond Culture." In Hmong/Miao in Asia. Edited by Nicholas Tapp, Jean Michaud, Christian Culas, and Gary Y. Lee. Chiang May, Thailand: Silk-worm Books, 2004.

Schellenberg, Murray. "Does Language Determine Music in Tone Languages?" Ethnomusicology: Journal of the Society for Ethnomusicology 56, no. 2 (2012): 269270.

Stalin, Joseph. Marxism and the National Question. Moscow: Co-operative Publishing Society of Foreign Works in the U.S.S.R., 1935.

Szego K. "Praxial Foundations of Multicultural Music Education.” In Praxial Music Education: Reflections and Dialogues. Edited by David J. Elliot. New York: Oxford University Press, 2003. 
Talley, Jennifer Lynn. "An American Song Book? An Analysis of the Flower Drum and Other Chinese Songs by Chin-Hsin Chen and Shih-Hsiang Chen." Master's thesis, Florida State University, 2010.

Tapp, Nicholas. "Hmong Religion.” Asian Folklore Studies, no. 48 (1989): 59-94.

Terry, Edith. How Asia Got Rich: Japan, China and the Asian Miracle. Armonk, NY: M.E. Sharpe, 2002.

Toner, P. G. "The Gestation of Cross-Cultural Music Research and the Birth of Ethnomusicology." In Humanities Research: Historizing Cross Cultural Research. Edited by B. Penny. Canberra. Australia: The Australian National University Press, 2008.

Turino, Thomas. Music as Social Life. Chicago, IL: University of Chicago Press, 2008.

United States Census Bureau. Accessed March 27, 2019. https://factfinder.census.gov/faces/tableservices/jsf/pages/productview.xhtml?src=CF.

Van Aalst, J.A. Chinese Music. Shanghai: The Inspector General of Customs, 1887.

Vita, Juliana. "Promoting Cultural Understanding Through Orff Schulwerk: Embracing Music in and as Culture." The Orff Echo 50, no. 2 (2018): 42.

Volk, Terese M. "Folk Music and Increasing Diversity in American Music Education," Journal of Research in Music Education 42 (1994): 285-305.

Volk, Terese M. "The History and Development of Multicultural Music Education as Evidenced in the "Music Educators Journal," Journal of Research in Music Education 41, No. 2 (summer 1993): 137-155.

Warner Dietz, Betty and Park, T.C. Folk Songs of China, Japan, Korea. New York: The John Day Company, 1964.

Waterman, C. A. Jùjú: A Social History and Ethnography of an African Popular Music. Chicago, IL: University of Chicago Press, 1990.

Wiant, Bliss. The Pagoda: Thirteen Chinese Songs. Delaware, OH: Cooperative Recreation Service, 1946.

Wong, Patrick, and Diehl, Randy. "How Can the Lyrics of a Song in a Tone Language be Understood?" Psychology of Music 30, no. 2 (2002): 202-09.

Zhou, Xiaojin. "How to Pronounce Chinese Names." last modified April 13, 2005. http://www.cs.cmu.edu/ zhuxj/readpinyin.html. 


\section{Chinese Sources}

Cao Cuiyun (曹翠云). “Tracing the History of Miao from Miao Language” (cong miao yuk an gu dai miao zu li shi wen hua heng ji 从苗语看古代苗族历史文化痕迹). Journal of Minzu University of China (Zhong yang min zu da xue xue bao 中央民族 大学学报) no. 1 (1982): 12-17.

Chen Fang (陈芳) and Zhang Kai (张凯). “Discussing the History and the Role of Singing in Children's Education in Dong Societies" (lun gui zhou dong zu 'yi ge ti shu' min jian er tong jiao yu chuan tong de xing cheng 论贵州侗族“以歌替书”民间 儿童教育传统的形成). Northern Music (bei fang yin yue 北方音乐), no. 12 (2017): 114-120.

China National Academy of Arts School of Music (中国艺术研究院音乐研究所). An Overview of Chinese National Music (min zu yin yue gai lun 民族音乐概论). Beijing: People's Music Publishing House, 1964.

Deng Jun (邓钧). 1999. “Cultural Context of Miao’s Lusheng Music” (miao zu lu sheng de ying yong chuan tong ji qi wen hua nei han 苗族芦笙的应用传统及其文化内涵. Musicology in China, no. 3 (1999): 116-132.

Deng Jun (邓钧). “Exploration of Polyphonic Morphology in Chinese Traditional Music and its Cultural Psychological Character" (zhong guo chuan tong yin yue zhong de duo sheng xing tai ji qi wen hua xin li te zheng tan wei 中国传统音乐中的多声形态及其 文化心理特征探微). Musicology in China (zhong guo yin yue xue 中国音乐学), no. 2 (2002).

Du Yaxiong (杜亚雄). Chinese Ethnic Minority Music (Zhong guo shao shu min zu yin yue 中国少数民族音乐). Beijing: China Federation of Literary and Art Circles Publishing, 1986.

Du Yaxiong (杜亚雄). Chinese Folk Song Map: Southern China (Zhong guo min ge di tu: nan fang juan 中国民歌地图南方卷). Hefei: Time Publishing and Media Company, 2013.

National Bureau of Statistics of China (中华人民共和国国家统计局). Accessed March 27, 2019. http://data.stats.gov.cn/easyquery.htm?cn=C01\&zb=A0305\&sj=2018.

Shi Chaojiang (石潮江). The History of Miao Migration (shi jie miao zu qian xi shi 世界 苗族迁徙史). Guizhou: Guizhou People's Publishing House 贵州人民出版社, 2006. 
Wu Xinfu (伍新福). “The Four Major Migration in Miao’s History” (lun miao zu li shi shang de si ci da qian xi 论苗族历史上的四次大迁徙). Ethno National Studies (min zu yan jiu 民族研究), no. 6 (1990): 103-110.

Wu Xiaodong (吴晓东). “Origin of Nomenclature and Surnames in Eastern Dialect of Miao Ethnicity” (dong bu fang yan miao zu zi cheng yu xing shi lai yuan kao 东部 方言苗族自称与姓氏来源考), Journal of Huaihua Teachers College (huai hua shi zhuan xue bao 怀化师专学报) 16, no. 2 (June 1997).

Yu Weiren (余未人). “Polyphonic Miao Folk Songs” (miao zu duo sheng bu min ge 苗 族多声部民歌). Colorful Guizhou (duo cai gui zhou 多彩贵州), no. 8, (April 2010): 57.

Yu, Jiafang (余甲方). Chinese Modern Music History (zhong guo jin dai yin yue shi 中 国近代音乐史). Shanghai: Shanghai People’s Press, 2006.

Zhang Guihua (张贵华) and Deng Guanghua (邓光华). The Dong's Big Song (dong zu da ge gai lun 侗族大歌概论). Beijing: Higher Education Publishing House, 2016.

Zhang Min (张民). “An exploration of the formation of the Dong nationality” (shi tan dong zu xing cheng 试探侗族形成), Guizhou Ethno Studies (gui zhou min zu yan jiu 贵州民族研究) 58 (1998): 95-104.

Zhou, Qing Qing (周青青). Chinese Folk Songs (zhong guo min ge 中国民歌). Beijing: People's Music Publishing, 1993. 


\section{Appendices}

Appendix A

\section{Song of Goat}

Dong's Folk Song, as sung by the Xiaohuang Village Choir
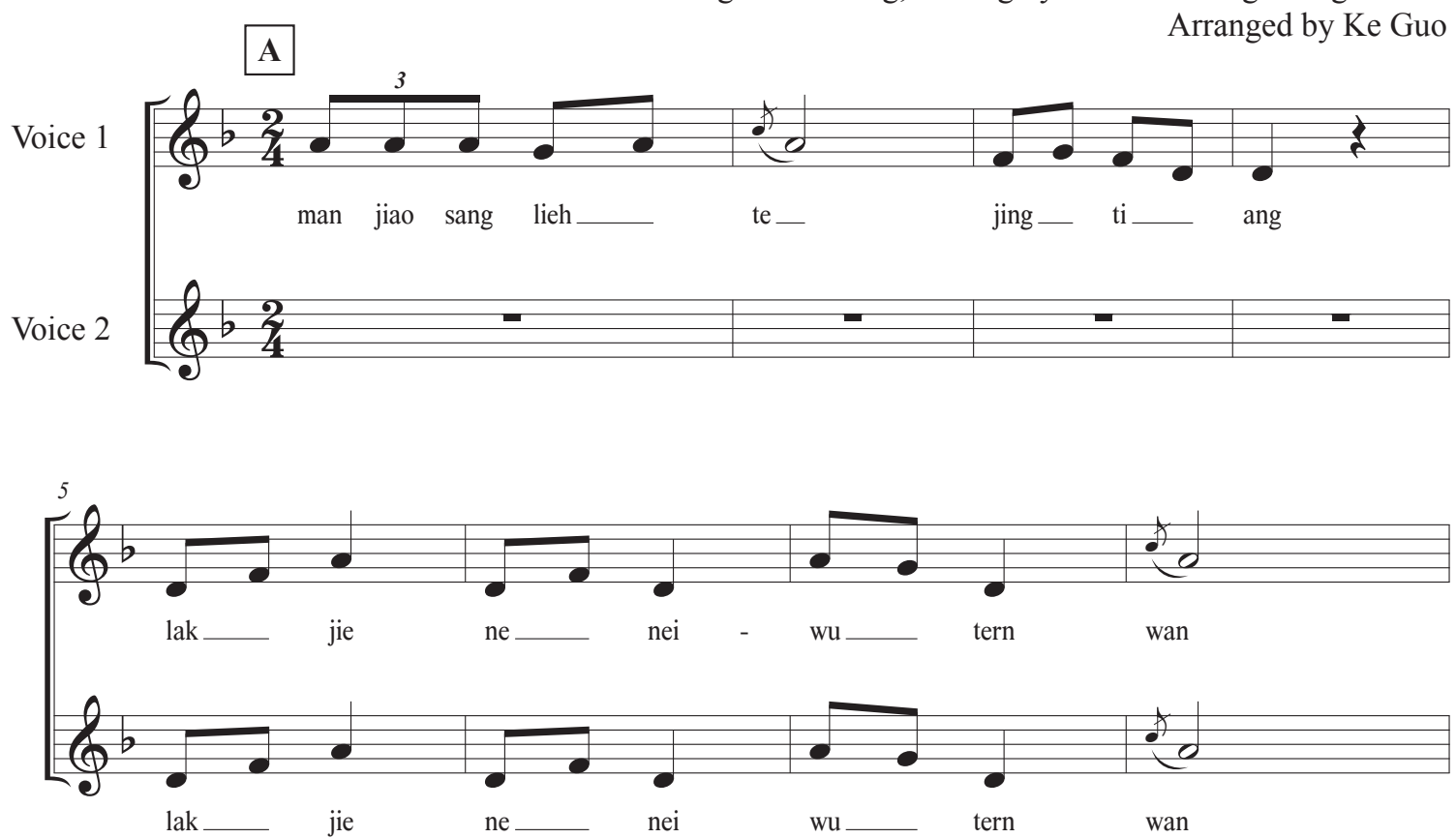

B
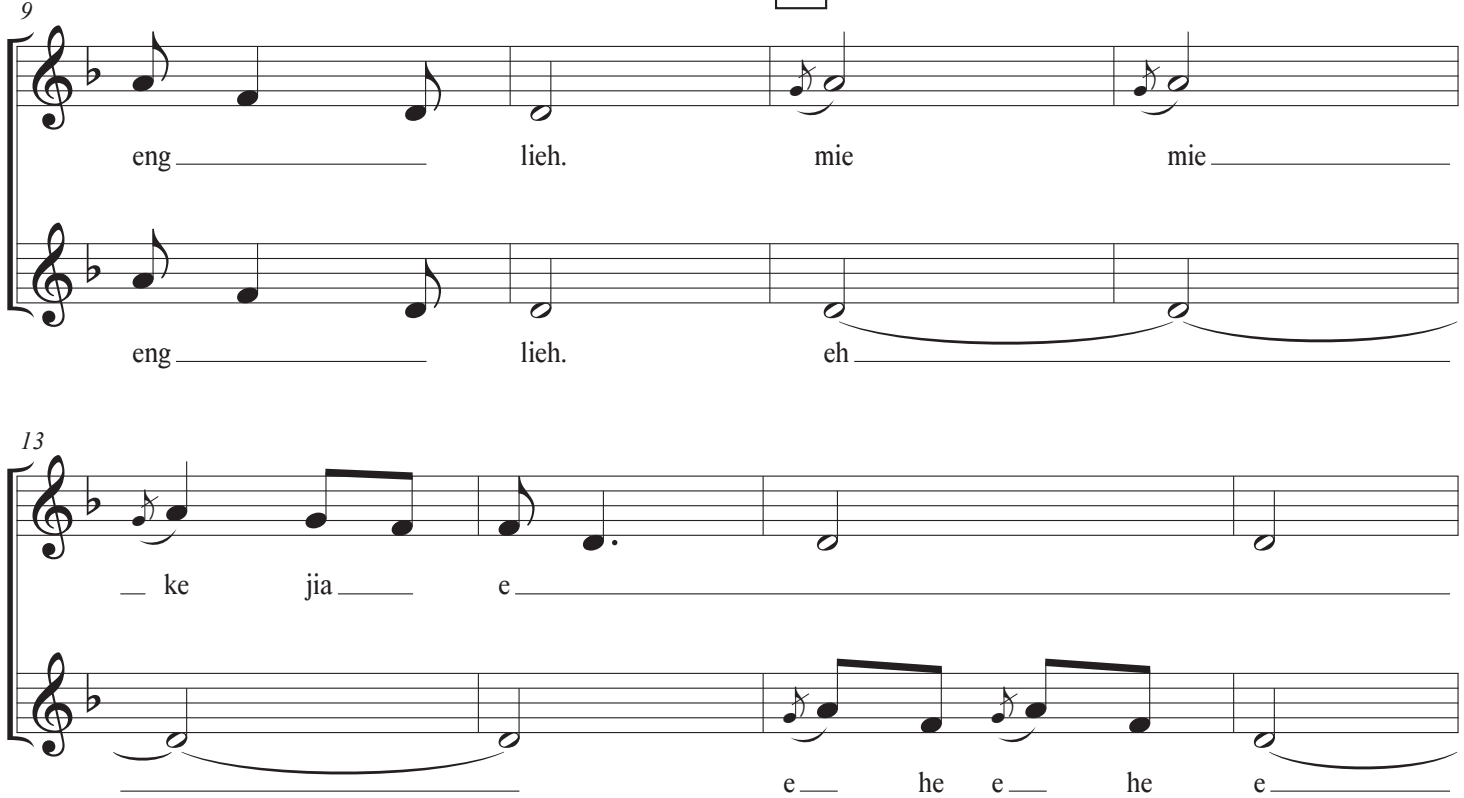

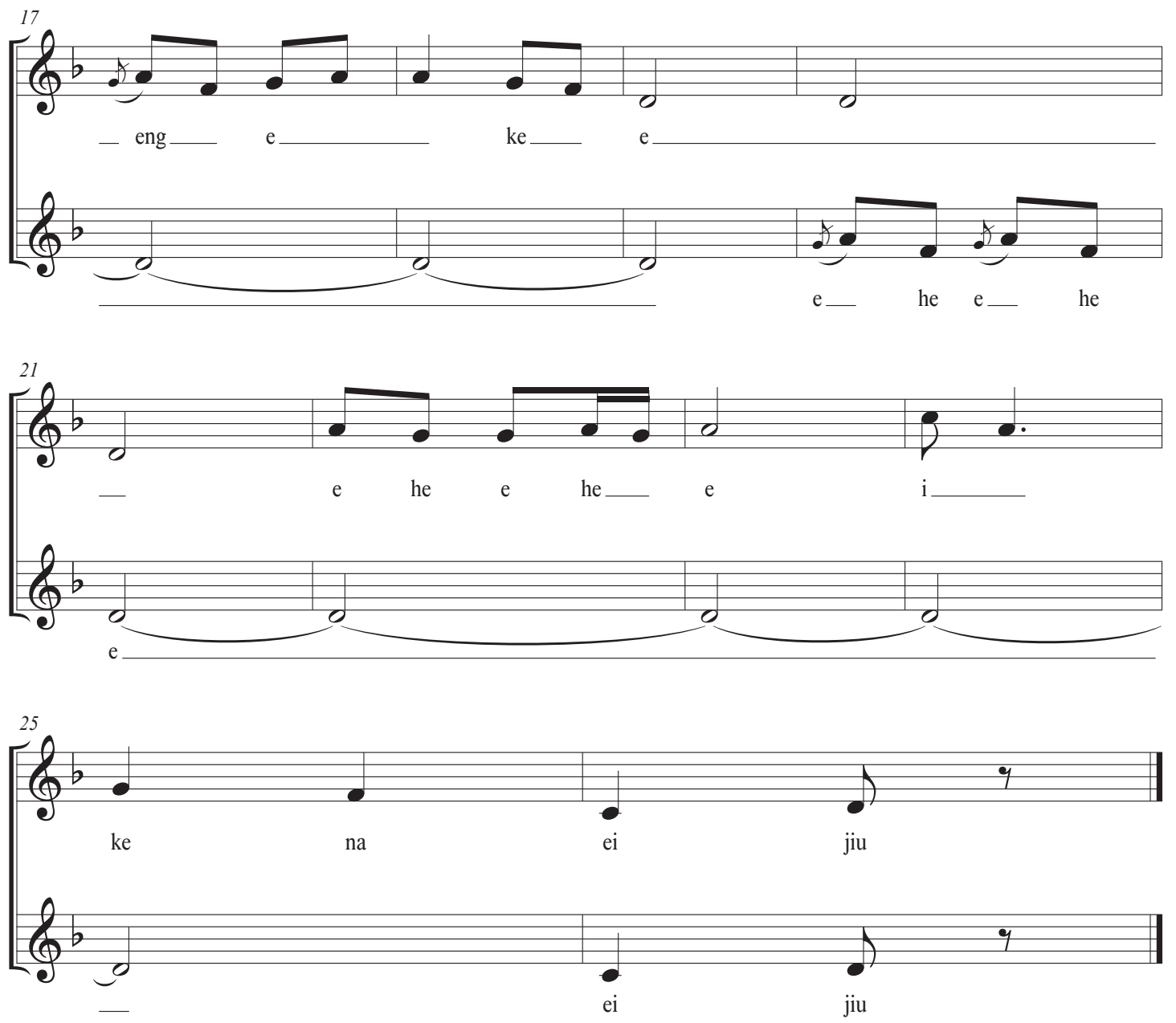

Content of Lyrics:

Little goats are running all over the hills.

Little goats are feeling hungry.

Mie $\sim$ Mie

Pronunciation guide:

a: ah, rounded vowel

i: ee, as in "sheep"

$\mathrm{o}$ : or, but without curling of the tongue

e: eh, as in "bless"

u: oo, as in "wood"

$\mathrm{j}$ : gi, as in "giraff" 


\section{Appendix B}

\section{Welcome! Our Guest!}

Miao's Folk Song, as sung by Tang Wengweng
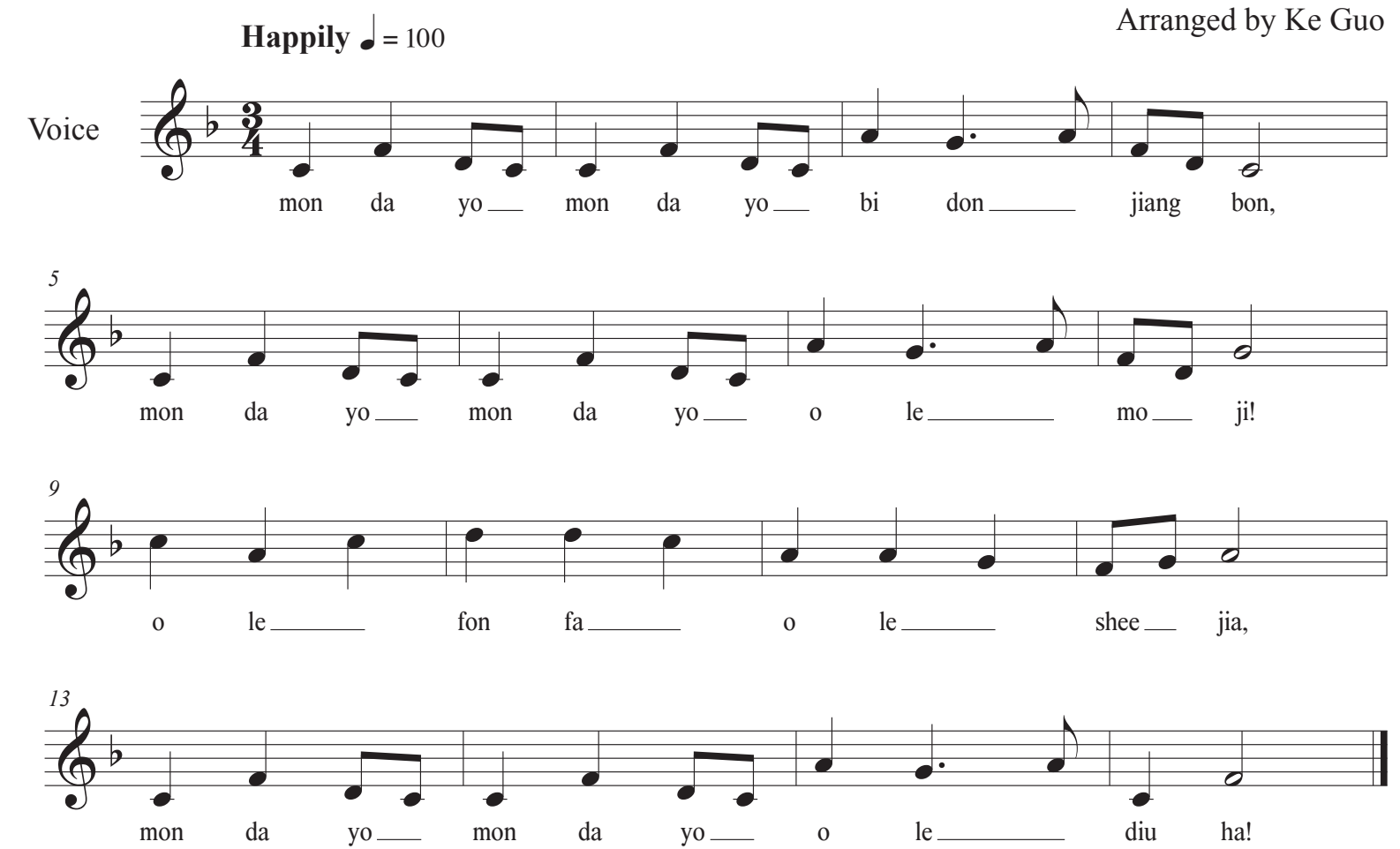

Content of Lyrics:

Here you come, here you come! We have companions!

Here you come, here you come! Come inside our house!

We will know each other well, and we will become friends.

Here you come, here you come! We are happy to have you with us!

Pronunciation guide:

a: ah, rounded vowel

i: ee, as in "sheep"

o: or, but without curling of the tongue

e: eh, as in "bless"

u: oo, as in "wood"

j: gi, as in "giraff" 
Appendix C

\section{Wooden Drum Dance \\ Movement 1: Walking Out of the Door}

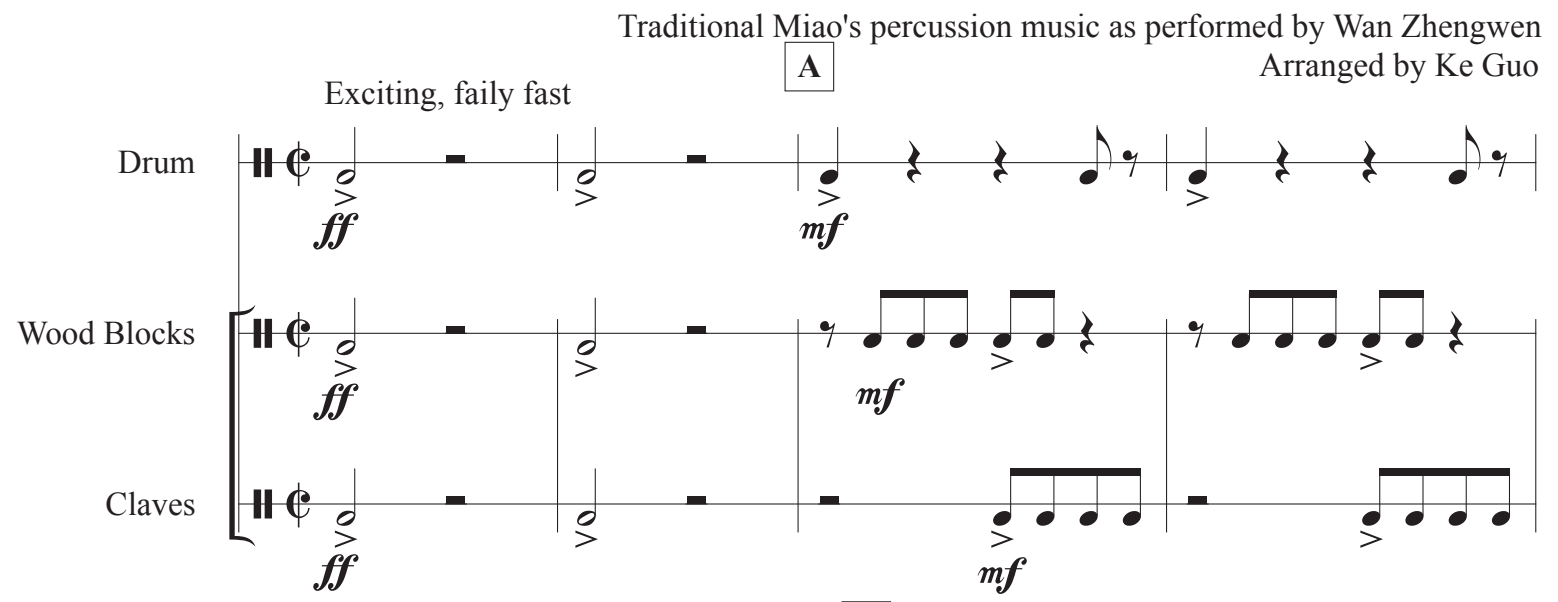

B

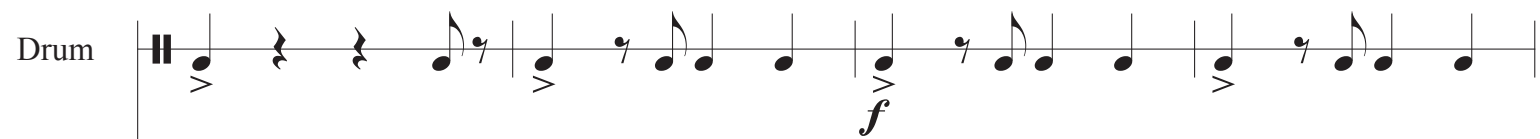

W. Bl.

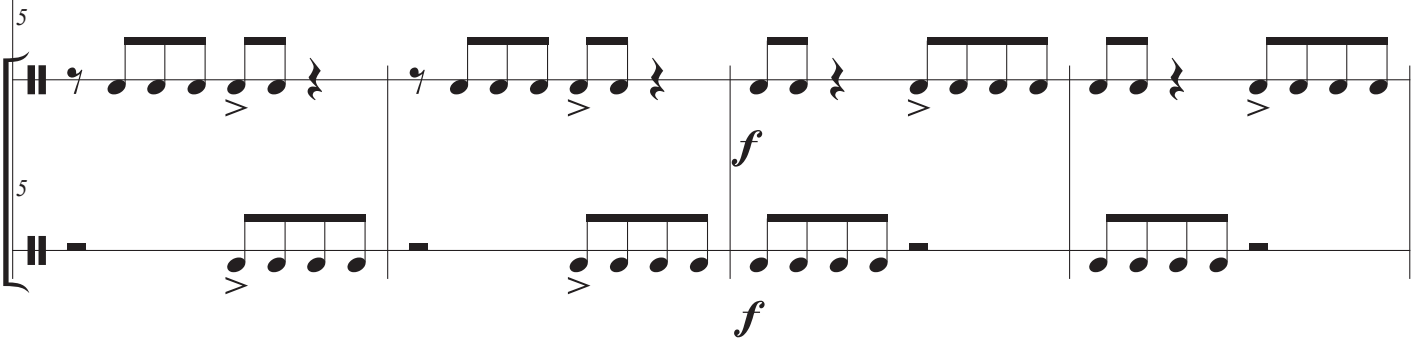

C

Drum

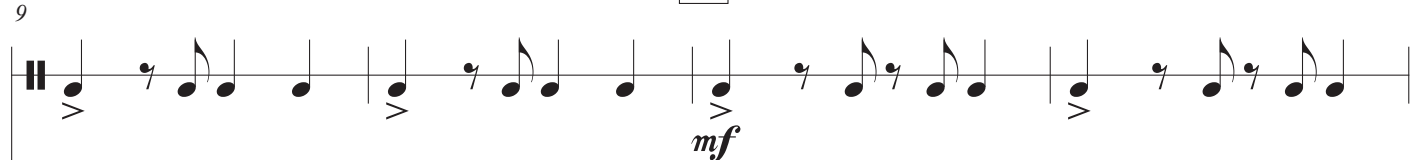

W. Bl.

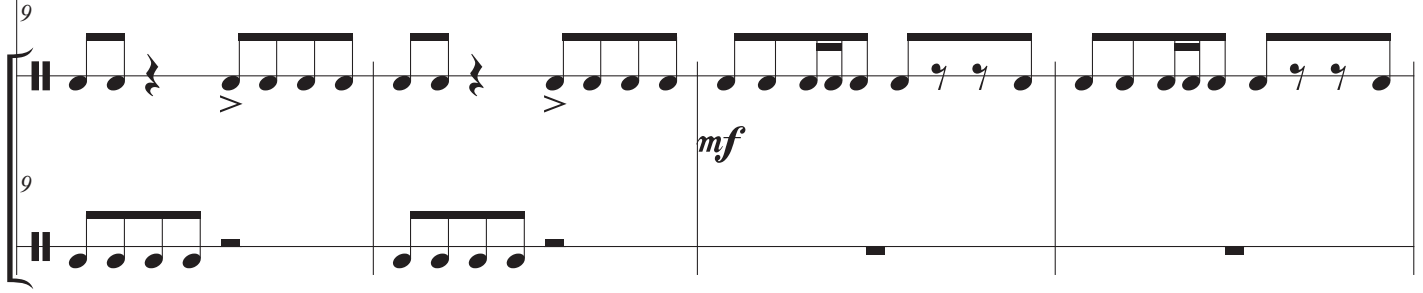


Wooden Drum Dance
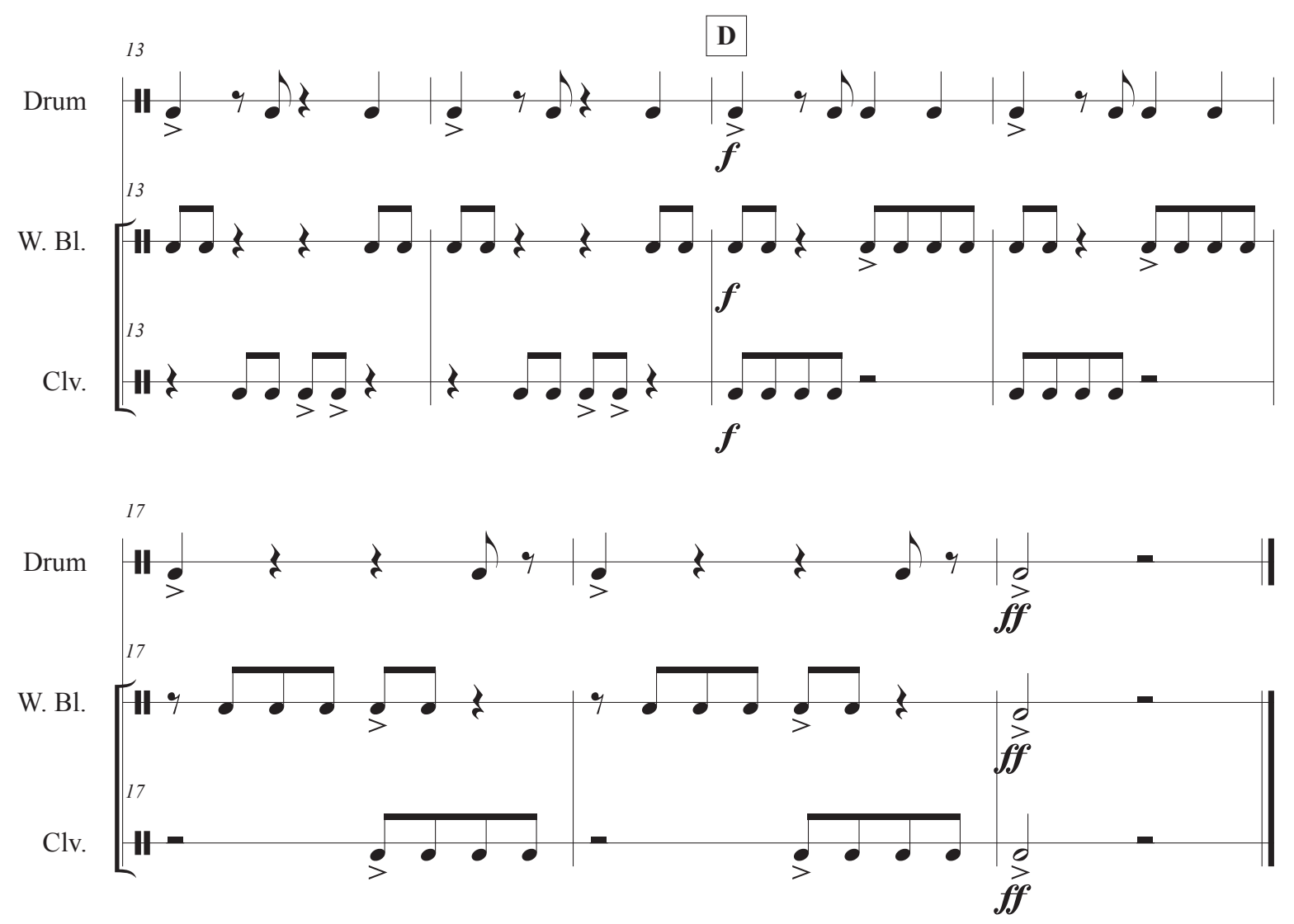
Appendix D

\author{
Permission Letter for Use of Copyrighted Material \\ 版权同意书
}

321 Santa Diana Terrace

Sunnyvale, CA 94085

$3 / 19 / 2019$

Fanpai Village, Taijiang County, Guizhou, China 556300

Dear Ms. Tang Wengweng,

I am completing a Master's Thesis at San José State University entitled "Creating Cultural Context for Dong and Miao Folk Music Through Orff-Inspired Methodology." I would like your permission to engrave and use your singing of the Miao folk song "Welcome! Our Guest!" I recorded in July 2018 in Taijiang County. The requested permission extends to any future revisions and editions of my thesis, including nonexclusive world rights in all languages, and to the prospective publication of my thesis. These rights will in no way restrict republication of the material in any other form by you or by others authorized by you.

If these arrangements meet with your approval, please sign this letter where indicated below and return it to me. Thank you very much.

唐翁翁女士,

我在硕士论文《探讨使用奥尔夫音乐教学法引入侗族苗族音乐的教学》中提及了您 演唱的苗族歌曲《迎客歌》, 特此征求您的同意使用我在 2018 年 7 月于台江县录制 的您的演唱版本。您的同意将会适用于本硕士论文的任何未来修订版本, 其他语言 的修订版本, 以及正式出版。这份同意书不会影响您或其他人使用您的演唱录像。

Sincerely,

Ke Guo 郭可

PERMISSION GRANTED FOR THE USE REQUESTED ABOVE:

对于以上内容同意:

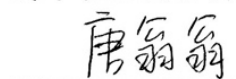

Tang Wengweng 唐翁翁

Date 日期: $3 / 19 / 2019$ 
Permission Letter for Use of Copyrighted Material

版权同意书

321 Santa Diana Terrace

Sunnyvale, CA 94085

$3 / 19 / 2019$

Fanpai Village, Taijiang County, Guizhou, China 556300

Dear Mr. Wan Zhengwen,

I am completing a Master's Thesis at San José State University entitled "Creating Cultural Context for Dong and Miao Folk Music Through Orff-Inspired Methodology." I would like your permission to engrave and use your performance of the Miao folk music and dance "Wooden Drum Dance" I recorded in July 2018 in Fanpai Village. The requested permission extends to any future revisions and editions of my thesis, including non-exclusive world rights in all languages, and to the prospective publication of my thesis. These rights will in no way restrict republication of the material in any other form by you or by others authorized by you.

If these arrangements meet with your approval, please sign this letter where indicated below and return it to me. Thank you very much.

万政文先生,

我在硕士论文《探讨使用奥尔夫音乐教学法引入侗族苗族音乐的教学》中提及了您 示范的反排苗族《木鼓舞》, 特此征求您的同意使用我在 2018 年 7 月于台江县录制 的您的示范版本。您的同意将会适用于本硕士论文的任何未来修订版本, 其他语言 的修订版本, 以及正式出版。这份同意书不会影响您或其他人使用您的演出录像。

Sincerely,

Ke Guo 郭可

PERMISSION GRANTED FOR THE USE REQUESTED ABOVE:

对于以上内容同意:

厅 政文

Wan Zhengwen 万政文

Date日期: 2019年3月21日 


\section{Permission Letter for Use of Copyrighted Material \\ 版权同意书}

321 Santa Diana Terrace

Sunnyvale, CA 94085

$3 / 19 / 2019$

Xiaohuang Village, Congjiang County,

Guizhou, China 557400

Dear Mr. Wu Rongde,

I am completing a Master's Thesis at San José State University entitled "Creating Cultural Context for Dong and Miao Folk Music Through Orff-Inspired Methodology." I would like your permission to engrave and use your singing of the Dong folk song "Song of Goat" I recorded in July 2018. The requested permission extends to any future revisions and editions of my thesis, including non-exclusive world rights in all languages, and to the prospective publication of my thesis. These rights will in no way restrict republication of the material in any other form by you or by others authorized by you.

If these arrangements meet with your approval, please sign this letter where indicated below and return it to me. Thank you very much.

\section{吴荣德先生,}

我在硕士论文《探讨使用奥尔夫音乐教学法引入侗族苗族音乐的教学》中提及了您 演唱的侗族歌曲《山羊歌》, 特此征求您的同意使用我在 2018 年 7 月于小黄村录制 的您的演唱版本。您的同意将会适用于本硕士论文的任何未来修订版本, 其他语言 的修订版本, 以及正式出版。这份同意书不会影响您或其他人使用您的演唱录像。

Sincerely,

Ke Guo 郭可

PERMISSION GRANTED FOR THE USE REQUESTED ABOVE:

对于以上内容同意:

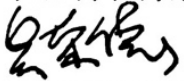

Wu Rongde 吴荣德

Date 日期: $03 / 18 / 2019$ 